$\mathrm{DOE} / \mathrm{PC} / 88911-\mathrm{TB}$

DE92 017807

\title{
THERMALLY INDUCED STRUCTURAL CHANGES IN COAL COMBUSTION
}

FINAL REPORT, JANUARY 1992

R. C. Flagan and G. R. Gavalas

Work Performed Under Grant No. DE-FG22-88PC88911

For

U.S. Department of Energy

Pitsburgh Energy Technology Center

Pittsburgh, PA 15236

By

California Institute of Technology

Pasadena, CA 91125 


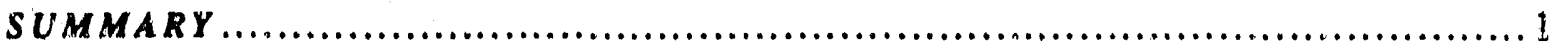

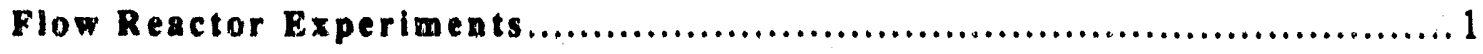

Electrodynamic Balance Experiments......................................... 2

Analysis of Combustion of Nonspherical Particles ............................4

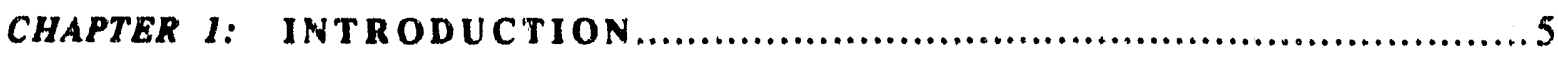

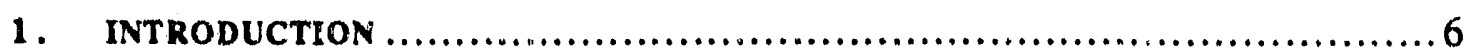

1.2 Organization of Report................................................ 8

CHAPTER 2: THE EFFECT OF TEMPERATURE-TIME HISTORY ON CHAR STRUCTURE AND REACTIVITY ............................................

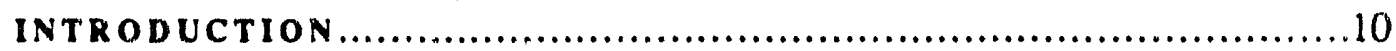

EXPERIMENTAL RESULTS............................................... 12

Char Formation ..................................................... 12

Char Characterization...............................................13

Char Reactivity ...................................................... 15

RESULTS AND DISCUSSION .............................................. 16

CONCLUSIONS............................................................ 19

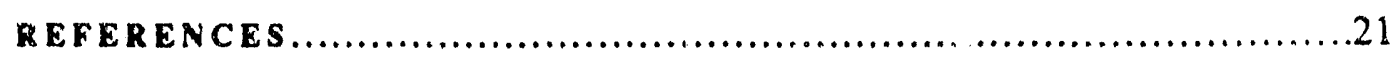

CHAPTER 3: EXPERIMENTS WITH THE ELECTRODYNAMIC BALANCE

The Effect of Char Formation Temperature on the Densification of a Bituminous Coal Char during Gasification..................................45

Laser Igntion of Levitated Char Particles................................69

CHAPTER 4: A THEORETICAL STUDY OF COMBUSTION OF NONSPHERICAL

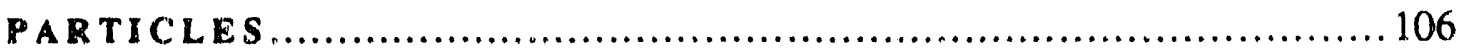

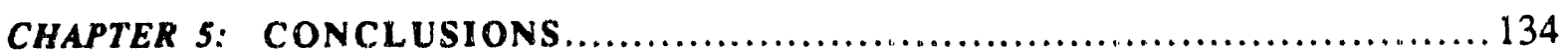


The effects of the temperature-time history during coal devolitization and oxidation on the physical properties and the reactivity of resulting char were studied experimentally for temperatures and residence times typical of pulverized combustion. Experiments wore also carried out at somewhat lower temperatures and correspondingly longer residence times.

An electrically heated laminar flow reactor was used to generate char and measure the rates of oxidation at gas temperatures about $1600 \mathrm{~K}$. Partially oxidized chars were extracted and characterized by gas adsorption and mercury porosimetry, optical and scanning electron microscopy, and oxidation in a thermogravimetric analysis system (TGA). A different series of experiments was conducted using a quadrople electrodynamic balance. Single particles were suspended electrodynamically and heated by an infrared laser in an inert or oxygen-containing atmosphere. During the laser heating, measurements were taken of particle mass, size/shape, and temperature.

A question pervading interpretation of drop tube oxidation experiments, or single particle oxidation experiments using the electrodynamic balance is the effect of particle shape. For convenience, previous modeling studies and data analyses have postulated spherical particles. In this part of the project we set out to examine the error made by assurning spherical particles and to find out how well a nonspherical particle may be approximated by a spherical particle of suitable effective radius.

The results of the two series of experiments and of the theoretical study will now' be briefly outlined and described in more detail in Chapters $1-4$ below.

\section{Flow Reactor Experiments}

Chars were generated from a hvA biturninous coal in a laminar flow tube reactor in an atmosphere of $\mathrm{N}_{2}$ or $1-5 \% \mathrm{O}_{2}$ in $\mathrm{N}_{2}$ and at $1600 \mathrm{~K}$ temperature. The chars were characterized by elemental analysis for carbon and hydrogen contents, $\mathrm{N}_{2}$ adsorption for BET surface area and pore size distribution, and by oxidation in a thernogravimetric analyzer at a temperature of $773 \mathrm{~K}$. When heated in neutral or oxidizing atmosphere, the great majority of the hvA bituminous coal (PSOC 1451) particles undergo a series of structural changes. Hollow spheres are formed, followed by particle fragmentation. In 1 or $5 \%$ oxygen, oxidation proceeds both externally and internally at approximately constant diarneter until the onset of fragmentation. For all of the chars, the surface area and the pore 
volume in the size range 15 so $120 \AA$ increased dramatically within the first $100 \mathrm{~ms}$ from the values of the original coal. The ratio of carbon to hydrogen increases with residence time. Carbon conversion at $1600 \mathrm{~K}$ also increased with increasing oxygen pressure, while the low temperature $\left(-500^{\circ} \mathrm{C}\right)$ char reactivity measured in the TGA experiments decreased. Significart structural reorganization occurred either simultaneously with devolatilization or after devolatilization depending on the oxygen concentration. The presence of oxygen appeared to accelerate the structural changes and decrease the reactivity of the char. The experimental results indicate a strong relation between char properties and experimental conditions. This relation could have important implications on the modeling of coal combustion and on combustion design and operation.

\section{Electrodynamic Balance Experiments}

An electrodynamic balance was constructed having hemispherical endcap electrodes and a right cylinder ring. The electrode cell was housed in an evacuable stainless steel chamber of $250 \mathrm{~cm}^{3}$ volume. The armosphere in the chamber was controlled by the flow of gases of the desired composition. A 20 -watt $\mathrm{CO}_{2}$ laser was used to heat the particle. Before, during, and after heating the particle was observed with a microscope and a video camera. The temperature of the particle was measured with a two-color IR pyrometer.

One series of experiments concentrated on the ignition behavior of Pittsburgh No. 8 coal char particles of 150.300 $\mu \mathrm{m}$ diameter and synthetic char particles (Spherocarb) of 140-240 $\mu \mathrm{m}$ diameter. In a typical experiment, a charged char particles was suspended in the electrodynamic balance and heated by a $500 \mathrm{~ms}$ pulse of radiation from a $\mathrm{CO}_{2}$ laser. The oxygen concentration in the ambient gas, initially only nitrogen, was slowly increased as successive laser pulses were given, until the particle ignited. Once ignition occurred, the particle lost charge and dropped from the center of the balance.

The temperature traces of particles that ignited clearly show an induction time, or ignition tirne lag, as predicted by the solution of the time dependent equation for a heated particle. The effect of increasing the oxygen concentration is also seen in the increasing equilibrium ternperature at sub-ignition conditions, though it was not quantifiable in this study. A simple isothermal sphere model was used with parameters obtained from the literature which adequately predicted the experimentally obtained time-temperature histories of igniting Spherocarb particles. A reasonable fit to the bituminous char data was achieved using rate parameters determined in an earlier drop tube study. These experirnents provide the first examples in which the oxidation of char during ignition is rigorously modeled and 
compared with existing literature data. The electrodynamic balance can be used in ignition experiments to measure the apparent char oxidation rate parameters, and probe particle-toparticle variations in the apparent kinetics.

The second series of experiments using the electrodynamic balance focused on the densification and other stuctural changes of char during heating and oxidation.

A typical experiment started by trapping a single particle in the elcctrodynamic balance. The size of the particle was measured in the horizontal and vertical directions using the eyepiece micrometer. Photographs were taken through the viewing microscope. The $\mathrm{CO}_{2}$ laser was allowed to stabilize with an external shutter closed. Particle heating was then initiated by opening the shutter. The pyrometer signal was monitored on the oscilloscope and recorded by the data acquisition system. The particle position was balanced manually. The heating pulse was ended by closing the external shutter. Photographs were again taken to record any shanges in particle size and shape.

Coal chars (Pittsburgh No. 8) generated at $1600 \mathrm{~K}$ and $1200 \mathrm{~K}$ were heated in nitrogen and in air. Heating the $1600 \mathrm{~K}$ char in $\mathrm{N}_{2}$ at about $1000 \mathrm{~K}$ did not induce any change in size or shape-the char was not densified. Likewise the "greener" char generated at $1200 \mathrm{~K}$ underwent no change in size or shape following heating at $1000 \mathrm{~K}$. When the $1600 \mathrm{~K}$ char was heated in air to as much as $56 \%$ conversion, no change in size or shape was observed but the particle became lacy and translucent, indicating full oxygen penetration into the macropores, and no densification. The $1200 \mathrm{~K}$ char, on the other hand, underwent significant shrinkage upon oxidation in air under the same conditions. The shrinkage was largely due to densification by thermal rearrangement of this "greener" char. Inasmuch as no shrinkage took place upon heating in nitrogen, the observed densification was not purely thermal but could only take place in the presence of oxygen. The synthetic char (Spherocarb) exhibited behavior similar to that of the $1200 \mathrm{~K}$ coal char. Heating in nitrogen engendered no shrinkage, but heating in oxygen resulted in significant shrinkage despite the fact that reaction proceeded in regime 1 (low Thiele modulus).

The experiments on shrinkage have important implications for modeling of char combustion. The particle size change is not merely a result of the balance between reaction and pore diffusion. The Thiele modulus may not be sufficient for predicting whether the particle burns at constant size, constant density or at an intermediate mode. Densification must also be considered, at least for "green" chars those that had not been previously exposed to very high temperacures. 


\section{Analysis of Combustion of Nonspherical Particles}

The analysis of nonspherical particle combustion was made for the regime of shrinking core reaction. The first problem addressed was the calculation of the pseudosteady temperature and oxidation rate for a particle of given shape. This problem involves the solution of the external diffusion and heat conduction equations with the reaction entering as a boundary condition over the particle surface. Using the boundary integral method, the problem was reformulated as a system of two coupled integral equations which were solved numerically yielding the following results. For particles of equal volume, the pseudosteady temperature is nearly independent of shape, but the combustion rate increases with increasing aspect ratio. The local combustion rate varies moderately over the particle surface increasing with the distance from the particle center. The total combustion rate depends on the particle surface area alone, i.e., particles of equal surface area but different volumes and shapes have the same rate. This dependence on the surface area is less than linear, becoming linear only in the limit of low Damköhler numbers. The complete transient problem addressing the evolution of particle shape and particle temperature during burnout, was similarly formulated by the boundary integral method and solved numerically. Over a broad range of parameters, the pseudosteady particle temperature and rate of oxidation are very nearly equal to those of spherical particles of equal volume and surface area respectively. The transient solutions obtained for parameters typical of pulverized combustion show that during burnout the particle becomes increasingly nonspherical. As expected, nonspherical particles burn faster than spherical particles of the same initial volume, but the difference in burnout times is less than $20 \%$ for initial aspect ratios between one and three. 


\section{CHAPTER I}

\section{INTRODUCTION}




\section{INTRODUCTION}

Coal combustion is a major source of energy for electric power generation in the United States. Currently $50 \%$ of electric power is generated from coal, $19 \%$ from nuclear fission, and the remainder from hydroelectric, oil- and gas-fired, and miscellaneous solar and wind power stations. Solar power generation is very expensive and is currently economical only in small scale specialized applications. Although technical progress is made continuously gradually reducing the cost, solar power is not expected to become a major factor in the next two decades. Wind power is becoming competitive but is limited to certain favorable geographic regions. Among the fossil fuels coal is by far the most abundant in the U.S. and will remain the major source of electrical power generation in the foreseeable future. The share of nuclear power generation is also expected to remain significant and possibly grow over the next few decades.

Although practiced for more than seventy years, pulverized coal combustion-the workhorse of the industry-is presently undergoing active development. The main issues as well known are the control of sulfur dioxide, nitrogen oxides and particulates. Several competing technologies have been developed but the cost of control remains high, hence the contin wing research and development effort. As far as sulfur oxide removal is concerned, postcombustion wet or dry processes and precombustion beneficiation are mature technology which, however, will continue undergoing incremental improvement. Nitrogen oxide control is less settled with combustion modification and postcombustion catalytic reduction, both undergoing development and limited commercialization. Modification by staged air addition, or special burner designs intervenes in the basic chemistry of combustion and hence can affect both $\mathrm{NO}_{\mathbf{x}}$ generation and the composition and size distribution of flyash. These pollution control issues cannot override the requirement of complete combustion within the residence times afforded by the boiler.

The design of coal-fired boilers has been, in the past, guided by experience and relatively simple empirical procedures. The demands of tighter pollution control and higher combustion efficiency, provide now the incentive for using detailed and fundamentally based mathematical models to assist the design of new or retrofit installations. A detailed mathematical model of a coal-fired boiler is inevitably very complex, for it must incorporate turbulen: fluid dynamics and heat transfer with the homogeneous and heterogeneous combustion chemistry. Two-dimensional and three-dimensional models have been developed tracking the fluid and particle phases and a simple treatment of the combustion 
chemistry. It is impractical to attempt a complete description of all these phenomena. Idealization and empiricism are still essential.

This research project has been addressed to certain problems in heterogeneous char oxidation. Although only one component of the combustion process, heterogeneous oxidation takes up the bulk of the residence time in the boiler and is responsible for the generation of most of the flyash pollutions. Seemingly a simple process in reality is a microcosm of physical and chemical phenomena and has been a long standing subject of experimental and theoretical research.

It is traditional to differentiate between the physical properties and chemical structure as controlling in distinct ways the course of heterogeneous oxidation. However at the level of the finest pores, below $10 \AA$ diameter, the physical and chemical properties blend and cannot be clearly differentiated. It remains useful, nevertheless, to retain this distinction and we shall do so in this discussion. In both experimental characterization and modeling work, the physical properties of interest are size/shape surface area, and pore size distribution, the latter often summarized into an effective pore diffusion coefficient. During burnout, the pores are enlarged with the surface area, pore size distribution and effective diffusivity changing accordingly. Recent modeling work has attempted to characterize these changes with idealized geometrical models but major difficulties remain. For example, the statistical averaging implicit in all pore models becomes highly questionable when the penetration depth of oxygen is comparable with the size of the larger voids in the char, as is often the case in pulverized combustion.

The chemical property needed to describe char oxidation is the intrinsic reaction rate, i.e., the rate per unit pore surface area. There is no unambiguous choice of surface area for this purpose. Both the $\mathrm{N}_{2}$ BET surface area and the Dubinin-Polanyi $\mathrm{CO}_{2}$ surface area have been used, and one may be better than the other for a given experimental situation. Whichever of the twe areas is used, however, the idea is that the local reaction rate $r$ can be expressed as the product of the local intrinsic rate $r_{i}$ and the local pore surface area per unit volume, $S(X)$ :

$$
r(p, T)=r_{i}(p, T) S(X)
$$

where $\mathrm{p}$ is the local pressure of oxygen, $\mathrm{T}$ is the local temperature, and where $\mathrm{X}$ is the local conversion. In this simple decomposition, which has been the basis of all detailed modeling work todate the intrinsic rate incorporates all chemical factors and would vary 
from char to char, but is assumed independent of conversion. The surface area on the other hand, varies with conversion tracking the changing pore geometry.

This project was addressed to the efforts of the thermal history of char on its subsequent reactivity towards oxidation. Thermal history here means the temperature-time history during both devolatilization and oxidation. Posed in terms of the reaction rate expression above, the issues under consideration are:

i) the effect of temperature time history of devolatilization on the intrinsic rate and the porous structure at the onset of oxidation

ii) whether the intrinsic rate (at fixed $T, c$ ) remains constant or varies during oxidation.

\subsection{Organization of Report}

Chapter 2 of this report describes the experiments on coal devolatilization, char characterization, and measurement of char reactivity at high temperatures $(\sim 1600 \mathrm{~K})$ and lower temperatures $(\sim 800 \mathrm{~K})$. These experinients focus on the effects of the thermal history on the physical properties and reactivity of the char.

Chapter 3 describes the experiments on the oxidation of single char particles in the electrodynamic balance. The major result of this chapter is that certain chars suffer thermal densification or shrinkage upon heating in the presence of oxygen, quite apart from the shrinkage due to burnout. Chapter 3 also describes some interesting ignition measurements carried out with the electrodynamic balance.

Chapter 4 is based on a paper recently accepted by COMBUSTION SCIENCE AND TECHNOLOGY. It describes our theoretical work on the combustion of nonspherical particles. This work is not directly related with the effects of thermally induced changes, but is of more general interest in the modeli.ig of particle combustion. 


\section{CHAPTER 2}

THE EFFECT OF TEMPERATURE-TIME

HISTORY ON CHAR STRUCTURE AND REACTIVITY 


\section{INTRODUCTION}

Devolatilization and char oxidation are the two major steps involved in coa' combustion. The first step is rapid and the second is slow. In pulverized coal combustion devolatilization takes $10-100 \mathrm{~ms}$. Char bumout requires as much as 1 second, making it the rate limiting step for the overall process. However, devolatilization determines the initial physical and chemical properties of the char, e.g., particle density, surface area, porosity, as well as molecular structure. These properties, in turn, govern the char combustion kinetics.

Wells and Smoot (1991) used canonical correlation analysis to determine the relationship between the reactivity and the chemical and physical properties. For different coals, rank had a significant correlation with reactivity. The same result was found for chars extracted by pyridine. For pyrolyzed chars, the relative importance of effective factors was found to be catalysis by metal ions $>$ porosity $>$ total hydrogen. The cation activity was found to be in the order of $\mathrm{Na}>\mathrm{Mg}>\mathrm{Ca} \gg \mathrm{K}$.

Anson et al. (1971) described in great detail the structural change of a low rank and a medium rank bituminous coal burning in air. On being exposed to high intensities of radiation, coal particles typically soften. The rapid generation of volatiles causes particle swelling and production of large holes on the particle external surfaces. With the completion of devolatilization, the swelling ceases, and after a short time interval (about 40 $\mathrm{ms}$ for $250 \mu \mathrm{m}$ diameter particles) the particles undergo a marked contraction forming rigid skeletons. After contraction, the initial burning of the residue took place at approximately constant diameter. Reactions occurred around the pore mouths until the char particles fragmented. Samples of lithotypes of both low and medium rank coals were heat-treated in the furnace at a temperature of $1073 \mathrm{~K}$ for $150 \mathrm{~ms}$. The measurements of the surface areas of these samples by xenon adsorption confirmed the trend toward increasing surface with

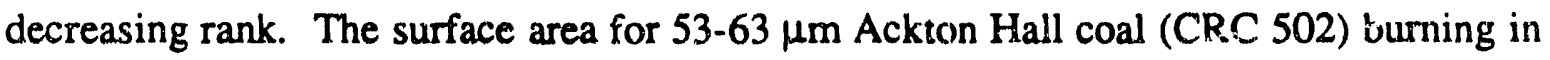
air at about $75 \mathrm{~ms}$ was about twice that of the original coal. As the residence time increased to $85 \mathrm{~ms}$, the surface area increased from 111 to $125 \mathrm{~m}^{2} / \mathrm{g}$ on dry ash free basis. The surface area started to drop near the completion of devolatilization. It was $88.5 \mathrm{~m}^{2} / \mathrm{g}$ at approximately $130 \mathrm{~ms}$, while the devolatilization ended at about $150 \mathrm{~ms}$. Under the same conditions, the measured surface area of Rawdon coal (CRC 902) was almost constant at residence time of $85 \mathrm{~ms}$, then decreased progressively with time. The surface area dropped rapidly around the time of the completion of devolatilization from $121 \mathrm{~m}^{2} / \mathrm{g}$ at $130 \mathrm{~ms}$ to 55 $\mathrm{m}^{2} / \mathrm{g}$ at $180 \mathrm{~ms}$. The variation of surface area of semi-anthracite coal particles during 
combustion was measured by Smith and Tyler (1972) at temperatures of $1400 \mathrm{~K}$ to $2200 \mathrm{~K}$ and oxygen fractions about 0.1 and $0.2 \mathrm{~atm}$. The surface areas first increased then steadily decreased with burnout. The peak appeared between about 15 to $35 \%$ burnout, corresponding to the coal particie sizes 78 to $6 \mu \mathrm{m}$. The surface areas also decreased with increasing gas temperatures. The particle size and density both decreased with burnout, indicating that oxygen partially penetrated into the pore structure.

Particle size, density, porosity, pore size, and surface area have been found to have imporant influence on the combustion behavior of particies. When combustion is limited to a shallow zone below the outer zurface, particles burn with constant density but with a steady reduction of size. When oxygen penetrates completely within a porous aarticle, combustion occurs at constan: size but with decreasing density. Thin-walled cenospheres were concluded to burn with reducing density but at constant size whether oxygen penetrated the pore or not (Smith, 1982).

Anson, et al. (1971) reported that the composition of coal influenced the morphology of hollow spheres formed during devolatilization. Particles of vitrain and clarain, composed mainly of vitrinite, produced spheres with thinner walls compared to those obtained from durain particles. Momeover for vitrain and clarain particles there was a nanural progression toward more extensive internal structures with decreasing rank.

The structural transformations that ocsur when carbons are heated to high temperatures have been studied extensively, but measurements of structural changes occurring on the shor time scale of pulverized coal combustion are extremely limited. Smith and Tyler (1972) collected partially burned chars of a semianthracite from a laminar flow furnace and examined them by optical microscopy, porosimetry and X-ray diffraction. The micropore surfice area was found to decrease with burnout. A sharpening of a graphite band in the X-ray pattem indicated that some structural ordering took place. Such ordering was also observed after partial combustion of glassy carbons (Levendis and Flagan, 1987). Uxygen was observed to catalyze the structural transformation (Levendis et al., 1989). Haussmann and Kruger (1988) measured the change in the hydrogen and nitrogen to carbon ratios with carbon conversion at $1750 \mathrm{~K}$ and $7.6 \% \mathrm{O}_{2}$, and at $1300 \mathrm{~K}$ and pure argon for $55 \mu \mathrm{m}$ Montana Rosebud subbituminous coal. In the oxidizing atmosphere, both $\mathrm{H} / \mathrm{C}$ and $\mathrm{N} / \mathrm{C}$ ratios decreased until around $50 \%$ carbon convcrsion, then varied very slowly. The chars exposed to pure argon underwent a decrease of the $\mathrm{H} / \mathrm{C}$ ratio, but almost no change in the $\mathrm{N} / \mathrm{C}$ ratio with carbon conversion. The change of $\mathrm{H} / \mathrm{C}$ ratio indicates reorganization of the carbon matrix, but the chemical structures evolved have not been 
sndied in any detail. The decriase in the reactivity of the carbonaceous material that is expected to accompany these changes could have important implications to combustnr design and operation. In the present work, we examine the structural changes occurring at combustion temperatures and tirnes spical of pulverized combustion and probs the effect of the changes on the rate of char oxidation.

\section{EXPERIMENTAL METHOUS}

\section{Char Formation}

Chars were made from a high-volatile A bituminous coal (PSOC 1451), the properties of which are given in Table 1. The coal was pulverized in a mechanized mortar and pestle in air. It was then size classified by sieving on a mechanical shaker "The 45-53 $\mu \mathrm{m}$ coal size fraction was dried by heating in nitrogen at $1000^{\circ} \mathrm{C}$ for one hour and then cooled to room temperature before char production. The experimental system has been described in detail elsewhere (Sahu, 1988) and is only briefly described here. Combustion experiments were conducted in a laminar flow tube fumace 'Applied Test System, Series 3310) consisting of an alumina tube of $5 \mathrm{~cm}$ internal diameter and $71 \mathrm{crn}$ length heated by Kanthal Super 33 elements. The gas temperatures were measured with a suction pyrometer. The isothermal zone of the reactor was about $30 \mathrm{~cm}$ long. The wall tempcrature was maintained at $1748 \mathrm{~K}$ to $1773 \mathrm{~K}$, depending on the residence time, to produce a gas temperature of $1600 \mathrm{~K}$ at the center of the isothermal zone in all experiments. The temperature at the ends of the isothermal zone dropped about $10 \%$. Coal particles were injected into the alumina tube through a water-cooled injector at a rate of $3 \mathrm{gm} \mathrm{hr}^{-1}$. Experiments were performed in pure nitrogen $o_{i}$ in mixtures of 1 or $5 \%$ oxygen in nitrogen. The coal chars were collected on $0.4 \mu \mathrm{m}$ uclepore filters with a water-cooled, gas dilution quench probe. The residence times of the coal particles inside the furnace were varied by adjusting the gas flow rate and the position of the sampling probe. Both size classified, dried coal and the chars produced in the drop-tube furmace were stored under nitrogen atmosphere.

\section{Char Characterization}

\section{Elemental Analysis}

The mass fractions of carbon, hydrogen, and nitrogen in various char samples were deternined by a Model 240 Elemental Analy cccr. These analyses were based on detecting 
and measuring the combustion products of carbon dioxide, water, and nitrogen in pure oxygen at a temperature of $860^{\circ} \mathrm{C}$.

\section{Surface Area}

The surface areas of the chars were obtained by a modified volumetric adsorption technique described by Northrop et al. (1987). The gas adsorption isotherms were measured by continuous addition of adsorbate gas $\left(\mathrm{N}_{2}\right.$ at $\left.77 \mathrm{~K}\right)$ to the sample (see Appendix A). The apparatus was calibrated with $\gamma$-alumina. The relative measurement uncertainty is abodl $\pm 15 \%$ for a surface ared of $1 \mathrm{~m}^{2} \mathrm{gm}^{-1}$ and decreases with increasing sample surface area. The repeatability of the measurements was tested with duplicates using (1) the same sample; (2) or different samples of the same material. Each pair of measurements agreed to within $20 \%$ (Table 2).

\section{Pore VG:ume Distribution}

The BET model is usually applied to a relative pressure range $0.04<P / P^{\circ}<0.30$, where $P^{\circ}$ is the vapor pressure of adsorbate. At higher relative pressure, capillary condensation occurs in porous solids due to the surface tension induced pressure difference across the curved meniscus of the condensed vapor. The size of the capillary can be calculated by the Kelvin equation,

$$
\ln \frac{P}{P^{\circ}}=\frac{2 \gamma \cos \theta}{L R T^{\prime}}
$$

where $\gamma$ is the surface tension, $v$ is the molar volume, $\theta$ is the contact angle, $L$ is the radius of a cylindrical pore. For a slit pore, $L$ is half the distance between the walls. $R$ is the gas constant and $T$ is the absolute temperature.

Using the capillary condensation model including multilayer adsorption in cylindrical pores, Wheeler (1946) deduced that the specific pore volume $V(r)$ was related to the volume of nitrogen desorbed over a small segment on the desorption branch of the isotherm $v(r)$ by

$$
v(r)=\left(\frac{r-t(r)}{r}\right)^{2} V(r)+\frac{d t}{d r} \int_{r_{0}}^{r} \frac{2 r^{\prime}-t\left(r^{\prime}\right)}{r^{2}} V\left(r^{\prime}\right) d r^{\prime}
$$


where $r$ is the radius of the pore, $t$ is the thickness of the adsorbed layer of gas. The first term on the right accounts for liquid evaporated from the pores, and the second term represents the amount of gas desorbed from free surfaces. However, Wheeler was not able to solve Eq. 2 for the unknown $V(r)$ at that time. Cranston and Inkley (1957) later developed a method to calculate $V(r)$. The volume of pores having radii, $r$, in the range $r_{1} \leq r \leq r_{2}$ is estimated to be

$$
V_{12}=R_{12}\left(v_{12}-k_{12} \sum_{r_{2}+\frac{\Delta_{r}}{2}}^{r_{\max }} \frac{r-t_{12}}{2 r^{2}} V_{r} \Delta_{r}\right)
$$

where

$$
R_{12}=\left(\frac{1}{r_{2}-r_{1}} \int_{r_{2}}^{r_{1}} \frac{r-t_{1}}{r} d r\right)^{-1}
$$

$k_{12}=4\left(t_{2}-t_{1}\right)$, and $t_{12}=\left(t_{2}+t_{1}\right) / 2 . V_{r} \Delta_{r}$ is the volume of pores having radii between $r$ and $r+\Delta_{r}$, where $\Delta_{r}$ is very small compared with $r$. The quantity $v_{l 2}$ is the total volume of nitrogen adsorbed during the adsorption step from pressure $P_{1}$ to pressure $P_{2}$, where $P_{1}$ corresponds to the critical radius $r_{1}$ and $P_{2}$ to radius $r_{2}$. The quantities $t_{i}$ and $t_{2}$ a re the adsorbed layer thicknesses at the pressures $P_{1}$ and $P_{2}$, respectively. The $t$ values were given by Lippens et al. (1964). We used Eq. 3 to estimate pore volume distributions from our adsorption measurements.

\section{Char Reactivity}

\section{High Temperature Conversion}

To calculate the conversion of the chars generated under different atmospheres and residence times, the ash content of the samples was used as a tracer by assuming that the mass of the ash remains constant. Measured amounts of air-dried chars were burned in air at a temperature of $800^{\circ} \mathrm{C}$ for more than 5 hours. The ash content was then determ: ned gravimetrically from mass measurements made before and after complete combust on. From the known ash content, the char conversion can be derived as follows: 


$$
\begin{aligned}
& M_{\text {caal }}=M_{\text {ash }}+M_{c} \\
& M_{\text {char }}=M_{\text {ash }}^{\prime}+M_{c}^{\prime}
\end{aligned}
$$

where $M_{c}$ is the mass of combustible material. The relative ash contents of the coal and char samples, $R_{\text {ash }}=\frac{M_{\text {ash }}}{M_{\text {coal }}}$, and $R_{\text {ash }}^{\prime}=\frac{M_{\text {ash }}}{M_{\text {char }}}$, are determined experimentally. The measurement error is about $\pm 5 \%$. The mass of char produced from a given mass of coal is,

$$
M_{\text {char }}=M_{\text {coal }} \frac{R_{\text {ash }}}{R_{\text {ash }}}
$$

Combining Eqs. 4 to 6, the conversion of combustible material, $\eta$, becomes

$$
\eta=\frac{M_{c o a l}-M_{c h a r}}{M_{c}}=\frac{R_{a s h}^{\prime}-R_{a s h}}{R_{a s h}^{\prime}\left(1-R_{a s h}\right)}
$$

\section{Low Temperature Conversion}

Chars were oxidized under a flow of $5 \% \mathrm{O}_{2}$ in $\mathrm{N}_{2}$ at $773 \mathrm{~K}$ in a Dupont model 951 Thermogravimetric Analyzer (TGA). The typical sample size was about $5 \mathrm{mg}$. The sample was first heated in nitrogen at a rate of $30 \mathrm{~K} \mathrm{~min}^{-1}$ to the desired temperature. Oxygen was then irnmediately introduced. The measurements were conducted under isothermal conditions. The gas flow rate was $150 \mathrm{~cm}^{3} \mathrm{~min}^{-1}$ for all runs. This flow rate was selected to avoid entrainment of the low density materials while eliminating diffusion resistance. The sample mass was continuously recorded using a data acquisition system. To correct for different ash contents of the various chars, the mass of ash was deducted from the total mass. Although the reaction was allowed to pruceed for 2 hours, some unreacted combustible material remained. The temperature of the TGA was increased to $1073 \mathrm{~K}$ after about $90 \%$ conversion to burn out completely the residual carbon then reduced back to $773 \mathrm{~K}$ when the ash mass was recorded. To discriminate between the TGA measurements and those obtained in drop-tube reactor experiments at high temperature, the TGA conversion is labeled $\chi$, and defined separately as 


$$
\chi=\frac{M_{\text {inisial }}-M_{\text {measured }}}{M_{\text {initial }} \cdot M_{\text {ash }}}
$$

where $M_{\text {initial }}$ is the sample mass at the moment oxygen was admitted.

\section{Results and Discussion}

Properties of chars produced under different conditions are listed in Table 3. The char morphology was examined by scanning electron microscopy. As Fig. 1 shows, the original coal particles were angular with a maximum aspect ratio about 5 . Upon exposure to $1600 \mathrm{~K}$ in nitrogen for $100 \mathrm{~ms}$ (Fig. 2), the particles started to change shape to spherical. At the same time the evolution of volatiles and trapped gases opened the pores on the particle surface (Fig. 2). These pores had a very broad size range from less than $1 \mu \mathrm{m}$ to larger than $20 \mu \mathrm{m}$. Numerous ash particles appeared on the surface of char particles. When the residence time was increased to $200 \mathrm{~ms}$, the particles became quite spherical (Fig. 3), and "Blow holes" (following the terminology of Anson et al., 1971) appeared on the particle surface. As the residence time was further increased to $300 \mathrm{~ms}$, the coal particles became cenospheres (Fig. 4). In 1\% oxygen, the "blow-holes" appeared only for the $100 \mathrm{~ms}$ sample (Fig. 5). At $200 \mathrm{~ms}$, the particles had lost a large fraction of their mass but kept their integrity by cross partitions (Fig. 6). Fragmentation occurred after $300 \mathrm{~ms}$ of combustion (Fig. 7). Raising the oxygen concentration increased the combustion rate. In $5 \%$ oxygen, the morphology of char particles collected at $100 \mathrm{~ms}$ was similar to that of the particles generated at $200 \mathrm{~ms}$ in $1 \%$ oxygen (Fig. 8). At $200 \mathrm{~ms}$ residence time, the large loss of mass caused some particles to lose their integrity (Fig. 9). The fragmentation was significant after $300 \mathrm{~ms}$ residence time (Fig. 10). Comparing the original coal and the chars produced in nitrogen and oxygen, the char particles are more spherical as a result of the softening and swelling of the coal particles upon injection in the furnace. Although the original coal was sieved into a narrow size cut, the irregular particle shape prevents a direct evaluation of the degree of swelling. This irregular shape as well as the variation of the chemical composition among individual coal particles resulted in char particles possessing varied visible structures. The char particles seemed to burn at constant size until they fragmented. Comparison of the chars generated in nitrogen and oxygen showed some differences. Firstly, a great number of pores of less than $5 \mu \mathrm{m}$ diameter appear on the surface of char particles produced at $100 \mathrm{~ms}$ in nitrogen. After devolatilization, cracks were formed at the thinner walls of the hollow particles (Figs. 3 and 4). Some particles were 
then broken into small fragments. In an oxidizing atmosphere, oxygen penetrated into the interior of the particles through the opened pores and mass removal by oxidation was observed around the pore mouths. Fragmentation took place only when almost all carbon was consumed (Figs. 6-8). Secondly, quite large ash particles appeared on the surface of nitrogen chars. The ash particles for oxygen chars were relatively small and adhered on the carbon skeleton. They grew gradually by coalescence as reactions proceeded.

Figs. 1 to 10 show the formation and growth of macropores. Information about the micropores $\left(15 \leq r \leq 120 \AA\right.$ ) and the total surface area was obtained by $\mathrm{N}_{2}$ adsorption. For all of the chars, the surface area and the volume of micropores increased dramatically within the first $100 \mathrm{~ms}$ over the values for the original coal, indicating new pore formation and the pore growth (Figs. 11 to 15). The trends at later times, however, differed. The surface areas and pore volumes of nitrogen chars increased with time. The peak observed at about $20 \AA$ in the pore volume distribution of $\mathrm{N} 2$ char, and the change of $\mathrm{C} / \mathrm{H}$ ratio (Table 3) suggested that there were still some small molecules released when the residence time was increased to $200 \mathrm{~ms}$. In oxygen atmospheres, both surface area and volume of micropores first increased and then decreased after $100 \mathrm{~ms}$. The decrease of micropores could be caused either by pore closure or pore growth to larger sizes. It should be noted that although the oxygen concentration in these experiments was only 1 to $5 \%$, the bulk gas concentration did not change appreciably along the reactor because of the small coal feed rate.

Little information is available about the change of char surface area with the pyrolysis time of coal. Anson et al. (1971) and Smith and Tyler (1972) reported direct observation of surface area changes during coal combustion. The surface area for 53-63 $\mu \mathrm{m}$ Ackton Hall coal (CRC 502) particles burning in air at about $75 \mathrm{~ms}$ was about twice that of the original coal (Anson et al., 1971). As the residence time increased to $85 \mathrm{~ms}$, the surface area increased continucusly, from 111 to $125 \mathrm{~m}^{2} \mathrm{~g}^{-1}$ on dry ash free basis. The surface area started to drop near the completion of devolatilization. It was $88.5 \mathrm{~m}^{2} \mathrm{~g}^{-1}$ at approxirnately $130 \mathrm{~ms}$, while the devolatilization ended at about $150 \mathrm{~ms}$. Smith and Tyler (1972) measured the variation of surface area of semi-anthracite coal particles during combustion at temperatures of $1400 \mathrm{~K}$ to $2200 \mathrm{~K}$ and oxygen pressures about 0.1 and 0.2 atm. The surface areas first increased then steadily dropped with increasing burnout. The peak appeared between about 15 to $35 \%$ burnout, corresponding to the coal particle sizes 78 to $22 \mu \mathrm{m}$. The surface areas also decreased with increasing gas temperatures. The particle size and density were found both to reduce with burnout, indicating that the oxygen partially penetrated into the pore structure. The surface area of char generated in nitrogen 
for two seconds was also reported to decrease when burning in air (Sahu, 1988). Smith and Tyler (1972) collected partially burned chars and examined them by optical microscopy, porosimetry and $\mathrm{X}$-ray diffraction. They reported that macropores $(>0.02$ $\mu \mathrm{m})$ increased with burnout, but micropores $(<0.02 \mu \mathrm{m})$ decreased. A sharpening of a graphite band in the $\mathrm{X}$-ray pattern indicated that some structural ordering took place. The decrease in surface area was believed to be related to the closure of micropores associated with thermally induced alterations in solid structure.

The ash content and the carbon conversion ( $\eta$ as defined in Eq. 7) in chars produced under different conditions are plotted in the Figs. 16 and 17. In our drop-tube reactor experiments, the bulk of devolatilization of coal particles in nitrogen was completed within $100 \mathrm{~ms}$ as shown by the approximately equal ash contents of N1 and N2 chars, although there were some changes of $\mathrm{C}, \mathrm{H}$, and $\mathrm{N}$ contents measured by elemental analysis. The volatile yield was $10 \%$ higher than the value given by the ASTM proximate volatile analysis (Table 1) due to high temperature and the rapid mass and heat transfer. The weight loss, or conversion, increased with oxygen concentration. For the chars generated in oxygen, conversion also increased with residence time. The conversion calculated with initial carbon the carbon remaining after pyrolysis in $\mathrm{N}_{2}$ for $100 \mathrm{~ms}$, and excluding ash is given by

$$
\eta^{\prime}=\frac{\eta-\eta_{N I}}{\left(I-\eta_{N I}\right)}
$$

are listed in Table 3. Even within $100 \mathrm{~ms}$, there was $26 \%$ fixed carbon burned in $1 \% \mathrm{O}_{2}$ and $18 \%$ more in $5 \% \mathrm{O}_{2}$. By $300 \mathrm{~ms}$, more than one third of the fixed carbon was lost in $1 \% \mathrm{O}_{2}$, and over $80 \%$ fixed carbon was consumed in $5 \% \mathrm{O}_{2}$. Jost er al. (1984) studied the devolatilization of pulverized coal in a flow tube reactor at gas temperatures between $1300 \mathrm{~K}$ and $2000 \mathrm{~K}$ and oxygen concentrations between $7 \%$ and $16 \%$. They reported that the devolatilization rates increased with increasing oxygen concentration for a given gas temperature. They suggested that energy from the oxidizing volatiles was fed back to the coal particles, increasing their temperature and thereby the vclatile release rate and yield. An increase of the particle temperature due to the oxidation of volatiles was also reported by Seeker et al. (1981). Devolatilization rates and yields increase with particle temperature have also been observed in experiments by Kimber and Gray (1967) and Kobayashi et al. (1977). 
The char conversions, $\chi$ as defined in Eq. 8, are measured with the TGA and plotted in Figs. 18 to 20. The apparent reaction rates in Figs. 18 to 20 were obtained by differentiating the conversion curves. The char reactivities were obviously affected by the charring history. In all cases the char reactivity decreased with the content of oxygen. As shown in Figs. 18 to 20, the apparent rates increase sharply during the first 5 to 10\% carbon conversion and then decrease. This phenomenon could result from the gradual chemisorption of oxygen. The sample was initially heated in nitrogen to reach the desired temperature. Oxygen was then immediately introduced. The gas composition over the sample, however, changes gradually from pure nitrogen to a final mixture of $5 \%$ oxygen in nitrogen. Jenkins et al. (1973) suggested that oxygen complex formation at the surface and char activation may also be important at this early stage of conversion. After the apparent rates reached the maximum, they decreased with time. The difference in apparent rate among the various chars decreased with conversion. After 60 to $70 \%$ carbon conversion, all the chars oxidized with quite similar rates. At the low temperature of the TGA experiments, the reaction is under kinetic control as it can be shown by an estimate of the Thiele modulus for the reaction. To achieve $70 \%$ conversion needs 40 :o 60 minutes. During this long period, the vore reactive fraction of the combustible material would have burned, leaving behind the more inern fraction. Significant reorganization of char structure could also have been completed. Therefore, the difference in chemical and physical properties of the various chars, which affect the reaction rate, could have been largely eliminated resulting in more uniform oxidation rates.

\section{Conclusions}

Structural changes of char and their effect on char reactivity have been examined under pulverized coal combustion conditions. When heated in neutral or oxidizing atmosphere, the great majority of the hvA bituminous coal (PSOC 1451) particles undergo a series of structural changes. Hollow sphere are formed, followed by particle fragmentation. In 1 or $5 \%$ oxygen, oxidation proceeds both externally and internally at approximately constant diameter until the onset of fragmentation. For all of the chars, the surface area and the pore volume in the size range 15 to $120 \AA$ increased dramatically within the first $100 \mathrm{~ms}$ compared with the original coal. The ratio of carbon to hydrogen increases with residence time. Carbon conversion at $1600 \mathrm{~K}$ also increases with increasing oxygen pressure. But the char reactivity measured at the low temperature TGA experiments was decreased. Significant structural reorganization occurred either simultaneously with devolatilization or continuously after devolatilization depending on the oxygen 
concentration. Oxygen appeared to accelerate the structural changes and to change the reactivity of the char.

\section{ACKNOWLEDGEMENTS}

This work was supported by the U.S. Department of Energy, University Coal Research Program under grant number DE-FG2.2-88PC88911. 


\section{REFERENCES}

Anson, D., Moles, F. D., and Street, P. J. (1971), Comb. \& Flame, 16, 265.

Cranston, R. W., and Inkley, F. A. (1957), Adv. In Cat., 2, 143.

Haussmann, G. J., and Kruger, C. H. (1988), 22nd Symp. (Int.) on Comb., The Combustion Institute, Pittsburgh, PA, 223.

Jenkins, R. G., Nandi, S. P. and Walker Jr., P. L. (1973), Fuel, 52, 288.

Jost, M., Leslie, 1., and Kruger, C. (1984), 20th Symp. (Int.) on Comb., The Combustion Institute, Pittsburgh, PA, 1531.

Kimber, G. M., and Gray, M. D. (1967), Comb. \& Flame, 11, 360.

Kobayashi, H., Howard, J. B., and Sarofim, A. F. (1977), 16th Symp. (Int.) on Combustion, The Combustion Institute, Pittsburgh, PA, 411.

Levendis, Y. A., and Flagan, R. C. (1987), Comb. Sci.\& Tech., 53, 117.

Levendis, Y. A., Flagan, R. C., and Gavalas, G. R. (1989), Comb. \& Flame, 76, 221.

Lippens, B. C., Linsen, B. G., and de Boer, J. H. (1964), J. cat., 3, 32.

Northrop, P. S. (1988), A Fundamental Study of Char Combustion: Chunges in Particle Morphology during Oxidation, Ph. D. Thesis, California Institute of Technology.

Northrop, P. S., Gavalas, G. R., and Flagan, R. C. (1987), Langmuir, 3, 300.

Sahu, R. (1988), On the Combustion of Bituminous Coal Chars, Ph. D. Thesis, California Institute of Technology.

Seeker, W. R., Samuelsen, G. S., et al. (1981), 18th Symp. (Int.) on Comb., The Combustion Institute, Pittsburgh, PA, 1213.

Smith, I. W. (1982), 19th Symp. (Int.) on Comb., The Combustion Institute, Pittsburgh, PA, 1045.

Smith, I. W. and Tyler, R. J. (1972), Fuel, 51, 312.

Wells, W. F. and Smoot, L. D. (1991), Fuel, 70, 454.

Wheeler, A. (1946), Catalyst Symposium, Gibson Island AAAS Conference. 
Table 1 Properties of Raw Coal

\begin{tabular}{|c|c|}
\hline PSOC\# & 1451 \\
\hline Rank & HVAB \\
\hline Location & Pennsylvania \\
\hline Seam & Pittsburgh \\
\hline Proximate Analysis (\%) & 2.54 \\
moisture & 13.32 \\
ash & 33.56 \\
volatiles & 50.58 \\
fixed carbon & \\
\hline Ultimate Analysis (\%) & 13.32 \\
ash & 70.05 \\
carbon & 4.55 \\
hydrogen & 1.33 \\
nitrogen & 1.33 \\
sulfur & 0.07 \\
chlorine & 6.81 \\
oxygen* & 7.5 \\
\hline FSI & \\
\hline
\end{tabular}

*moisture excluded 
Table 2 Repeatability of the Surface Area Measurements

a. The measurements with the same sample:

\begin{tabular}{|c|c|c|c|c|}
\hline Sample & $\begin{array}{c}\text { Sample Size } \\
(\mathrm{gm})\end{array}$ & $\begin{array}{c}\text { Surface area } \\
\left(\mathrm{m}^{2}\right) \\
\end{array}$ & $\begin{array}{c}\text { Specific Surface Area } \\
\left(\mathrm{m}^{2} / \mathrm{gm}\right)\end{array}$ & $\frac{\Delta S}{S i}$ \\
\hline $\begin{array}{l}1 \% \mathrm{O}_{2} \\
200 \mathrm{~ms}\end{array}$ & 0.0596 & $\begin{array}{l}0.412 \\
0.511\end{array}$ & $\begin{array}{c}8.28 \\
10.43\end{array}$ & $\begin{array}{l}0.259 \\
0.205\end{array}$ \\
\hline $\begin{array}{l}5 \% \mathrm{O}_{2} \\
200 \mathrm{~ms} \\
\end{array}$ & 0.1066 & $\begin{array}{l}0.378 \\
0.453 \\
\end{array}$ & $\begin{array}{l}3.54 \\
4.25 \\
\end{array}$ & $\begin{array}{l}0.198 \\
0.166 \\
\end{array}$ \\
\hline $\begin{array}{l}5 \% \mathrm{O}_{2} \\
300 \mathrm{~ms}\end{array}$ & 0.0908 & $\begin{array}{l}0.410 \\
0.482\end{array}$ & $\begin{array}{l}4.51 \\
5.31\end{array}$ & $\begin{array}{l}0.176 \\
0.149\end{array}$ \\
\hline$\gamma-\mathrm{Al}_{2} \mathrm{O}_{3}$ & 0.0136 & $\begin{array}{l}2.12 \\
2.37\end{array}$ & $\begin{array}{l}155.1 \\
173.9\end{array}$ & $\begin{array}{l}0.118 \\
0.105\end{array}$ \\
\hline
\end{tabular}

b. The measurements with the same material:

\begin{tabular}{|c|c|c|c|c|}
\hline Sample & $\begin{array}{c}\text { Sample Size } \\
(\mathrm{gm}) \\
\end{array}$ & $\begin{array}{c}\text { Surfac : vea } \\
\left(\mathrm{m}^{2}\right) \\
\end{array}$ & $\begin{array}{c}\text { Specific Surface Area } \\
\left(\mathrm{m}^{2} / \mathrm{gm}\right)\end{array}$ & $\frac{\Delta S_{\max }}{S_{\mathrm{i}}}$ \\
\hline $\mathrm{N}_{2}{ }^{*}$ & 0.2181 & 2.77 & 15.7 & 0.013 \\
\hline $200 \mathrm{~ms}$ & 0.2145 & 2.68 & 15.5 & 0.013 \\
\hline $1 \% \mathrm{O}_{2}$ & 0.1164 & 0.811 & 8.36 & 0.248 \\
\hline $200 \mathrm{~ms}$ & 0.0596 & 0.511 & 10.43 & 0.198 \\
\hline \multirow{3}{*}{$\gamma-\mathrm{Al}_{2} \mathrm{O}_{3}$} & 0.1405 & 24.0 & 170.8 & 0.092 \\
\hline & 0.0497 & 8.39 & 168.8 & 0.093 \\
\hline & 0.0136 & 2.12 & 155.1 & 0.101 \\
\hline
\end{tabular}

*The char was 53-90 $\mu \mathrm{m}$, and generated from 38-74 $\mu \mathrm{m}$ coal. 
Table 3 Characterization of PSOC 1451 1600K Chars

\begin{tabular}{|c|c|c|c|c|c|c|c|c|c|c|c|}
\hline \multirow[t]{2}{*}{ char } & \multirow{2}{*}{$\begin{array}{l}\text { time } \\
\text { (ms) }\end{array}$} & \multirow[t]{2}{*}{ name } & \multirow{2}{*}{$\begin{array}{l}\mathrm{R}_{\text {ash }} \\
(\%)\end{array}$} & \multicolumn{2}{|c|}{ conversion (\%) } & \multicolumn{2}{|c|}{$S\left(\mathrm{~m}^{2} \mathrm{gm}^{-1}\right)$} & \multicolumn{3}{|c|}{ mean mass fraction $(\%)$} & \multirow[t]{2}{*}{$\mathrm{C} / \mathrm{H}$} \\
\hline & & & & $\eta^{1}$ & $\eta^{\prime 2}$ & total & d.a.f. ${ }^{3}$ & C & $\mathbf{H}$ & $N$ & \\
\hline \multirow{3}{*}{$\mathbf{N}_{2}$} & 100 & N1 & $\begin{array}{c}18.0 \\
(21.6)^{4} \\
\end{array}$ & 46.6 & - & $\begin{array}{c}4.15 \\
(3.04)^{4} \\
\end{array}$ & $\begin{array}{c}4.58 \\
(3.27)^{4} \\
\end{array}$ & 68.02 & 0.86 & 1.14 & 79.09 \\
\hline & 200 & N2 & $\begin{array}{c}17.7 \\
(22.63)^{4} \\
\end{array}$ & 45.5 & - & $\begin{array}{c}14.2 \\
(12.7)^{4} \\
\end{array}$ & $\begin{array}{c}16.8 \\
(15.7)^{4} \\
\end{array}$ & 83.49 & 0.98 & 1.08 & 85.19 \\
\hline & 300 & N3 & $=$ & - & - & - & - & 82.97 & 0.81 & 0.845 & 102.4 \\
\hline \multirow{3}{*}{$1 \% \mathrm{O}_{2}$} & 100 & 011 & $\begin{array}{c}22.9 \\
(21.7)^{5} \\
\end{array}$ & 60.5 & 26.0 & $\begin{array}{r}10.2 \\
(9.33)^{5} \\
\end{array}$ & $\begin{array}{c}12.6 \\
(11.3)^{5} \\
\end{array}$ & 73.96 & 0.80 & 1.32 & 93.03 \\
\hline & 200 & 012 & $\begin{array}{c}22.5 \\
(27.5)^{4} \\
\end{array}$ & 59.6 & 24.3 & $\begin{array}{c}6.97 \\
(5.01)^{4} \\
\end{array}$ & $\begin{array}{c}8.36 \\
(6.08)^{4} \\
\end{array}$ & 74.51 & 0.69 & 1.30 & 108.0 \\
\hline & 300 & 013 & 25.5 & 65.7 & 35.8 & - & - & 74.99 & 0.65 & 1.20 & 115.4 \\
\hline \multirow{3}{*}{$5 \% \mathrm{O}_{2}$} & 100 & 051 & 28.3 & 70.3 & 44.4 & 17.2 & 23.1 & 64.63 & 0.88 & 1.21 & 73.17 \\
\hline & 200 & 052 & 37.2 & 80.2 & 62.9 & 3.54 & 4.34 & 60.04 & 0.73 & 1.12 & 82.81 \\
\hline & 300 & O53 & 58.4 & 91.6 & 84.3 & 4.51 & 7.77 & 48.16 & 0.64 & 0.835 & 75.83 \\
\hline
\end{tabular}

*1. $R_{\mathrm{ash}}=10.5(\%) ; \quad 2 . \eta_{\mathrm{N} 1}^{\prime}=46.6(\%) ; \quad 3 . \mathrm{S}_{\mathrm{ssh}}=2.19\left(\mathrm{~m}^{2} \mathrm{gm}^{-1}\right)$

4. The char was $53-90 \mu \mathrm{m}$, and generated from $38-74 \mu \mathrm{m}$ coal; the coal feed rate is 5 gm hour ${ }^{-1}$.

5. The char was generated from 53-61 $\mu \mathrm{m}$. 


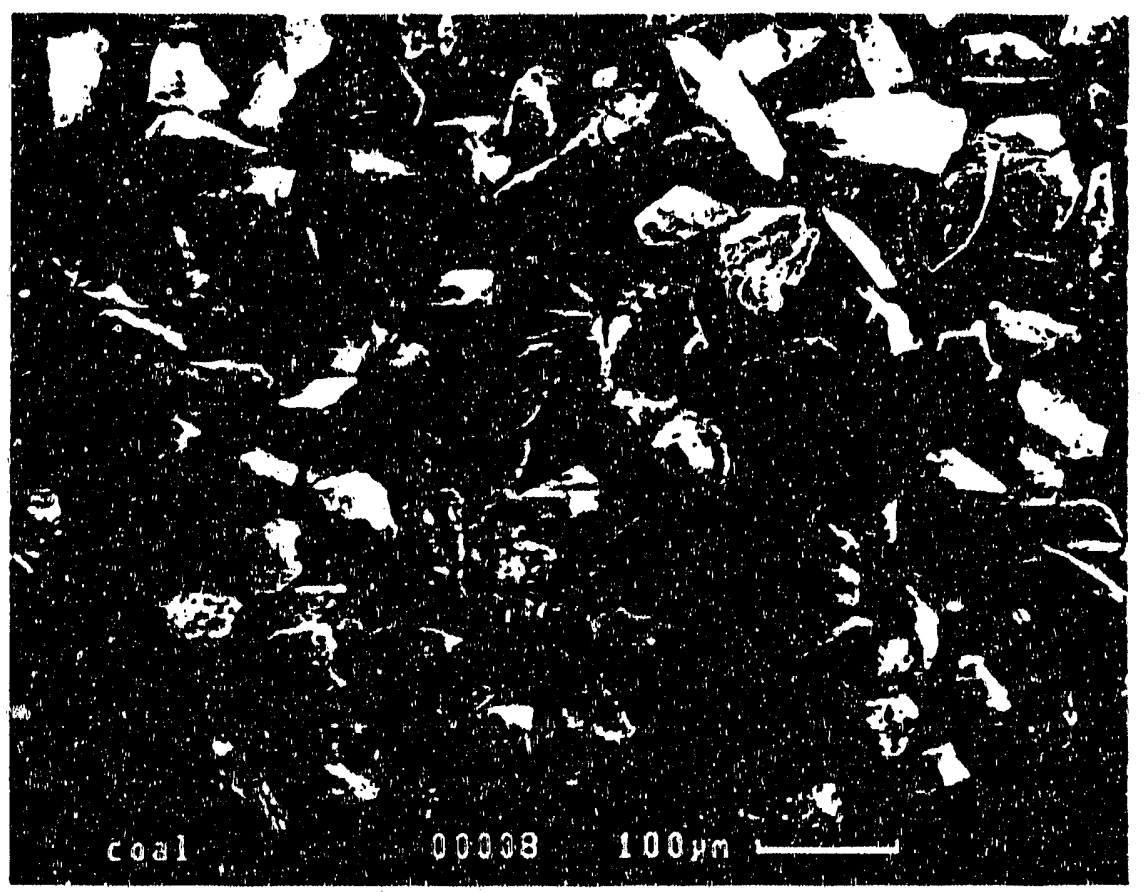

Fig. 1 Unreacted PSOC 1451 coal particles 

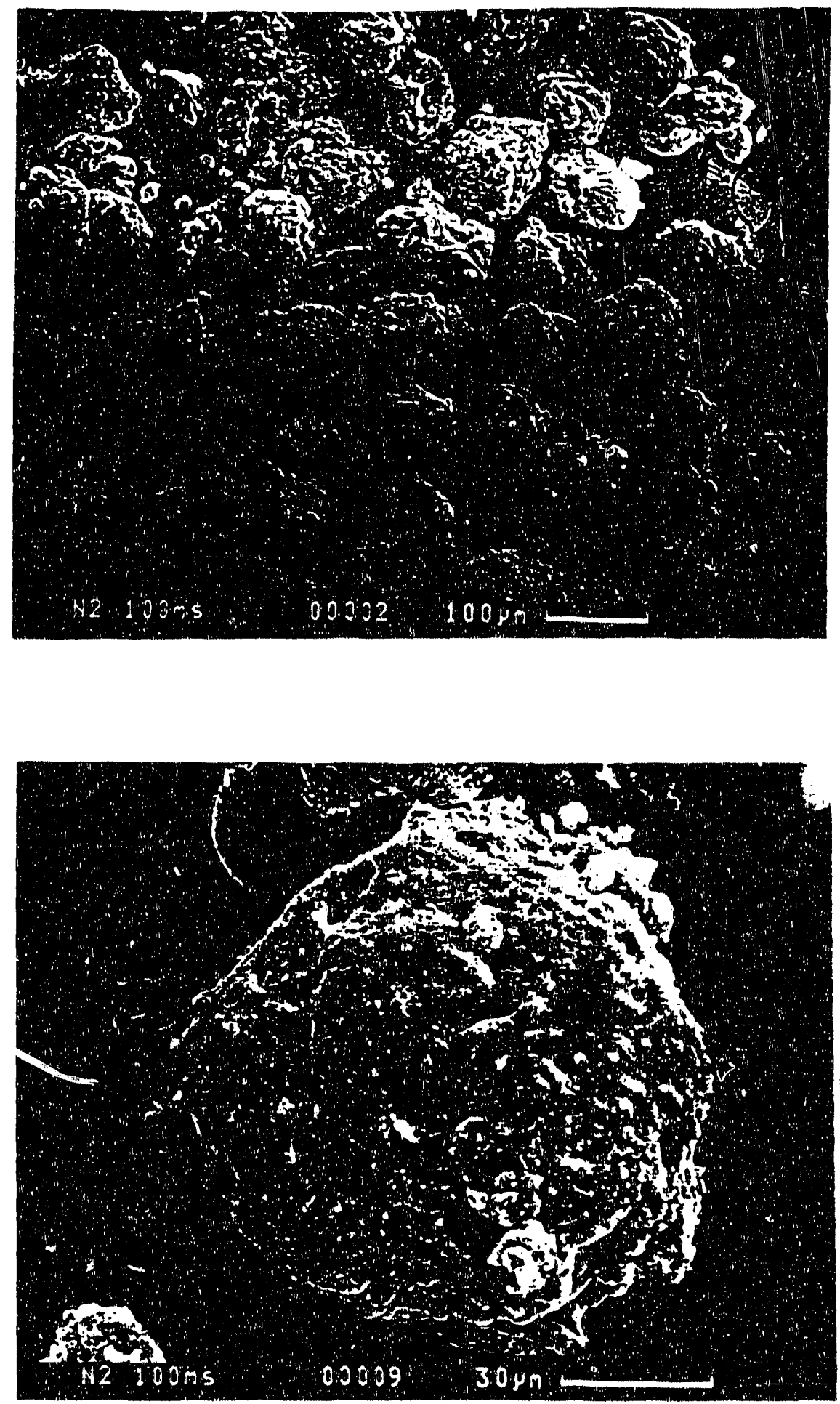

Fig. 2 Char particles produced in $\mathrm{N}_{2}$ at, $00 \mathrm{~ms}$ 

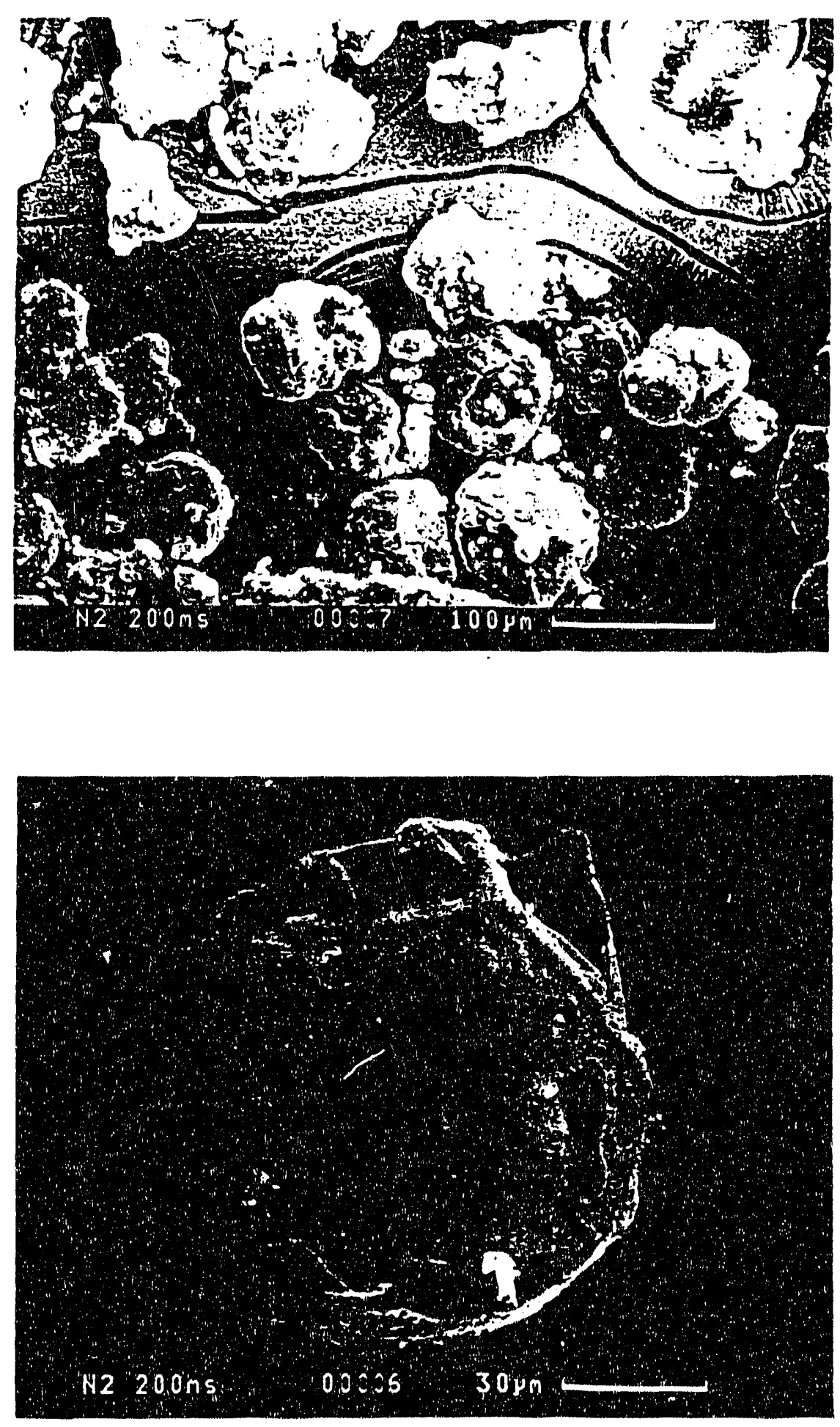

Fig. 3 Char particles produced in $\mathrm{N}_{2}$ at $200 \mathrm{~ms}$ 

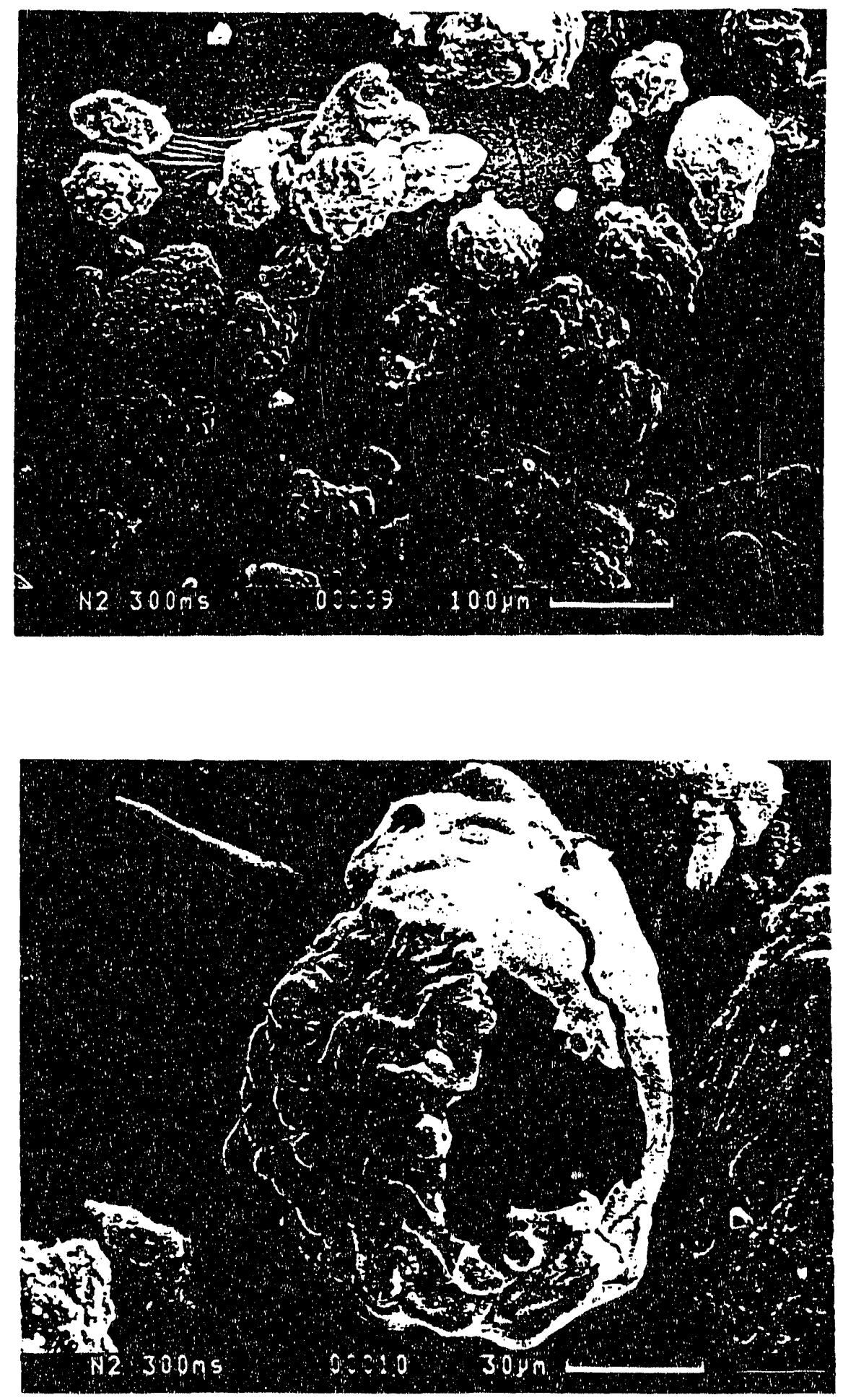

Fig. 4 Char particles produced in $\mathrm{N}_{2}$ at $300 \mathrm{~ms}$ 

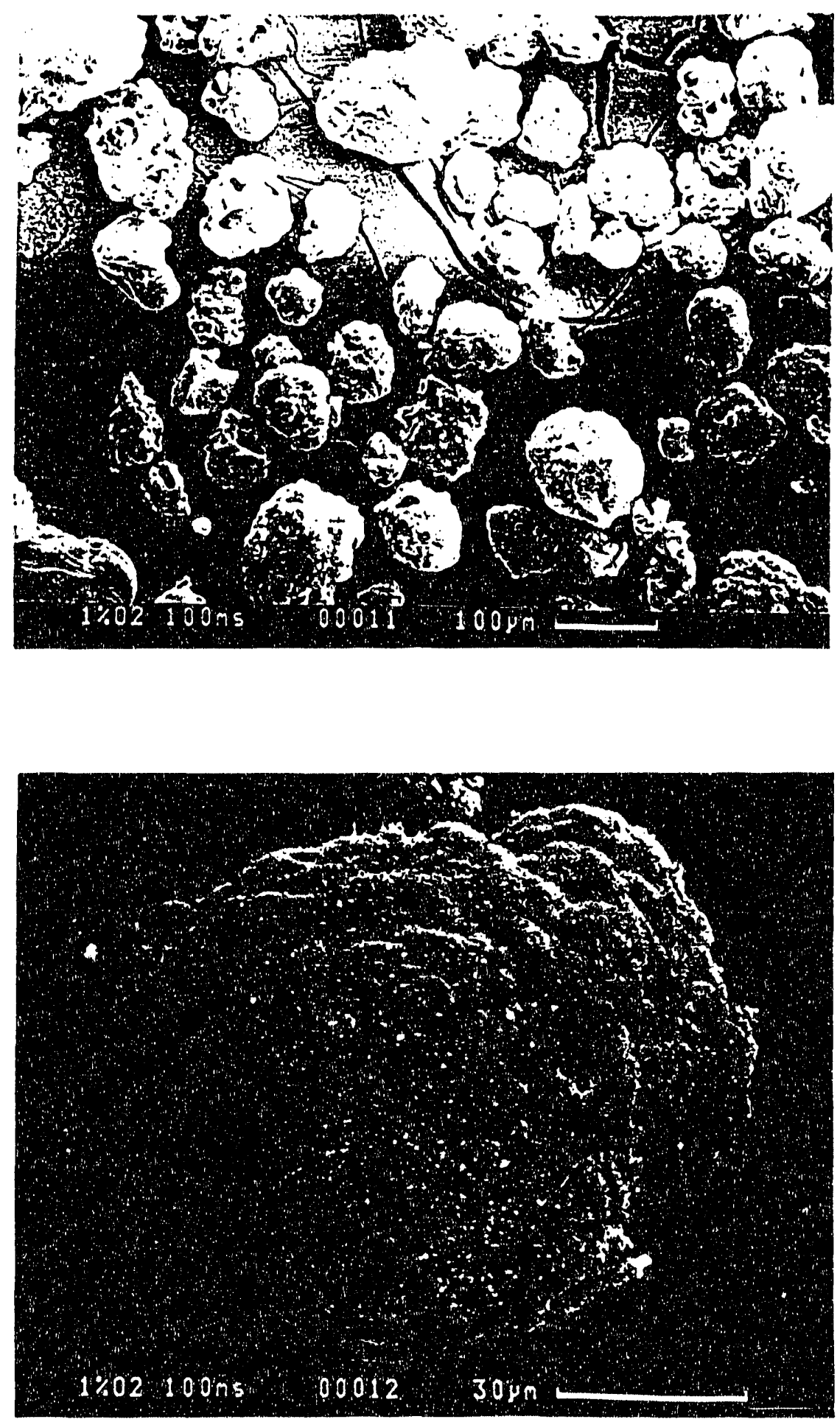

Fig. 5 Char particles produced in $1 \% \mathrm{O}_{2}$ at $100 \mathrm{~ms}$ 

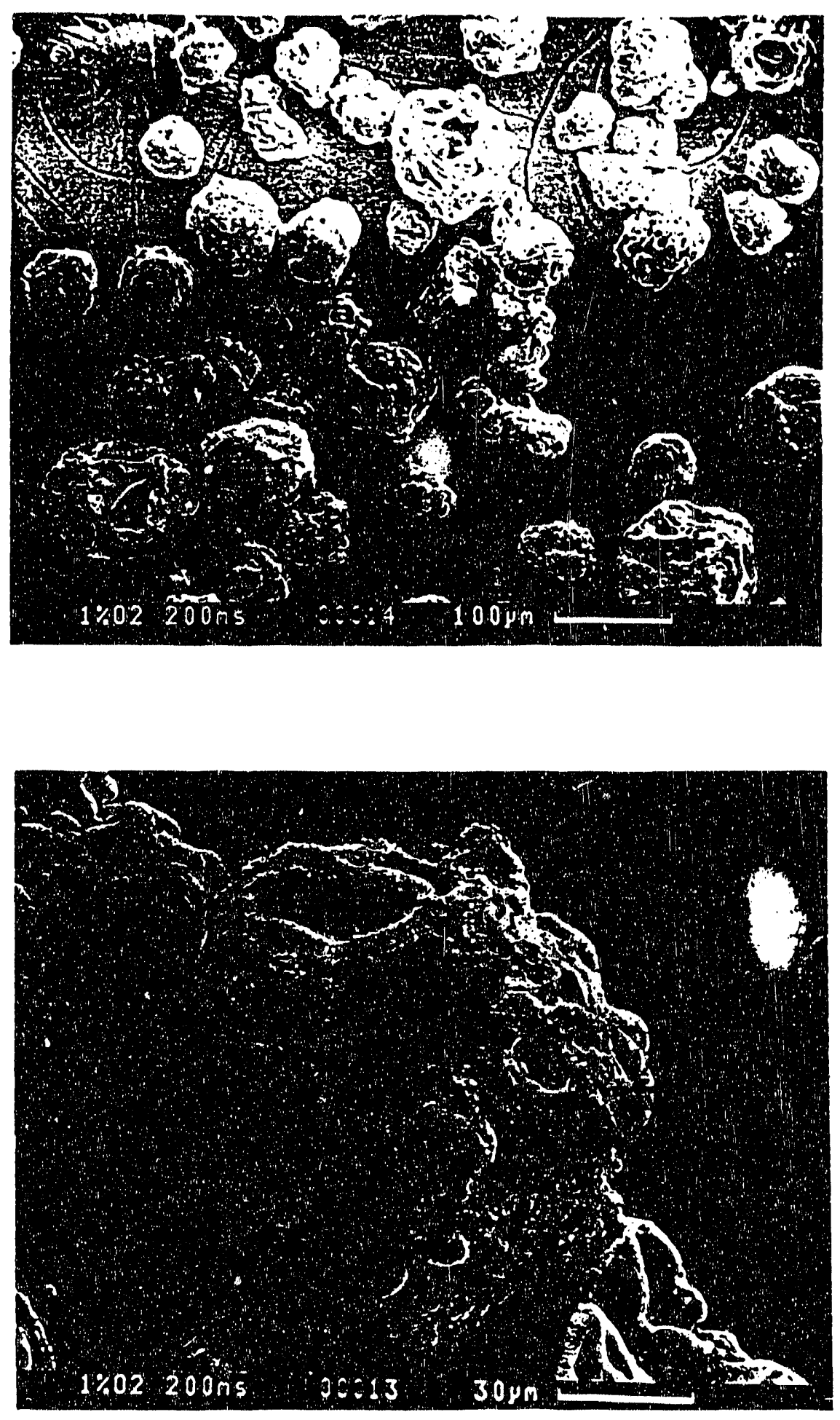

Fig. 6 Char particles produced in $1 \% \mathrm{O}_{2}$ at $200 \mathrm{~ms}$ 

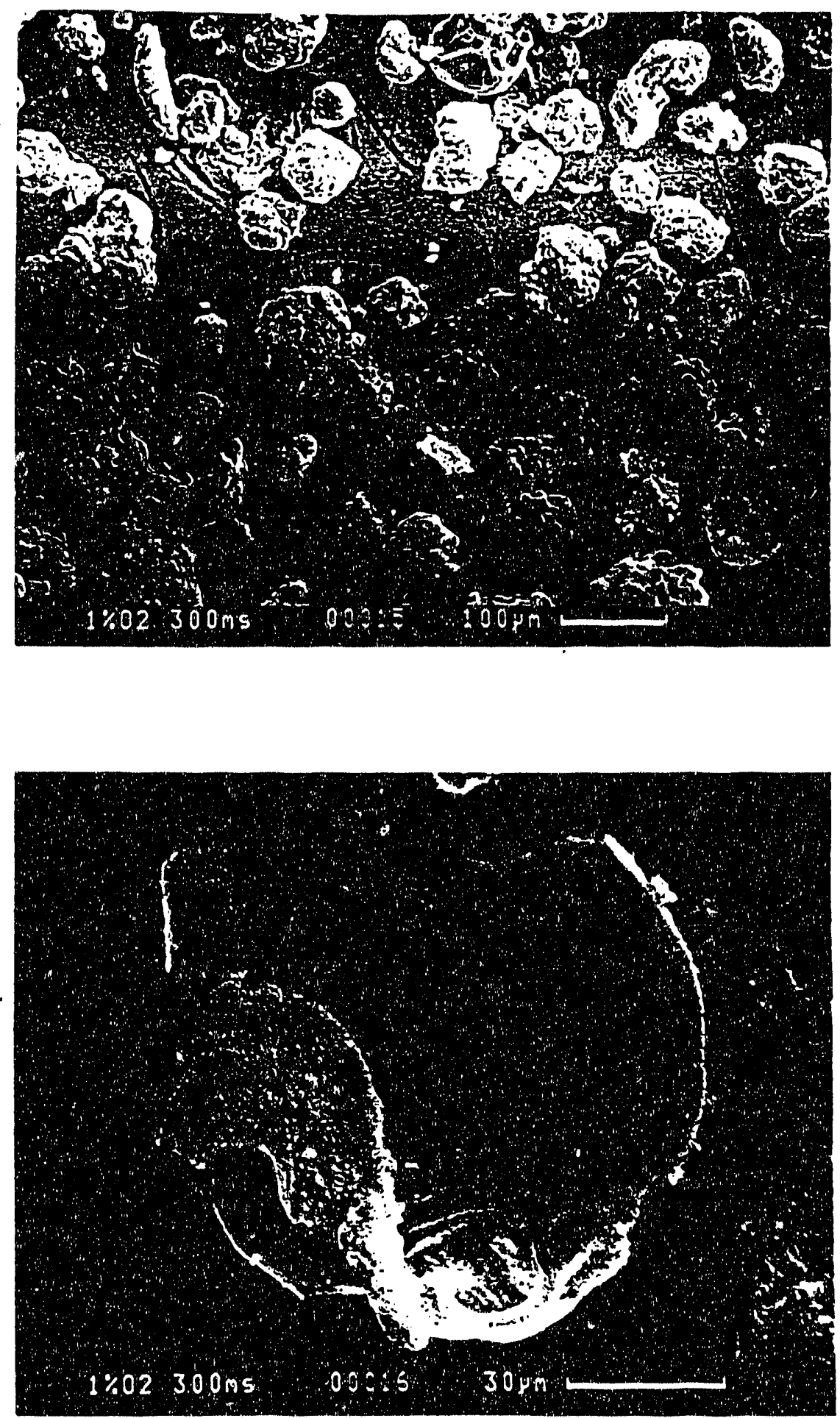

Fig. 7 Char particles produced in $1 \% \mathrm{O}_{2}$ at $300 \mathrm{~ms}$ 

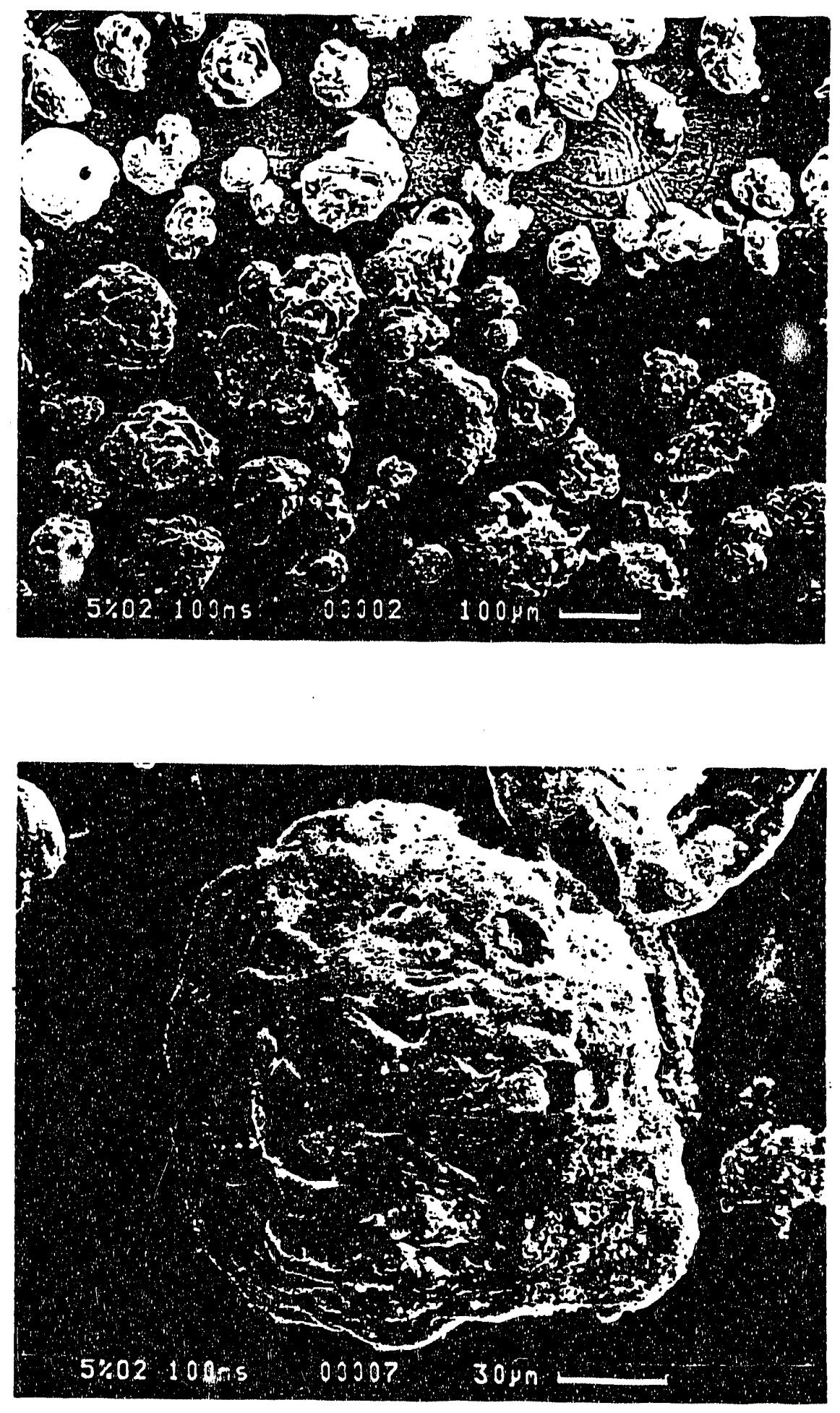

Fig. 8 Char particles produced in $5 \% \mathrm{O}_{2}$ at $100 \mathrm{~ms}$ 

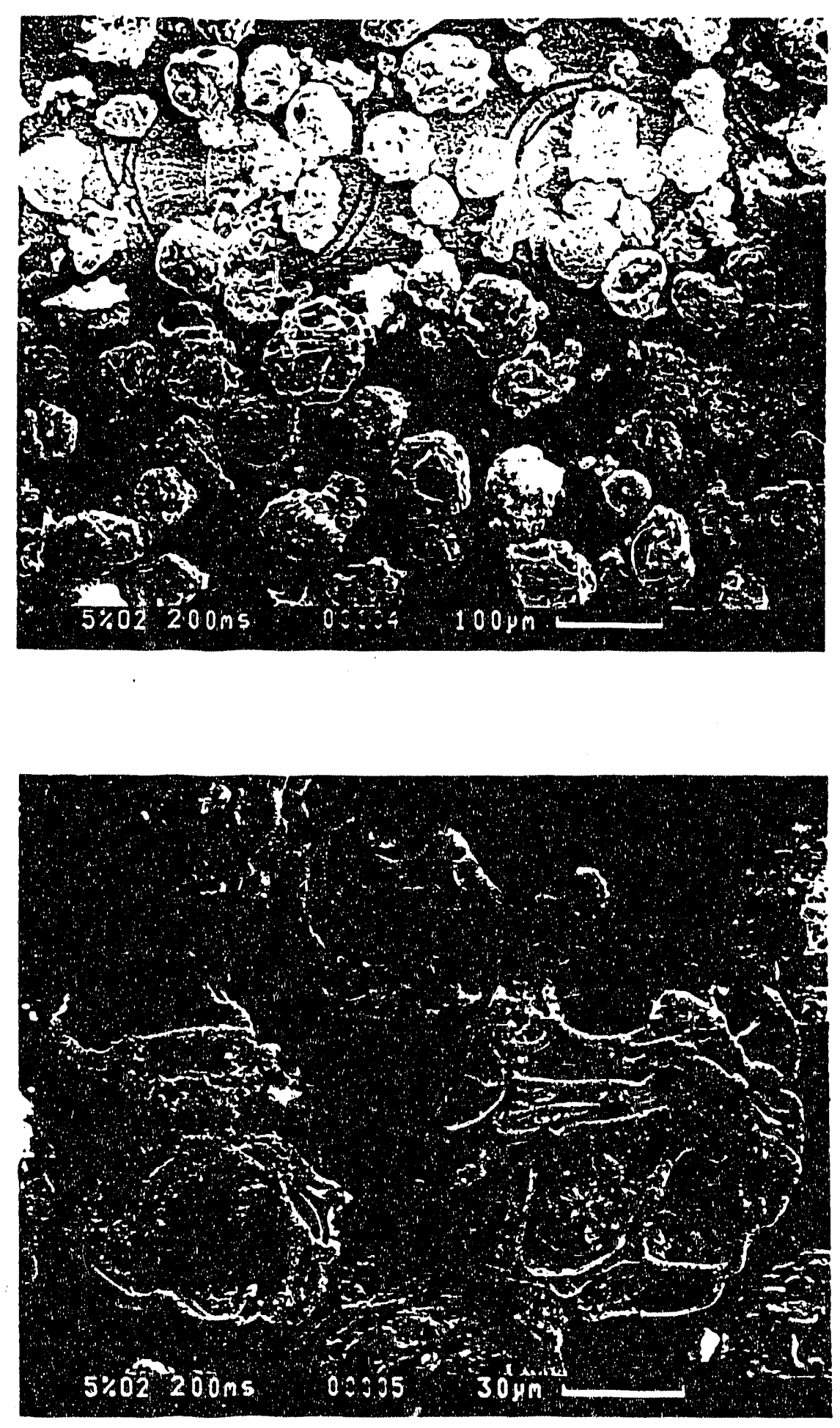

Fig. 9 Char particles produced in $5 \% \mathrm{O}_{2}$ at $200 \mathrm{~ms}$ 


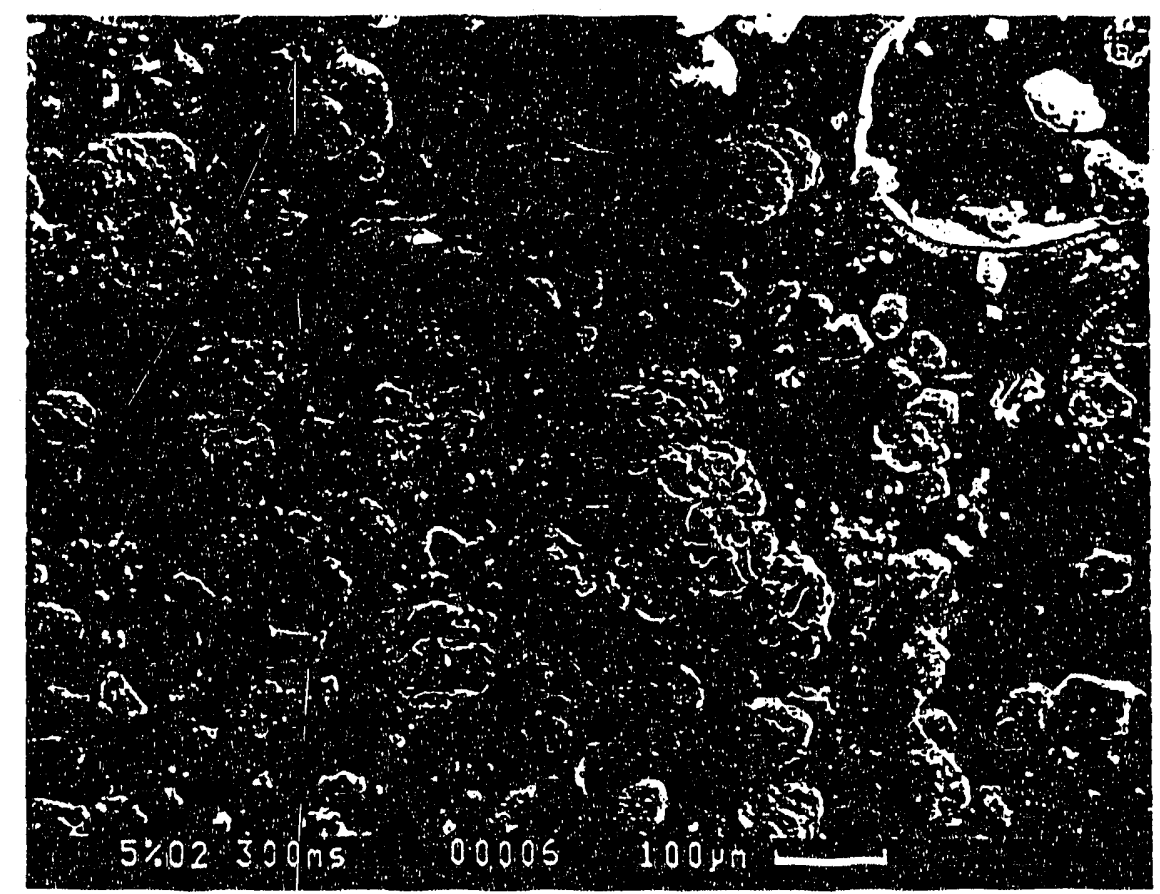

Fig. 10 Char particles produced in $5 \% \mathrm{O}_{2}$ at $300 \mathrm{~ms}$ 


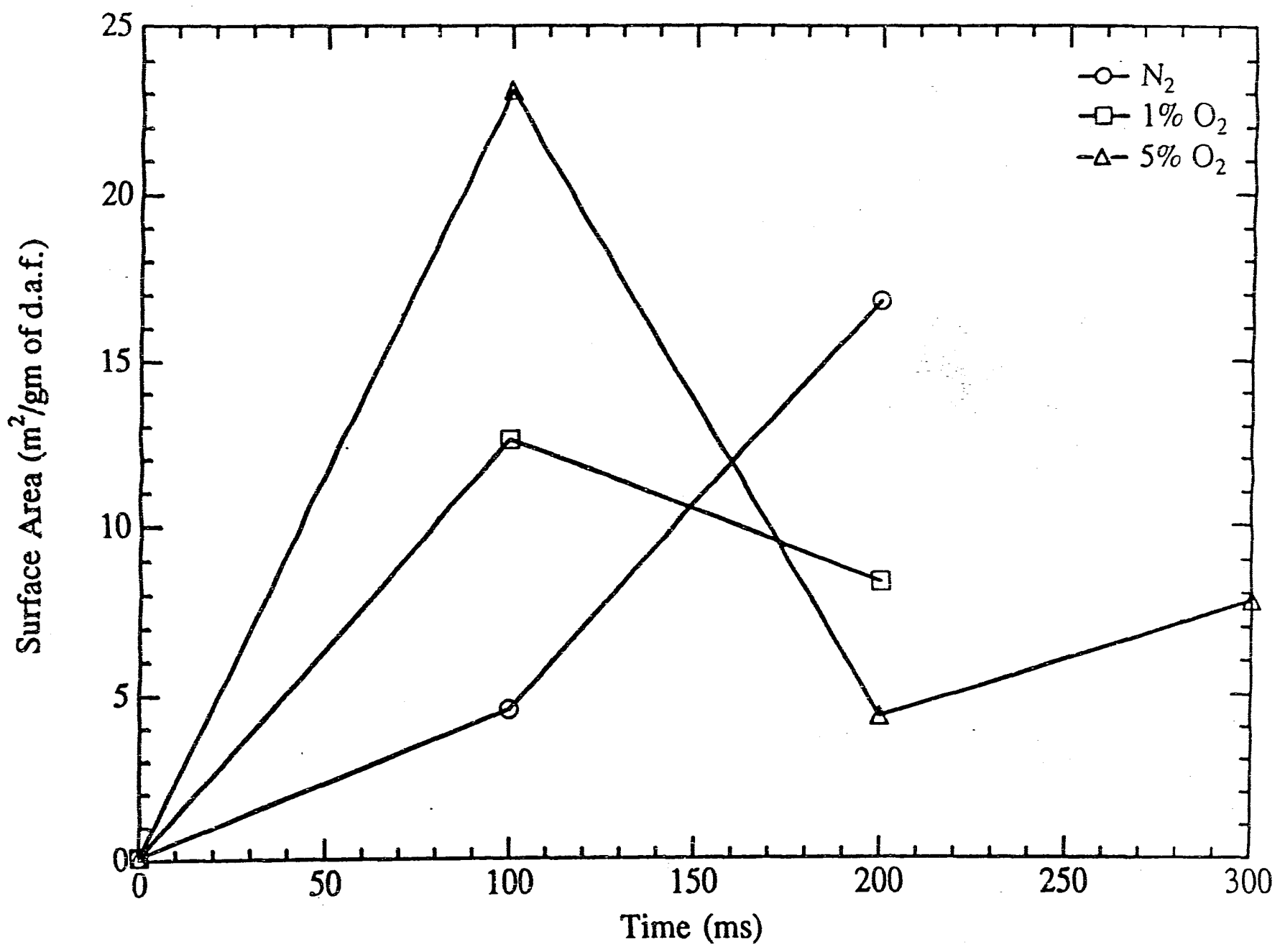

Fig. 11 Surface area of various chars at $1600 \mathrm{~K}$ derived from drop-tube reactor experiments (dry ash free basis) 


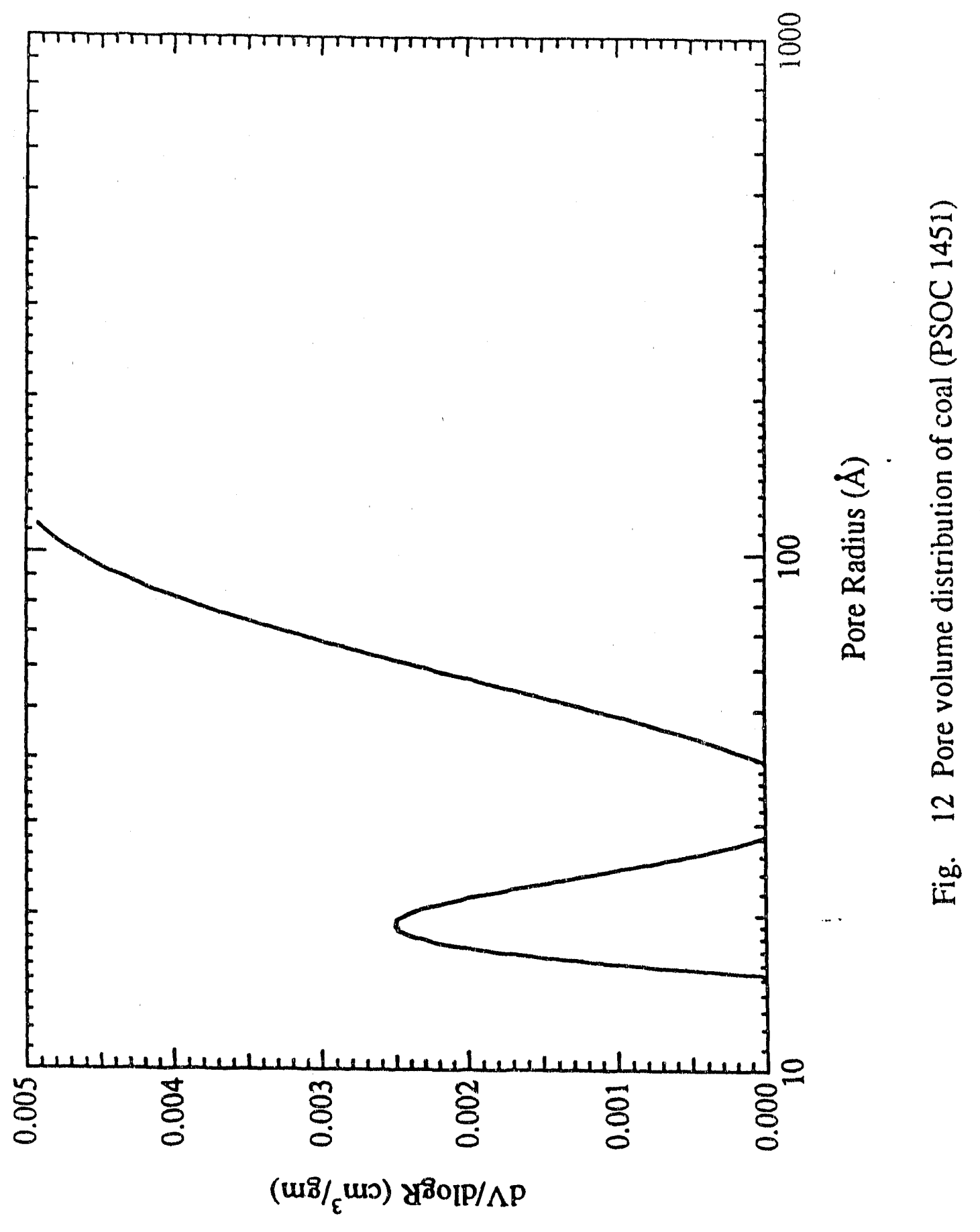




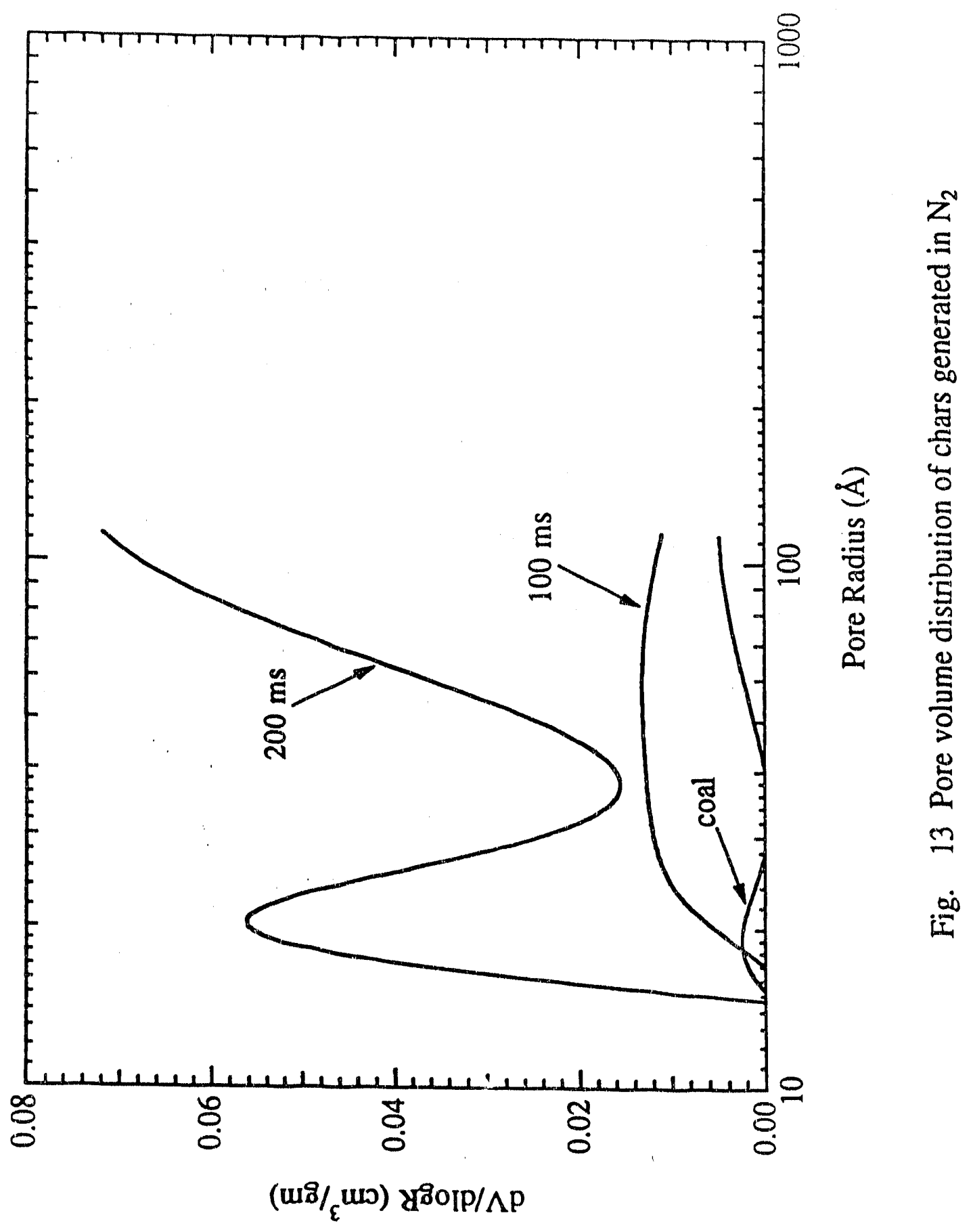




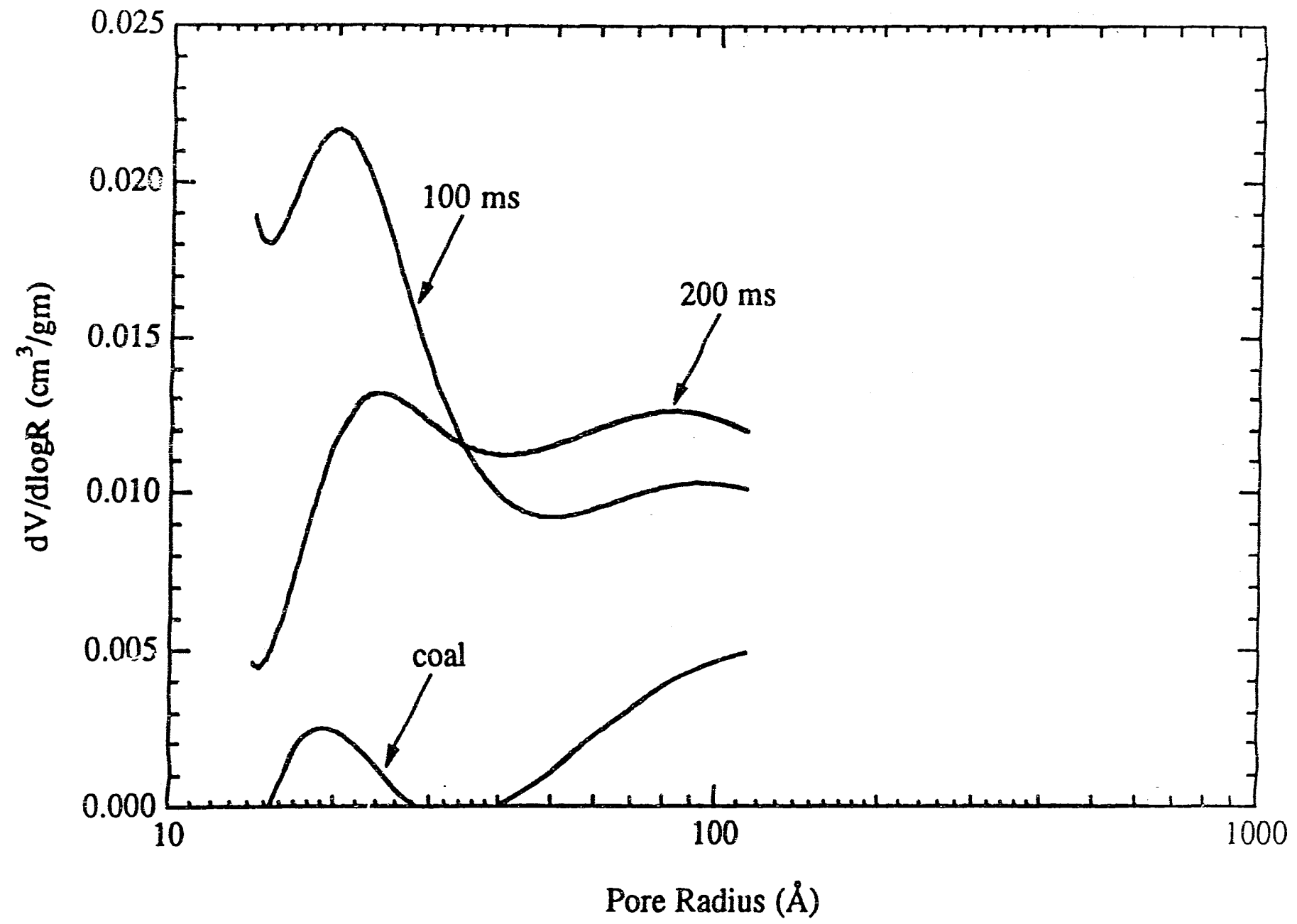

Fig. 14 Pore volume distribution of chars generated in $1 \% \mathrm{O}_{2}$ 


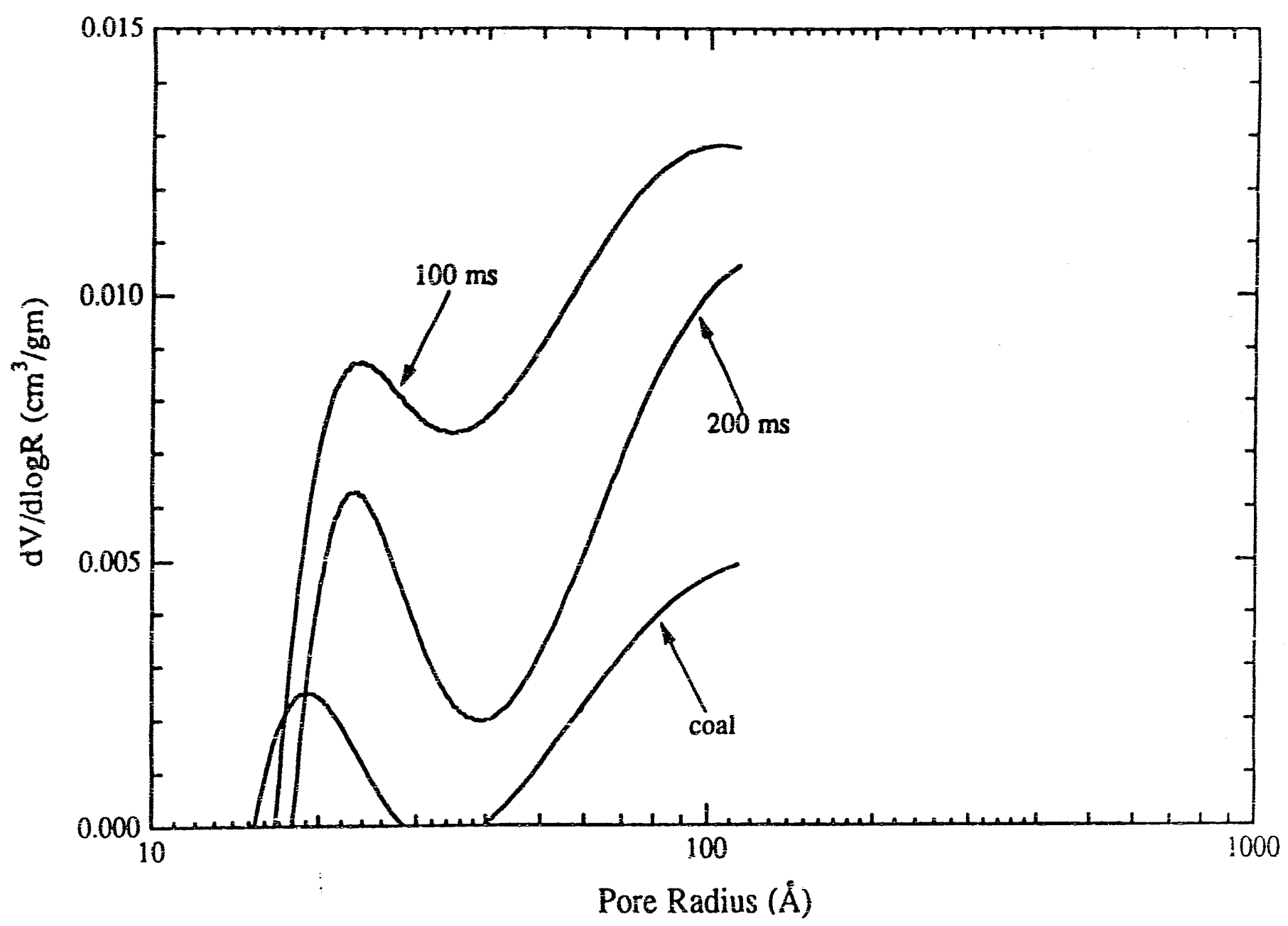

Fig. 15 Pore volume distribution of char generated in $5 \% \mathrm{O}_{2}$ 


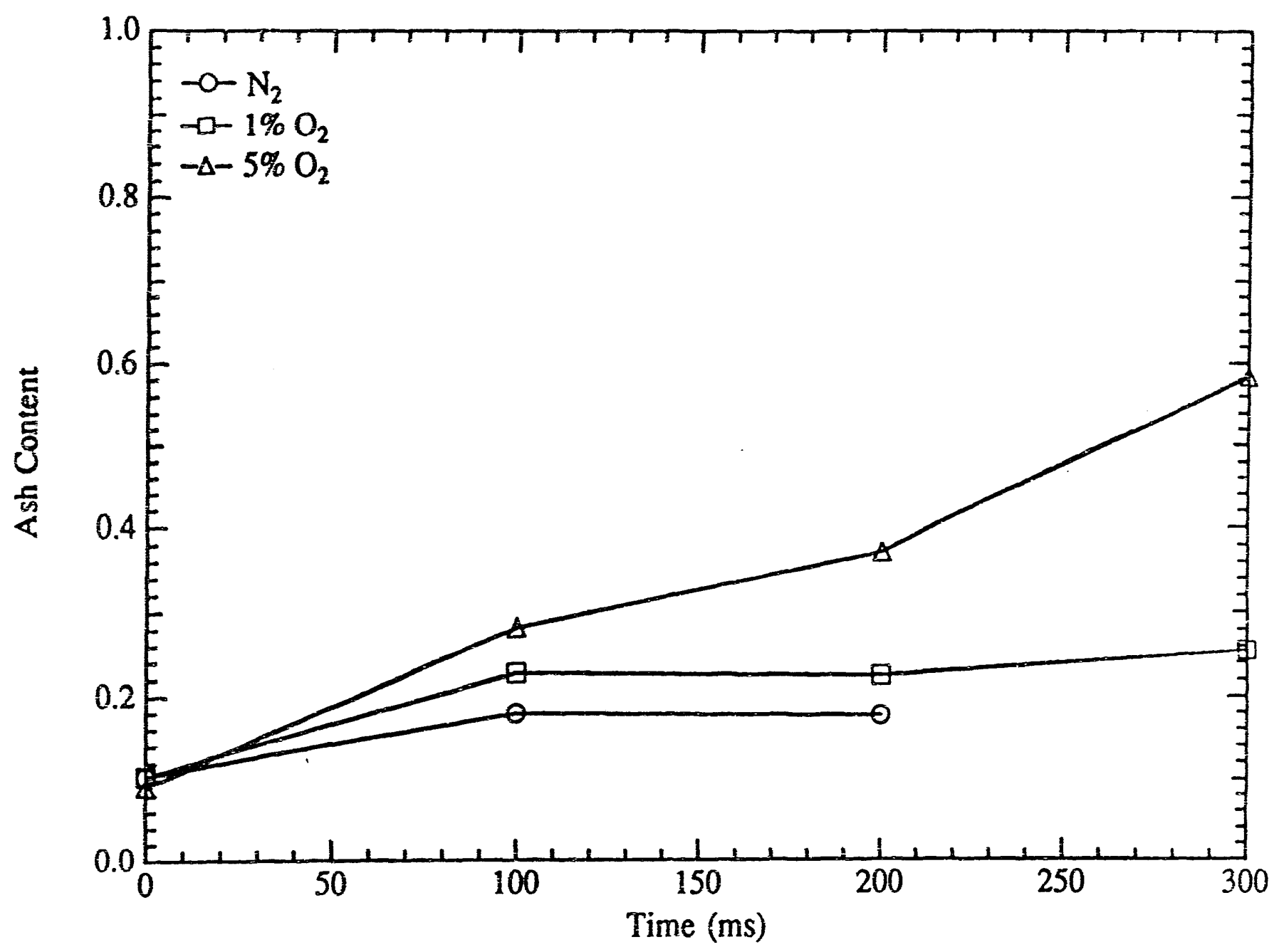

Fig. 16 Ash content of various chars at $1600 \mathrm{~K}$ derived from drop-tube reactor experiments 


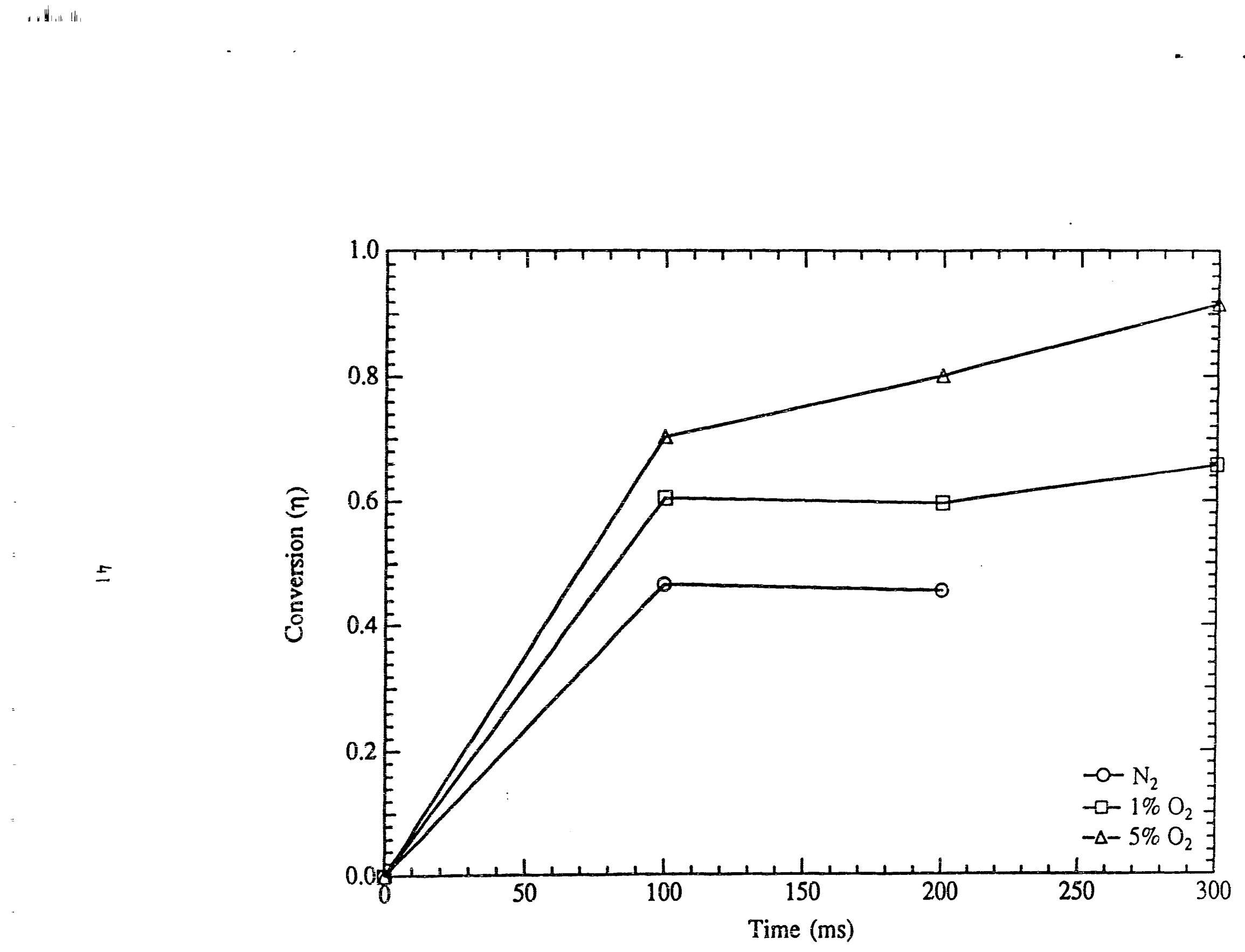

Fig. 17 Conversion of various chars at $1600 \mathrm{~K}$ derived from drop-tube reactor experiments (dry ash free basis) 


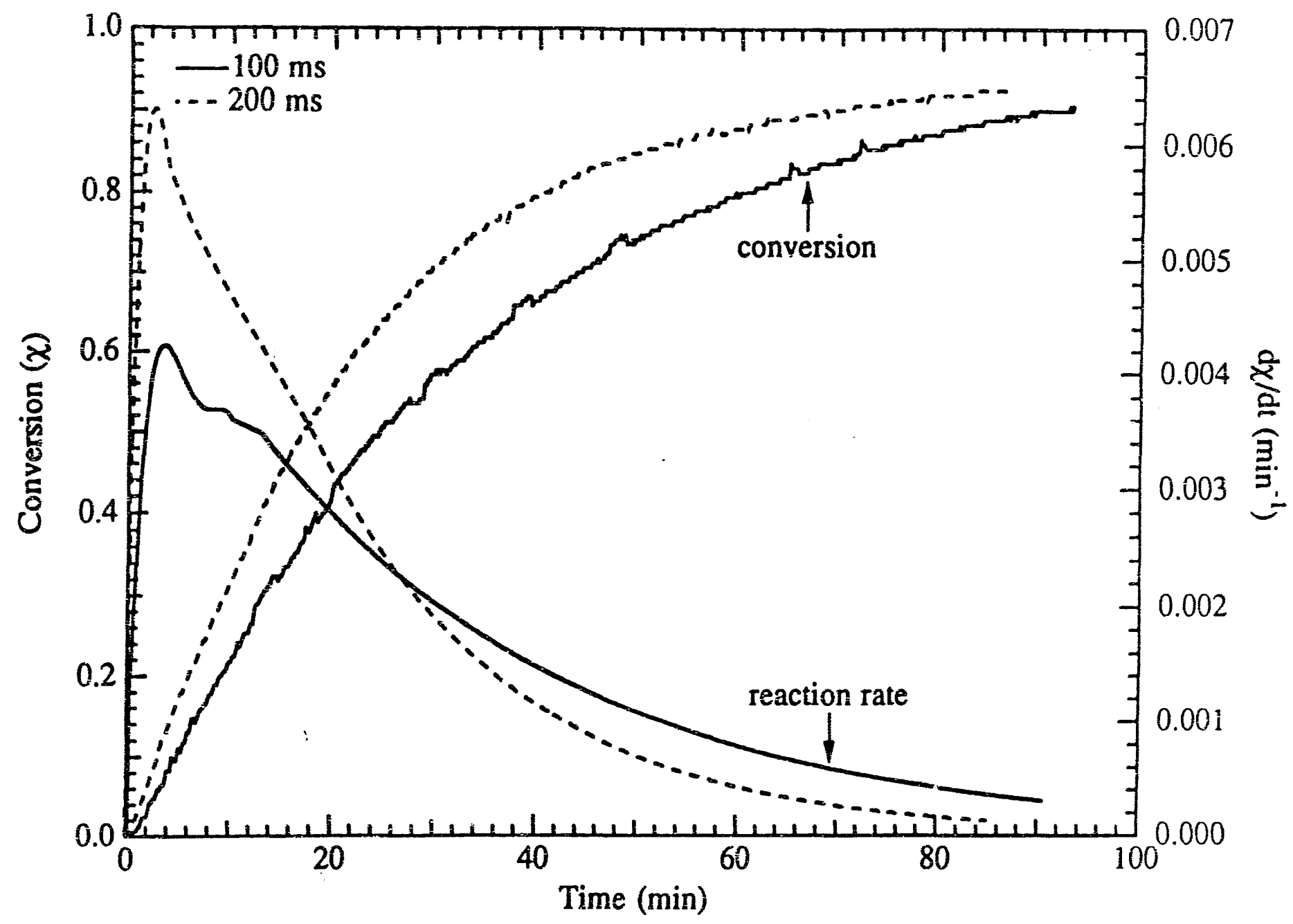

Fig. 18 TGA measurements of conversion and low temperature reactivities of chars generated at $1600 \mathrm{~K}$ in $\mathrm{N}_{2}$ 


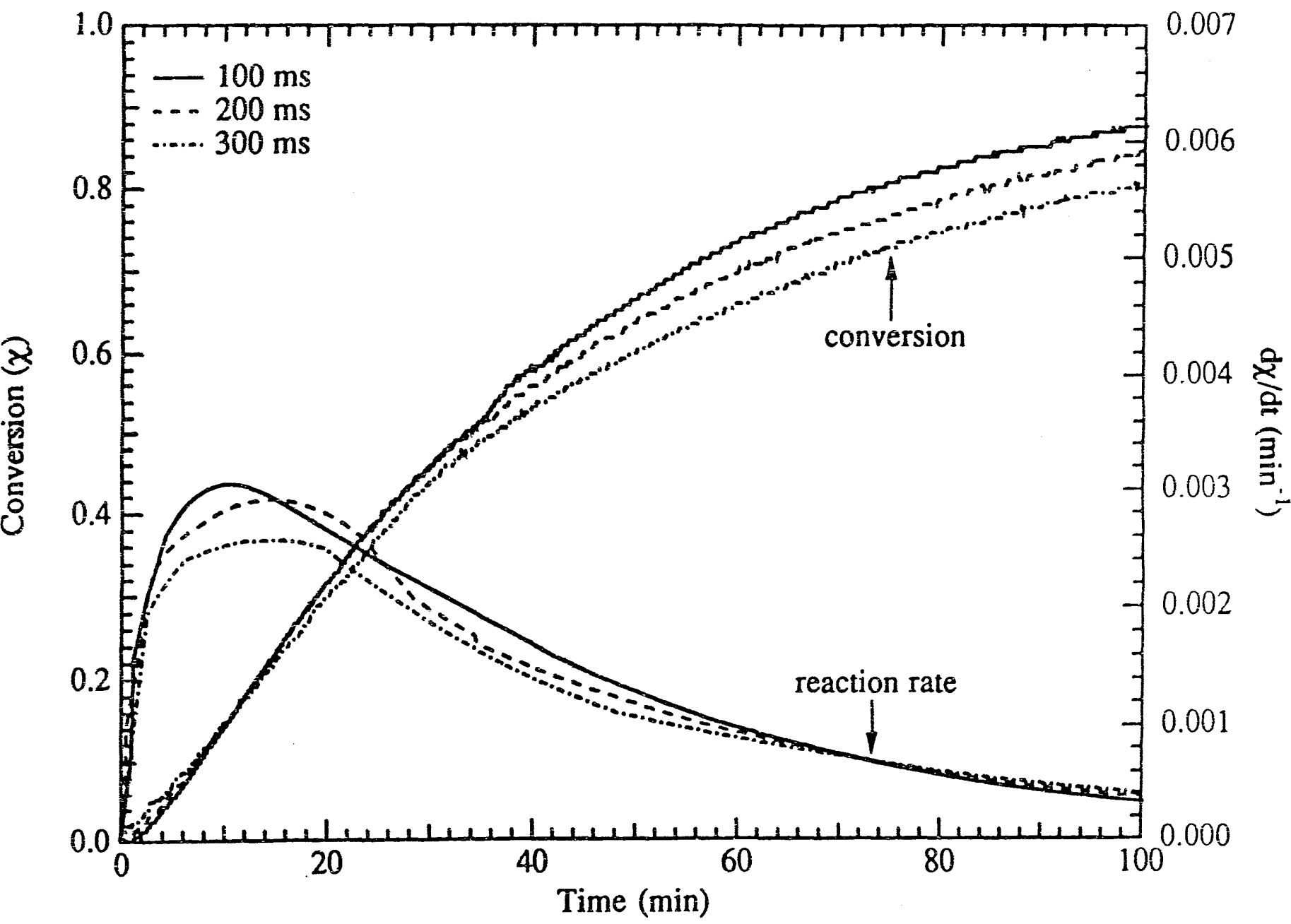

Fig. 19 TGA measurements of conversion and low temperature reactivities of chars generated at $1600 \mathrm{~K}$ in $1 \% \mathrm{O}_{2}$ 


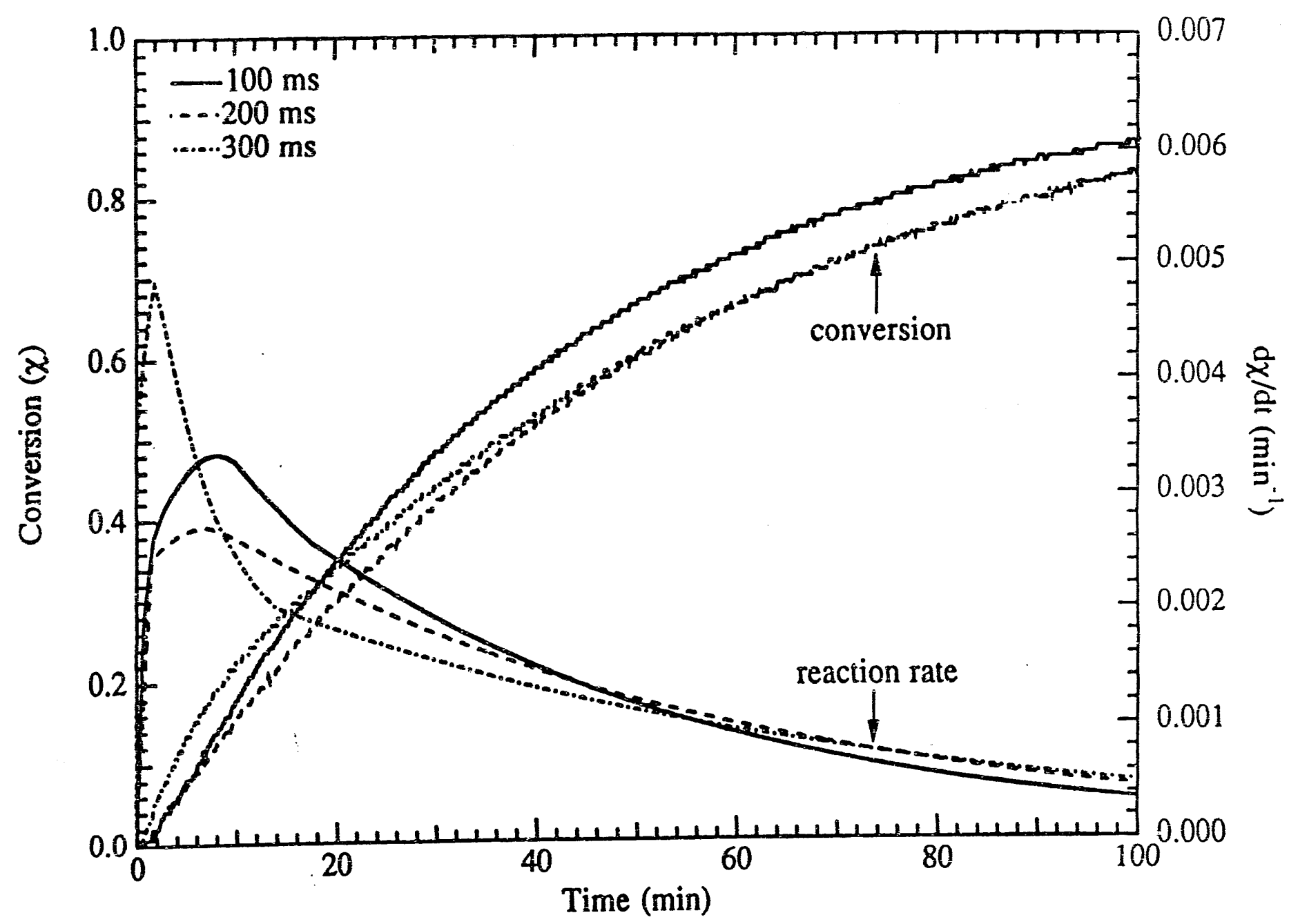

Fig. 20 TGA measurements of conversion and low temperature reactivities of chars generated at $1600 \mathrm{~K}$ in $5 \% \mathrm{O}_{2}$ 


\section{CHAPTER 3}

\section{EXPERIMENTS WITH THE ELECTRODYNAMIC BALANCE}

The Effect of Char Formation Temperature on the Densification of a Bituminous Coal Char during Gasification (Manuscript to be submitted for publication)

\section{Laser Ignition of Levitated Char Particles}

(Manuscript to be submitted for publication) 


\title{
The Effect of Char Formation Temperature on the Densification of a Bituminous Coal Char during Gasification
}

\author{
B. A. Wong*, G. R. Gavalas $\nmid$ and R. C. Flagan $\dagger$ \\ *Department of Environmental Engineering Science \\ †Department of Chemical Engineering, \\ California Institute of Technology, Pasadena, CA 91125
}

\begin{abstract}
It has been observed that certain char particles shrink when oxidized under kinetically limited conditions, instead of reacting at constant diameter, as expected. This study was performed to determine whether or not char from PSOC 1451 coal, prepared at different temperatures would also shrink during low temperature gasification. Coal chars, formed at $1200 \mathrm{~K}$ and $1600 \mathrm{~K}$, were levitated in the electrodynamic balance and heated with a carbon dioxide laser. The $1200 \mathrm{~K}$ char did shrink, while the $1600 \mathrm{~K}$ char reacted at constant diameter, as expected under the kinetically limited conditions. Therefore, the time and temperature history of a char is an important factor in determining how it might react during subsequent oxidation.
\end{abstract}

*Author to whom correspondance should be addressed at the Chemical Industry Institute of Toxicology, P. O. Box 12137, Research Triangle Park, NC 27709. 


\section{Introduction}

The combustion of pulverized coal occurs in two steps: First, as the coal p.rticle heats up, devolatilization occurs. Moisture and low vapor pressure organic componer s are first driven off, and thermal decomposition of some of the carbonaceous structure cr. uurs (Field ${ }^{1}$; Smoot and Smith ${ }^{2}$ ) resulting in tar evaporation. The residual material, te med char, is enriched in carbon and mineral components. The char reacts with oxygen and burns out until only the mineral matter remains. Depending on the particle temperature, char oxidation occurs in one of three regimes. The first, at low temperatures, is the kinetically limited regime (regime I). The reaction rate is controlled by the kinetics of the surface reaction of carbon with oxygen. The oxygen can diffuse through the pores $o$ i the particle faster than it reacts, so the oxygen concentration is uniform throughout ihe por $1 \mathrm{~s}$ particle. At higher particle temperatures, the reaction rate becomes so fast that ne oxidation is controlled by the diffusion of oxygen through the porous particle as well as by the surface reaction. In this diffusion limited regime (regime II), oxygen from the bulk gas penetrates only partially through the particle, and the oxygen concentration goes to zero at the center of the particle (Walker, et al. ${ }^{3}$ ). In the thind regime (regime IIn), boundary lay: $=$ r diffusion controls the oxidation rate. The reaction of carbon with oxygen is so fast that the oxygen concentration is essentially zero at the surface of the particle, and the rate is controlled by the diffusion of oxygen through the boundary layer surrounding the chaparticle (Smoot and Smith ${ }^{2}$ ).

If we define $\chi$ as the conversion, or the ratio of mass of carbon reacted to the initia: carbon mass, $m_{0}$

$$
\chi=\frac{\mathrm{m}_{0}-\mathrm{m}}{\mathrm{m}_{0}}
$$

then

$$
\left(1+\frac{m_{a}}{m_{0}}-\chi\right)=\frac{\rho d^{3}}{\rho_{0} d_{0}^{3}}
$$

where $\mathrm{m}_{\mathrm{a}}$ is the mass of the ash in the particle. Equation 2 can be divided into two equations

$$
d=d_{0}\left(1+\frac{m_{2}}{m_{0}}-x\right)^{\alpha}
$$




$$
\rho=\rho_{0}\left(1+\frac{m_{a}}{m_{0}}-\chi\right)^{\beta}
$$

where $3 \alpha+\beta=1\left(\right.$ Smith $\left.^{4}\right)$. In the kinetically limited regime, carbon loss occurs throughout the particle, provided that the temperature of the particle is uniform, and oxygen is able to penetrate through to all of the inside surface area, i.e., there are no closed pores. In regime $I$, the diameter stays essentially constant and $\alpha=0$, while the density decreases linearly and $\beta=1$, until the conversion is nearly complete. In Figure 1 , showing the relative volume, $\left(d / d_{0}\right)^{3}$ as a function of conversion, the top line corresponds to regime $I$. If a particle burns in Regime III, carbon loss will occur only near the external surface of the particle. The density will remain constant and the diameter of the particle will decrease, so $\alpha=1 / 3$ and $\beta=0$ (constant density line in Figure 1). The area in between, then corresponds to Regime II and the transitions between I and II and between II and III. In theory, then, following the diameter or density of a particle as a function of conversion should provide information about the regime of reaction. Note that the calculations and data presented in Figure 1 describe an ash free material, i.e., Spherocarb. For a mineralbearing material, the volume would decrease to that of the mineral residue at $100 \%$ conversion.

Smith ${ }^{5}$ observed that for a semi-anthracite in the temperature range $1400-2200 \mathrm{~K}$. the particles decreased in size and density as they reacted. This was also observed by Waters et al. ${ }^{6}$ for Spherocarb particles in the same temperature range. Smith cited the fact that the particles decreased in size and density as an indication that the particles were burning between regimes I and II. Smith and Waters calculated $\alpha=0.25$ and $\beta=0.25$. Neither Smith ${ }^{5}$ nor Waters et al. ${ }^{6}$ observed any influence of temperature on the particle size or density change because of the experimental scatter in the data.

Hurt et al. ${ }^{7}$, observed that some chars, notably Spherocarb and sucrose char, did not gasify at a constant diameter in regime I (temperature less than $873 \mathrm{~K}$ ), as expected, but instead "shrank." At $60 \%$ conversion, the spherocarb particle diameter was about 81 to $87 \%$ of the initial diameter. For a sucrose char, the particle shrank to about 88 to $92 \%$ of the initial diameter, at $60 \%$ conversion. The particle density was not measured directly but, based on the change in size with mass loss, the density did not decrease as much as predicted, hence, the particles of both materials were said to have "densified." Other chars (Montana Lignite, Pittsburgh \#8 bituminous) did not shrink, but maintained their initial diameter through $60 \%$ conversion. 
The Spherocarb data of Waters et al. ${ }^{6}$ is shown with the Spherocarb data of Hurt et al. ${ }^{7}$ in Figure 1. The best fit line for Water's data, with $\alpha=0.25$ is compared with the best fit line for Hurt's data, with $\alpha=0.177$ (calculated by the authors). The line shifts towards the constant diameter line at higher temperatures, as expected. The observed shrinkage either means that the coal structure changed, as they postulated, or the particles did not burn in the kinetically limited regine. Since Hurt et al. observed, at the same low temperatures as the shrinking chars, that some chars did oxidize without shrinkage, the former possibility is the more likely. They also observed that external features, such as pore diameters, decreased in size at the same rate as the particle diameter (Hurt et al. ${ }^{7}$ ). If the reaction was occurring without shrinking, the pore diameters might be expected to enlarge as the particle reacted. In a later paper, Hurt et al. ${ }^{8}$ presented evidence that oxygen penetrates completely into the microporous regions of the spherocarb at temperatures of 673 to $873 \mathrm{~K}$. The reactivity of the Spherocarb carbon was found to be independent of particle size with the calculated effectiveness factor equal to unity, indicating that all the pore surface participated in the reaction. The adsorption equilibrium time in BET gas adsorption measurements of the char surface area was much shorter for Spherocarb than for sucrose char, a completely microporous char. From this evidence, Hurt et al. ${ }^{8}$ concluded that the oxygen penetrated completely through the micropores of the Spherocarb and reacted there under kinetically limited conditions.

Hurt observed shrinkage and densification in some but not all chars. Presumably, then, structural changes that a char may undergo during oxidation depend on the initial coal or carbon structure. Some coals, particularly bituminous coals, appear to be quite "plastic" and upon devolatilization, may swell to several times their original size (Field et al. ${ }^{1}$ ). The resulting chars may have very large macropores, and become cenospheric. It might seem, then, that chars made from such swelling coals would be prone to structural changes during subsequent oxidation. This study was undertaken to determine if a swelling coal char from the bituminous coal PSOC 1451 does indeed densify, and if so, the effect of char formation temperature on the densification phenomenon. 


\section{EXPERIMENTAL}

The particles used in this study were Spherocarb and char made from a high volatile bituminous coal (Pittsburgh seam PSOC 1451). Spherocarb is a commercially available carbon material (sold as Carbosphere by Ailtech Associates, Inc.). It consists of spherical particles of high purity carbon with a high specific surface area (nominally $1000 \mathrm{~m}^{3} / \mathrm{g}$ ). Spherocarb has networks of both micro and macropores with $0.39 \mathrm{~cm}^{3} / \mathrm{g}$ in micropores, and a porosity of 0.33 in pores $>200 \AA$ (Floess et al..$^{9}$ ).

Coal char particles were made from PSOC 1451 bituminous coal by Sahu et al. ${ }^{10}$ Briefly, the chars were made as follows: PSOC 1451 coal was ground and sieved. Coal particles in the 104 to $125 \mu \mathrm{m}$ fraction were entrained in a stream of nitrogen and passed through a drop tube furnace to a temperature of 1200 or $1600 \mathrm{~K}$ for two seconds. The collected particles were washed in tetrahydrofuran and resieved. Chars in the 125 to 175 $\mu \mathrm{m}, 175$ to $208 \mu \mathrm{m}$ and 208 to $295 \mu \mathrm{m}$ size ranges were selected for study.

Table 1 lists measurements by Sahu et al. ${ }^{10}$ of the apparent density, $\sigma_{A}$, total porosity, $\varepsilon_{\mathrm{A}}$, porosity of pores less than $64 \AA$, and pore volume and pore surface area based on mercury porosimetry for PSOC 1451 coal and chars. The apparent density decreases as char formation temperature increases, as does the total porosity. Only the $1600 \mathrm{~K}$ char shows an appreciable microporosity, i.e., 19\%. The pore volume and surface area increase as the coal is converted to char, however, there are only slight differences between chars. According to Sahu et al., chars formed at lower temperatures developed bimodal pore size distributions, while high temperature chars developed trimodal pore size distributions. The $1200 \mathrm{~K}$ char showed a bimodal distribution of pore volume and pore area with significant volume in the macropore region and significant area in the micropore region. The $1600 \mathrm{~K}$ char contained similar micro and macroporosity, but, additionally, showed significant area and volume in the socalled transition pore region, around a pore diameter of $500 \AA$ (Sahu et al. ${ }^{10}$ ). For the 127 to $175 \mu \mathrm{m}$ fraction of the $1600 \mathrm{~K}$ char, the total porosity was $47 \%$, while the pore volume fraction contained in pores smaller than 64 $\AA$ was $19 \%$. The total porosity of $1200 \mathrm{~K}$ char was $33 \%$, with no significant microporosity. The physical properties listed for the chars are average values for the entire size range. As we chose to work with the larger char particles, it is expected that the macroporosity for these particles are even larger than that listed in the table. The large chars, particularly the 208 to $295 \mu \mathrm{m}$ diameter particles, were cenospheres. 
The use of the electrodynamic balance for studying char oxidation has been described elsewhere by Spjut et al. ${ }^{11}$, Hurt et al. ${ }^{7}$ and Bar-Ziv et al. ${ }^{12}$. A brief description of the system used in this study is presented here. The electrodynamic balance consists of two endcap electrodes with a DC voltage across the electrodes. A charged particle is suspended in the electric field against gravity. A ring at midplane between the endcap electrodes is charged with an $\mathrm{AC}$ voltage. If the particle deviates in any direction from the center of the cell, the parucle is subject to a time-averaged force from the AC field that pushes the particle back toward the center (Davis ${ }^{13}$ ).

A microscope with a total magnification of $15 \mathrm{x}$ was used to view the particle. A 10x eyepiece micrometer (American Optical Co.) was used to measure the size of the particle in the horizontal and vertical directions. The suspended particles were videotaped using a catadioptric microscope (Questar QM-1) and a video camera (COHU, Inc., model 4810). The output from the video camera was shown on a monitor (Electrohome, EVM) and recorded by a videotape recorder (Panasonic AG-1830). Still photographs were obtained by photographing the monitor, or by using an adapter coupled to a standard $35 \mathrm{~mm}$ SLR camera that fit over the viewing microscope and a standard $15 x$ eyepiece.

The particle suspended in the EDB was heated with the radiation from a 20 Watt carbon dioxide laser emitting at $10.6 \mathrm{~m}$. The $\mathrm{t}$ sam was split and directed by mirrors into the chamber vertically to heat the particle from top and bottom. The intensity of the beam intercepted by the particle was controlled by $\mathrm{ZnSe}$ lenses and by moving the focal point closer or farther from the particle.

The temperature of the particle was measured using a two-color optical pyrometer. Radiation emitted from the heated particle is collimated by a $\mathrm{CaF}_{2}$ lens and split by a grating beam splitter. One arm of the split beam was focused by a $\mathrm{CaF}_{2}$ lens through a $3.4 \pm$ $0.0685 \mu \mathrm{m}$ interference filter onto a liquid nitrogen cooled $\mathrm{InSb}$ detector. The other arm was focused through a $1.5 \pm 0.037 \mu \mathrm{m}$ interference filter onto a thermoelectrically cooled InGaAs detector. The outputs from the detectors was sent to a logratio amplifier (Analog Devices 757). The output from the logratio amplifier was monitored on an oscilloscope and sent to a data acquisition system.

A typical experimented started by trapping a single particle in the electrodynamic balance. The size of the particle was measured in the horizontal and vertical directions using the eyepiece micrometer. Photographs were taken through the viewing microscope. The $\mathrm{CO}_{2}$ laser was allowed to stabilize with an external shutter closed. Particle heating was 
then initiated by opening the shutter. The pyrometer signal was monitored on the oscilloscope and recorded by the data acquisition system. The particle position was balanced manually. The heating pulse was ended by closing the external shutter. Photographs were again taken to record any changes in particle size and shape. In many cases, after heating, the particle was rotating about a vertical axis. If the particle was very irregularly shaped, photographs were attempted when the particle rotated through its original position, if that could be determined. Particle sizing was repeated, at the same orientation, if possible.

\section{RESULTS}

The Spherocarb and char particles were heated at temperatures up to $1000 \mathrm{~K}$. Figures 2 and 3 show the temperature traces of a Spherocarb and a $1600 \mathrm{~K}$ char heated in air. The particle temperature could be maintained only to within $50 \mathrm{~K}$. Irregular particle shape, strong photophoretic forces, and long term fluctuations in the intensity of the laser contributed to the temperature fluctuations. The primary focus of this paper is on the structural rearrangements of the char during kinetically limited oxidation. As long as the peak temperature experienced did not take the particle out of Regime I oxidation, the fluctuations should not affect the basic results.

The effectiveness factor was calculated for the Spherocarb and char particles at $1000 \mathrm{~K}$ to verify that the oxidation reaction was occurring in the kinetically limited regime. The classical calculation of the Thiele modulus and effectiveness factor ( Smith $^{14}$ ) were carried out using the effective diffusivity reported by Hurt et $a .^{8}$ and Arrienius rate parameters for the intrinsic rate coefficient reported by Floess et al. ${ }^{9}$ A Thiele modulus of 0.15 at $1000 \mathrm{~K}$ was calculated, which gives an eifectiveness factor of unity. The method discussed by $S_{\text {mith }}{ }^{15}$ was used to calculate the effectiveness factor for the bituminous char particles. Based on the measured reaction rates and the effective diffusivities reported by Sahu et al. ${ }^{10}$, the effectiveness factors for all the char particles studied were also unity at $1000 \mathrm{~K}$.

Photographs of the backlit particles showing their silhouettes are shown next. Figures $4 a$ and $4 b$ show a Spherocarb particle, before and after heating for 10 minutes in nitrogen. The particle has clearly retained its size and general surface features. Another Spherocarb particle before heating in air is shown in Figure 4c. The same particle, after $62 \%$ conversion is shown in Figure $4 d$. Note that the top and bottom of the particle are flattened, at the locations of the incident laser beams where the temperature was higher and 
the oxidation faster. The horizontal diameter is reduced from $196 \mu \mathrm{m}$ to $175 \mu \mathrm{m}$, and is indicative of the shrinking of Spherocarb.

Figures 5a and 5b show PSOC 1451 coal char made at $1200 \mathrm{~K}$ before and after 10 minutes heating in nitrogen. This particle clearly retains its size, shape and overall feanures. Figure $5 \mathrm{c}$ shows a photograph of a $1200 \mathrm{~K}$ char, before heating in air, wlile Figure 5d shows the same char, at $48 \%$ conversion. The diameter decreased from $230 \mathrm{~m}$ to $200 \mathrm{~m}$, clearly showing some shrinkage.

Figures 6a and 6b show PSOC 1451 coal char made at $1600 \mathrm{~K}$ before and after 11 minutes heating in nitrogen. Again, there is no change in the size or appearance of the particle after heating in nitrogen. Figure $6 \mathrm{c}$ shows a photograph of a $1600 \mathrm{~K}$ char, before heating, and Figure $6 \mathrm{~d}$ shows the same char, at $56 \%$ conversion in air. The vertical dimension remains approximately the same at $222 \mu \mathrm{m}$, and the horizontal dimension also remains approximately the same at $160 \mu \mathrm{m}$. Note also, that the particle becomes lacy and translucent. As the cenospheric chars oxidize, the thin walls become more transparent.

The experiments in nitrogen show that the shrinkage of the particles is not due simply to heating, but in some way, is related to reaction with oxygen. When the char is heated in oxygen, some particles shrink, others do not. The relative volume as a function of conversion of Spherocarb is plotted in Figure 7. Each symbol represents a different Spherocarb particle. The dotted lines connect data from experiments on one particle. The particle volume was estimated by assurning that it was an oblate spheroid with volume $\frac{4}{3} \pi \mathrm{a}^{2} \mathrm{~b}$ where $\mathrm{a}$ is the major axis and $\mathrm{b}$ is the minor axis. The relative volume and conversion for Spherocarb particles is listed in Table 2. The relative volumes determined in the present experiment appear to lie somewhat lower than the measurements of Hurt et al. ${ }^{7}$ and approach the range of measurements of Smith ${ }^{5}$ and Waters et al. ${ }^{6}$. As noted above, a comparison of the data of Hurt et al. with Smith and Waters et al. suggest that the shrinkage increases with increasing temperature. The slightly higher temperatures of the present experiments may account for the differences with the observations of Hurt et al. ${ }^{7}$, but experimental differences cannot be ruled out. Unfortunately, the uncertainties in each data set preclude quantitative determination of this temperature dependence within each set of measurements.

Figure 8 shows the relative volume versus conversion for the bituminous char. The points for the $1200 \mathrm{~K}$ char (the open squares) are scattered, but generally show significant shrinkage, roughly along the same line as the data of Hurt et al. ${ }^{7}$ for 
Spherocarb. The points for the 160.$) \mathrm{K}$ char (solid circles) mostly lie very close to the constant density line along the top of the graph. In cases where the particles were irregularly shaped, the size was measured from the extreme points in the vertical or horizontal directions. Volumes were calculated assuming that the particles could be modeled as oblate or prolate spheroids. Table 3 lists the relative volumes and conversions for the char particles.

\section{DISCUSSION AND CONCLUSIONS}

The reasons for the observed shrinkage or densification of some chars are as yet unknown. It has been shown that the particles are reacting in the kinetically limited regime and not the diffusion limited regime. The $1200 \mathrm{~K}$ and the $1600 \mathrm{~K}$ char both contained macropores, but only the $1600 \mathrm{~K}$ char contained significant microporosity. Hence, it might be expected that the $1600 \mathrm{~K}$ char show some diffusion limitations, but this is not the case. The larger coal char particles that were used in this experiment were quite cenospheric in nature, and should be even more macroporous than the average values listed in Table 1. Smith ${ }^{4}$ indicated that a cenosphere should burn at constant diameter and decreasing density, even if the reactions were linited to the outer surface. Thus, it seems unlikely that oxygen diffusion limitations would be a cause of shrinkage of the cenospheric $1200 \mathrm{~K}$ but not the cenospheric $1600 \mathrm{~K}$ char. Clearly then, the $1200 \mathrm{~K}$ char is shrinking as it is reacting, while the $1600 \mathrm{~K}$ char is reacting at constant diameter.

If diffusion limitations can be ruled out, then structural changes in the carbon must be occurring. Hurt et al. ${ }^{7}$ speculated that as the char loses carbon, atomic rearrangements causes the loss of pore volume in the fine pores. These atomic rearrangements lead to a graphitization accompanied by an increase in the density. Sahu et al. ${ }^{10}$ also speculated that charring at the higher temperatures led to a loss of the finer pores. They noted that as a PSOC 1451 bituminous coal char was oxidized, the total surface area increased and reached a maximum at around $60 \%$ conversion. When exarnined as a function of char devolatilization temperature, it was observed that the surface area at $50 \%$ conversion was greater for the chars formed at lower temperatures. They postulated that the reduction of surface area at higher charring temperatures resulied from a closure of the smaller pores due to a structural ordering of carbon. The $1600 \mathrm{~K}$ char, then may be more graphitized and less prone to shrinking than the $1200 \mathrm{~K}$ char. In a study of the oxidation kinetics of synthetic chars (amorphous carbon), Levendis et al. ${ }^{16}$ observed that as the oxidation temperature increased, there was increased graphitization of the synthetic chars. Oxygen accelerated the 
graphitization process. Thus, there is evidence that as chars react, the carbonaceous material undergoes graphitization. The extent to which a char shrinks during low temperature oxidation may depend on the extent of graphitization of the initial carbon particle during the devolatilization process.

The reactions that take place during devolatilization may provide some information about the difference in behavior between the $1600 \mathrm{~K}$ char and the $1200 \mathrm{~K}$. Solomon et al. ${ }^{17}$ describe a two-step devolatilization process in which the raw coal is pictured as a complex of aromatic and hydroaromatic carbon clusters linked by aliphatic bridges. In the initial pyrolysis step, the weakest bridges are broken. The lightest molecular weight fragments may vaporize, the heavier fragments may remain with the parent coal. During this time, functional group decomposition also releases $\mathrm{CO}_{2}, \mathrm{H}_{2} \mathrm{O}$, methane and other light gases. In the second step of pyrolysis, cross-linking between the remaining aromatic clusters occurs. Solomon et al. ${ }^{18}$ found that there are two distinct cross-linking events, occurring at different temperatures. At a heating rate of $0.5 \mathrm{C} / \mathrm{s}$, the low temperature cross-linking occurs between about 200 and $450 \mathrm{C}$, and the moderate temperature cross-linking occurs between 450 and $600 \mathrm{C}$. It is conceivable that at the much higher heating rates and short exposure time $(2 \mathrm{~s})$ used to produce the bituminous char used in these studies, the crosslinking is less complete for the $1200 \mathrm{~K}$ char than for the $1600 \mathrm{~K}$ char. Thus, as a char undergoes subsequent oxidation, cross-linking also occurs, leading to the shrinkage. However, as the heating in nitrogen showed, the densification effect requires reaction with oxygen and not simply heating to elevated temperatures. Therefore, in this scenario, the cross-linking is assisted by the carbon-oxygen reaction.

There is a significant implication of these results for researchers using or producing char oxidation models. Most models assume that, as char oxidation progresses, the pores enlarge and the surface recedes, but the basic carbon structure does not change. Results from this experiment and those from the Spherocarb densification study of Hurt et al. ${ }^{7}$ show that the models must account for changes in density which can not be characterized simply by the oxidation regimes in which the reaction is taking place. These density changes are not only dependent on the initial coal structure, but also upon on the temperature time history of char formation. Thus, a complete description of char oxidation will require both the information about the basic structure (density, porosity, surface area, etc.) and knowledge of the history of the char to account for possible carbon structural changes and shrinking during the oxidation process. 


\section{ACKNOWLEDGEMENTS}

This work was supported by the U.S. Department of Energy, University Coal Research Program under grants DE-FG22-89PC89765 and DE-FG22-88PC88911. 


\section{REFERENCES}

(1) Field, M. A.; Gill, D. W.; Morgan, B. B.; Hawksley, P. G. W. Combustion of Pulverized Coal, The British Coal Utilisation Research Association, Leatherhead, 1967.

(2) Smoot, L. D.; Smith, P. J. Coal Combustion and Gasification. Plenum Press, New York, 1985.

(3) Walker, P. L., Jr., Rusinko, F., Jr., Austin, L. G., Advan. Catalysis. 1959, 11, 134.

(4) Smith, I. W. Nineteenth Symp. (Int.) Comb. The Combustion In titute. pp. 1045$1065,1982$.

(5) Smith, I. W. Combust. Flame. 1971, 17, 421-428.

(6) Waters, B. J.; Squires, R. G.; Laurendreau, N. M.; Mitchell, F E. Combust. Flame. 1988, 74, 91-106.

(7) Hurt, R. L.; Dudek, D. R.; Longwell, J. P.; Sarofim, A. F. Carbon. 1988, 26, 433-449.

(8) Hurt, R. L.; Sarofin, A. F.; Longwell, J. P. Energy Fuels. 1991, 5, 290-299.

(9) Floess, J. K.; Longwell, J. P.; Sarofim, A. F. Energy Fuels. 1988, 2, 18-26.

(10) Sahu, R.; Levendis, Y. A.; Flagan, R. C.; Gavalas, G. R. Fuel. 1988, 67, 275-283.

(11) Spjut, R. E.; Sarofim, A. F.; Longwell, J. P. Langmuir. 1985, 1, 35: 360.

(12) Bar-Ziv, E.; Jones, D. B.; Spjut, R. E.; Dudek, D. R.; Sarofim, A. F. Combust. Flame. 1989,.75, 81-106.

(13) Davis, E. J. In Surface and Colloid Science (E. Matijevic, ed.). Vol. 14. Plenum Press, New York, 1987.

(14) Smith, J. M. Chemical Engineering Kinetics. McGraw-Hill Book Company, NewYork, 1970.

(15) Smith, I. W. Fuel. 1978, 57, 409-414.

(16) Levendis, Y. A.; Flagan, R. C.; Gavalas, G. R. Combust. Flame. 1989, 76, 221 241 .

(17) Solomon, P. R.; Hamblen, D. G.;Carangelo, R. M.; Serio, M. A.; Desnpande, G. V. Energy Fuels. 1988, 2, 405-422.

(18) Solomon, P. R.; Serio, M. A.; Deshpande, G. V.; Kroo, E. Energy Fuets. 1990, 4, $42-54$. 
Table 1

Properties of Chars

\begin{tabular}{|c|c|c|c|c|c|}
\hline Coal or Char & $\begin{array}{l}\sigma_{\mathrm{A}} \\
\mathrm{g} / \mathrm{cm}^{3}\end{array}$ & $\begin{array}{l}\varepsilon_{\mathrm{A}} \\
<7 \mu \mathrm{m} \\
\%\end{array}$ & $\begin{array}{l}\varepsilon \\
<32 \AA \\
\%\end{array}$ & $\begin{array}{l}\mathrm{V}_{\mathrm{Hg}} \\
\mathrm{cm}^{3 / \mathrm{g}}\end{array}$ & $\begin{array}{l}S_{\mathrm{Hg}} \\
\mathrm{m}^{2} / \mathrm{g}\end{array}$ \\
\hline $\begin{array}{l}\text { PSOC } 1451 \\
\text { coal }\end{array}$ & 1.18 & 17 & & 0.14 & 7.9 \\
\hline $1200 \mathrm{~K}$ char & 1.0 & 33 & 0 & 0.43 & 11.6 \\
\hline $1400 \mathrm{~K}$ char & 0.9 & 40 & 0 & 0.57 & 11.4 \\
\hline $\begin{array}{l}1600 \mathrm{~K} \\
\text { char } 53-90 \mathrm{~m} \\
\text { from } 53-90 \mathrm{~m}\end{array}$ & 0.98 & 47 & 2 & 0.46 & 14.7 \\
\hline $\begin{array}{l}127-147 \mathrm{~m} \\
\text { from } 90- \\
125 \mathrm{~m}\end{array}$ & 0.92 & 47 & 19 & 0.35 & 14.9 \\
\hline Spherocarb & 0.56 & $33^{1}$ & $.39^{2}$ & & $864^{3}$ \\
\hline
\end{tabular}

${ }^{1}$ Pores larger than $200 \AA$ by mercury porosimetry (Floess et al., 1988).

${ }^{2}$ Micropore volume, $\mathrm{cm}^{3} / \mathrm{g}$ for an average pore radius of $6.7 \AA$, determined by nitrogen adsorption (Floess et al., 1988).

${ }^{3} \mathrm{BET}$ surface area by $\mathrm{N}_{2}$ adsorption (Waters et al., 1988). 
Table 2

Spherocarb Data

\begin{tabular}{|c|c|c|c|c|}
\hline Particle & Series & $\begin{array}{c}\text { Temperature } \\
\mathrm{K}\end{array}$ & $\begin{array}{c}\text { Conversion } \\
\%\end{array}$ & $\begin{array}{l}\text { R.elative Volume } \\
\qquad\left(d / d_{0}\right)^{3}\end{array}$ \\
\hline $\bar{A}$ & TS0372 & $\begin{array}{l}930 \pm 20 \\
920 \pm 20 \\
950 \pm 50 \\
880 \pm 30 \\
890 \pm 30\end{array}$ & $\begin{array}{l}17.6 \\
32.2 \\
42.3 \\
64.0 \\
71.7\end{array}$ & $\begin{array}{l}.77 \\
.70 \\
.60 \\
.45 \\
.31\end{array}$ \\
\hline B & TS0373 & $1000 \pm 50$ & 60.8 & .75 \\
\hline C & TS0374 & $\begin{array}{c}1010 \pm 15 \\
990 \pm 30 \\
940 \pm 40 \\
930 \pm 30 \\
900 \pm 40\end{array}$ & $\begin{array}{r}8.9 \\
30.9 \\
43.9 \\
53.9 \\
63.5\end{array}$ & $\begin{array}{l}.94 \\
.79 \\
.62 \\
.54 \\
.47\end{array}$ \\
\hline $\mathrm{D}$ & TS0471 & $\begin{array}{l}970 \pm 20 \\
960 \pm 20 \\
930 \pm 30 \\
910 \pm 30\end{array}$ & $\begin{array}{l}12.2 \\
36.8 \\
55.2 \\
75.6\end{array}$ & $\begin{array}{l}.94 \\
.81 \\
.60 \\
.31\end{array}$ \\
\hline$E$ & TS0473 & $\begin{array}{c}900 \pm 10 \\
820 \pm 20 \\
900 \pm 100\end{array}$ & $\begin{array}{l}24.0 \\
55.1 \\
67.2\end{array}$ & $\begin{array}{l}.79 \\
.63 \\
.41\end{array}$ \\
\hline $\mathrm{F}$ & TS0474 & $\begin{array}{l}820 \pm 20 \\
860 \pm 40\end{array}$ & $\begin{array}{r}4.4 \\
40.1\end{array}$ & $\begin{array}{l}.92 \\
.65\end{array}$ \\
\hline$G$ & TS0475 & $\begin{array}{l}760 \pm 100 \\
790 \pm 100 \\
790 \pm 100\end{array}$ & $\begin{array}{l}11.7 \\
23.8 \\
41.8\end{array}$ & $\begin{array}{l}.88 \\
.86 \\
.80\end{array}$ \\
\hline $\mathrm{H}$ & TS0512 & $\begin{array}{l}910 \pm 20 \\
900 \pm 20 \\
890 \pm 25\end{array}$ & $\begin{array}{r}9.8 \\
21.4 \\
31.8\end{array}$ & $\begin{array}{l}.92 \\
.79 \\
.76\end{array}$ \\
\hline I & TS0513 & $\begin{array}{l}980 \pm 30 \\
960 \pm 20 \\
930 \pm 20\end{array}$ & $\begin{array}{l}12.3 \\
36.0 \\
55.8\end{array}$ & $\begin{array}{l}.90 \\
.80 \\
.54\end{array}$ \\
\hline $\mathrm{J}$ & TS0921 & $\begin{array}{c}980 \pm 15 \\
1030 \pm 30\end{array}$ & $\begin{array}{r}4.0 \\
52.1\end{array}$ & $\begin{array}{l}.95 \\
.60\end{array}$ \\
\hline $\mathrm{K}$ & TS0522 & $920 \pm 40$ & 78.9 & .27 \\
\hline L & TS0523 & $\begin{array}{c}1000 \pm 20 \\
1000 \pm 100\end{array}$ & $\begin{array}{l}43.9 \\
82.6\end{array}$ & $\begin{array}{l}.82 \\
.39\end{array}$ \\
\hline $\mathbf{M}$ & TSO524 & $1070 \pm 100$ & 61.3 & .62 \\
\hline $\mathrm{N}$ & TS0525 & $\begin{array}{l}890 \pm 15 \\
880 \pm 15\end{array}$ & $\begin{array}{l}17.4 \\
52.4\end{array}$ & $\begin{array}{l}.95 \\
.67\end{array}$ \\
\hline
\end{tabular}


Table 3

Char Data

\begin{tabular}{|c|c|c|c|c|}
\hline Particle & Series & $\begin{array}{c}\text { Temperature } \\
\mathrm{K}\end{array}$ & $\begin{array}{c}\text { Conversion } \\
\%\end{array}$ & $\begin{array}{l}\text { Relative Volume } \\
\left(\mathrm{d} / \mathrm{d}_{0}\right)^{3}\end{array}$ \\
\hline $\begin{array}{l}A(1200 K) \\
B(1200 K)\end{array}$ & $\begin{array}{l}\text { TC0771 } \\
\text { TC0781 }\end{array}$ & $\begin{array}{l}790 \pm 50 \\
790 \pm 50\end{array}$ & $\begin{array}{r}9.6 \\
42.9 \\
63.5\end{array}$ & $\begin{array}{l}100 \\
.85 \\
.46\end{array}$ \\
\hline $\mathrm{C}(1200 \mathrm{~K})$ & TC0782 & $790 \pm 50$ & 33.6 & .69 \\
\hline $\mathrm{D}(1200 \mathrm{~K})$ & TC0783 & $790 \pm 50$ & 79.5 & .28 \\
\hline$E(1200 K)$ & TC0784 & $790 \pm 50$ & 70.5 & .54 \\
\hline$F(1200 \mathrm{~K})$ & TC0785 & $790 \pm 50$ & 48.3 & 100 \\
\hline$G(1200 K)$ & TC0786 & $790 \pm 50$ & $\begin{array}{l}43.2 \\
15.4\end{array}$ & $\begin{array}{l}.72 \\
.82\end{array}$ \\
\hline$H(1600 K)$ & TC0861 & & $\begin{array}{l}17.9 \\
52.1\end{array}$ & $\begin{array}{l}.99 \\
.76\end{array}$ \\
\hline$I(1600 \mathrm{~K})$ & TC0871 & & 29.3 & .98 \\
\hline$J(1600 \mathrm{~K})$ & TC0872 & & 19.4 & .93 \\
\hline$K(1600 K)$ & TC0874 & & 38.4 & 100 \\
\hline L. $(1600 \mathrm{~K})$ & TC0875 & $700 \pm 100$ & 10.7 & .95 \\
\hline$M(1600 K)$ & TC0881 & $880 \pm 100$ & 28.3 & .95 \\
\hline $\begin{array}{l}N(1600 \mathrm{~K}) \\
\mathrm{O}(1600 \mathrm{~K})\end{array}$ & $\begin{array}{l}\text { TC0882 } \\
\text { TC0902 }\end{array}$ & $\begin{array}{l}880 \pm 100 \\
850 \pm 100 \\
840 \pm 100\end{array}$ & $\begin{array}{l}42.4 \\
76.0 \\
63.8\end{array}$ & $\begin{array}{r}100 \\
.95 \\
.95\end{array}$ \\
\hline$P(1200 K)$ & TC0911 & $780 \pm 100$ & 51.4 & .77 \\
\hline$Q(1400 K)$ & TC0913 & $840 \pm 100$ & 51.6 & .51 \\
\hline$R(1200 K)$ & TC1041 & $770 \pm 100$ & 48.2 & .64 \\
\hline
\end{tabular}




\section{Figure Captions}

Figure 1. Graph of relative volume of particle vs. conversion. The top line is the line of constant diameter. The diagonal line is the line of constant density.

Figure 2. Temperature trace for a Spherocarb particle heated in the electrodynamic balance.

Figure 3. Temperature trace for a char particle made at $1600 \mathrm{~K}$ from PSOC 1451 bituminous coal.

Figure 4. a. Photograph of backlit Spherocarb particle before being heated in the electrodynamic balance; $b$. Photograph of the same Spherocarb particle after $62 \%$ conversion. Note the flattened top and bottom, where the laser beam was heating the particle; c. Photograph of Spherocarb before reacting; d. Photograph of Spherocarb after heating in nitrogen.

Figure 5. a. Photograph of $1200 \mathrm{~K}$ char before reacting; b. Photograph of $1200 \mathrm{~K}$ char after heating in nitrogen; c. Photograph of $1200 \mathrm{~K}$ char before reacting; d. Photograph of $1200 \mathrm{~K}$ char after $48 \%$ conversion. Note the relatively uniform size change.

Figure 6. a. Photograph of $1600 \mathrm{~K}$ char before heating; b. Photograph of $1600 \mathrm{~K}$ char after heating in nitrogen; $c$. Photograph of $1600 \mathrm{~K}$ char before reacting; d. Photograph of $1600 \mathrm{~K}$ char after $56 \%$ conversion. The char now looks lacy or translucent. The exterior dimensions are nearly the same.

Figure 7. Relative volume of Spherocarb particles reacted at low temperatures.

Figure 8. Relative volume of bituminous char vs. conversion. The $\mathrm{x}$ are $1200 \mathrm{~K}$ char, and the circles are $1600 \mathrm{~K}$ char. 
Figure 1

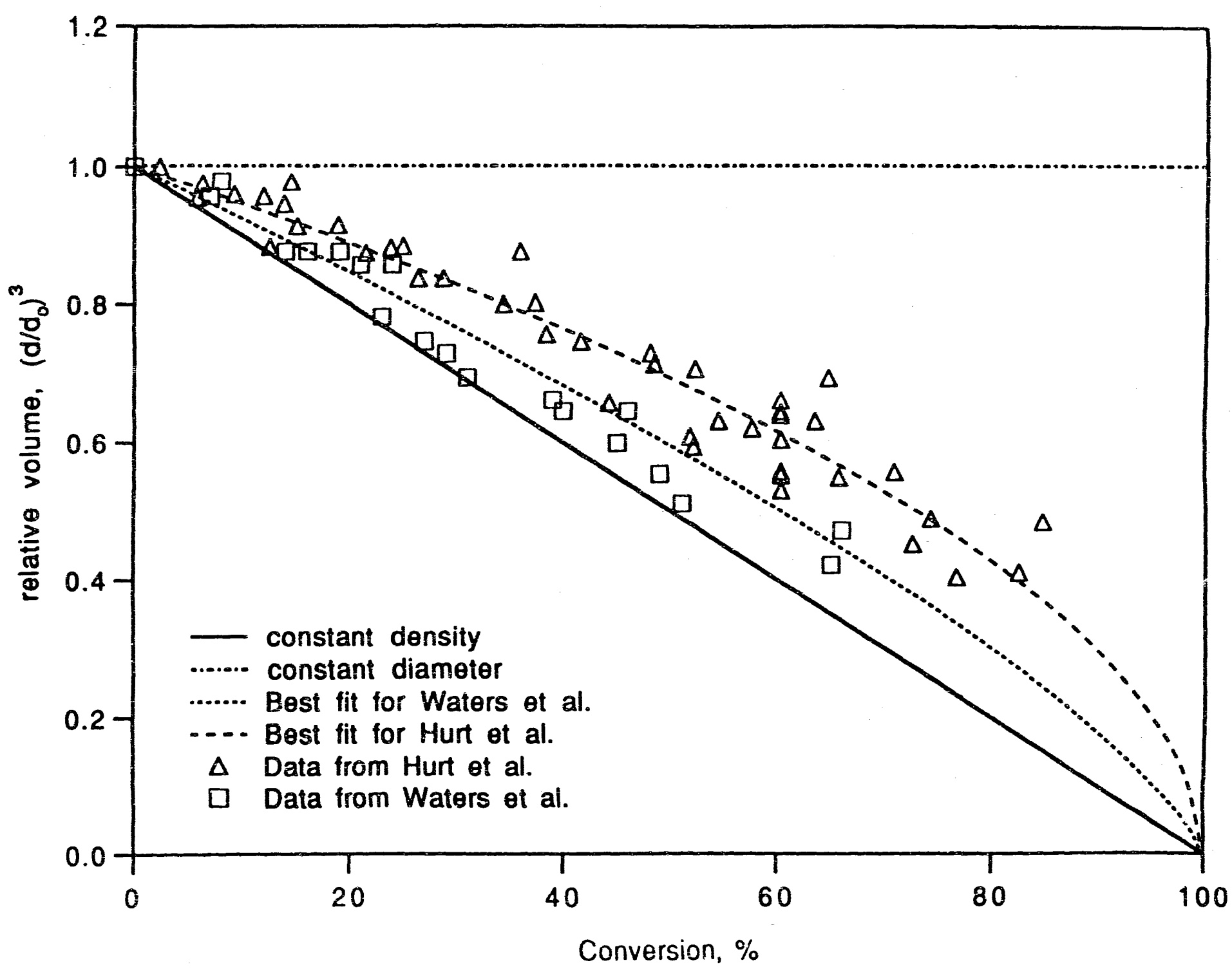


Figure 2

Char Oxidation IC1032a

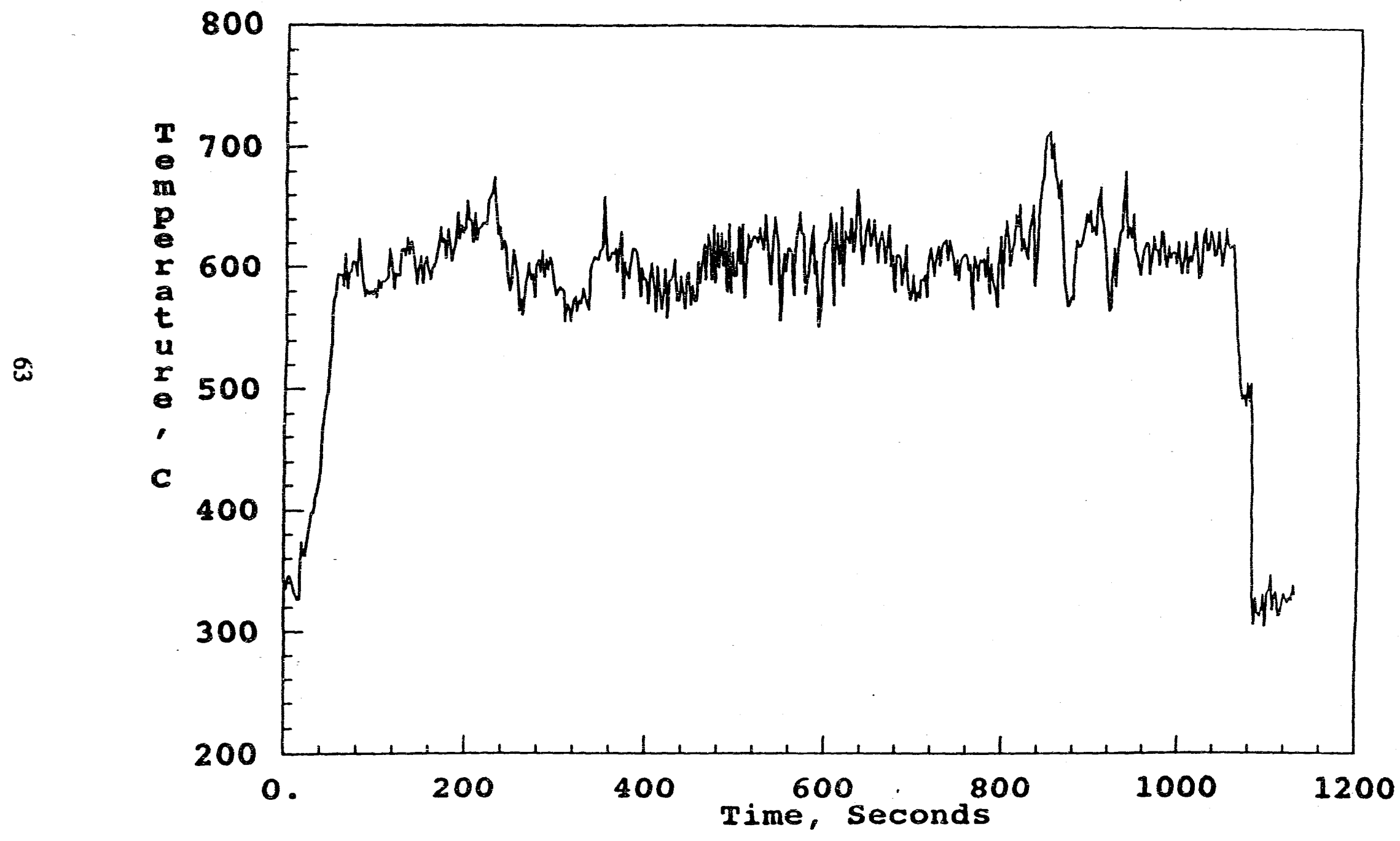


Figure 3

Char Oxidation

Ic0873a

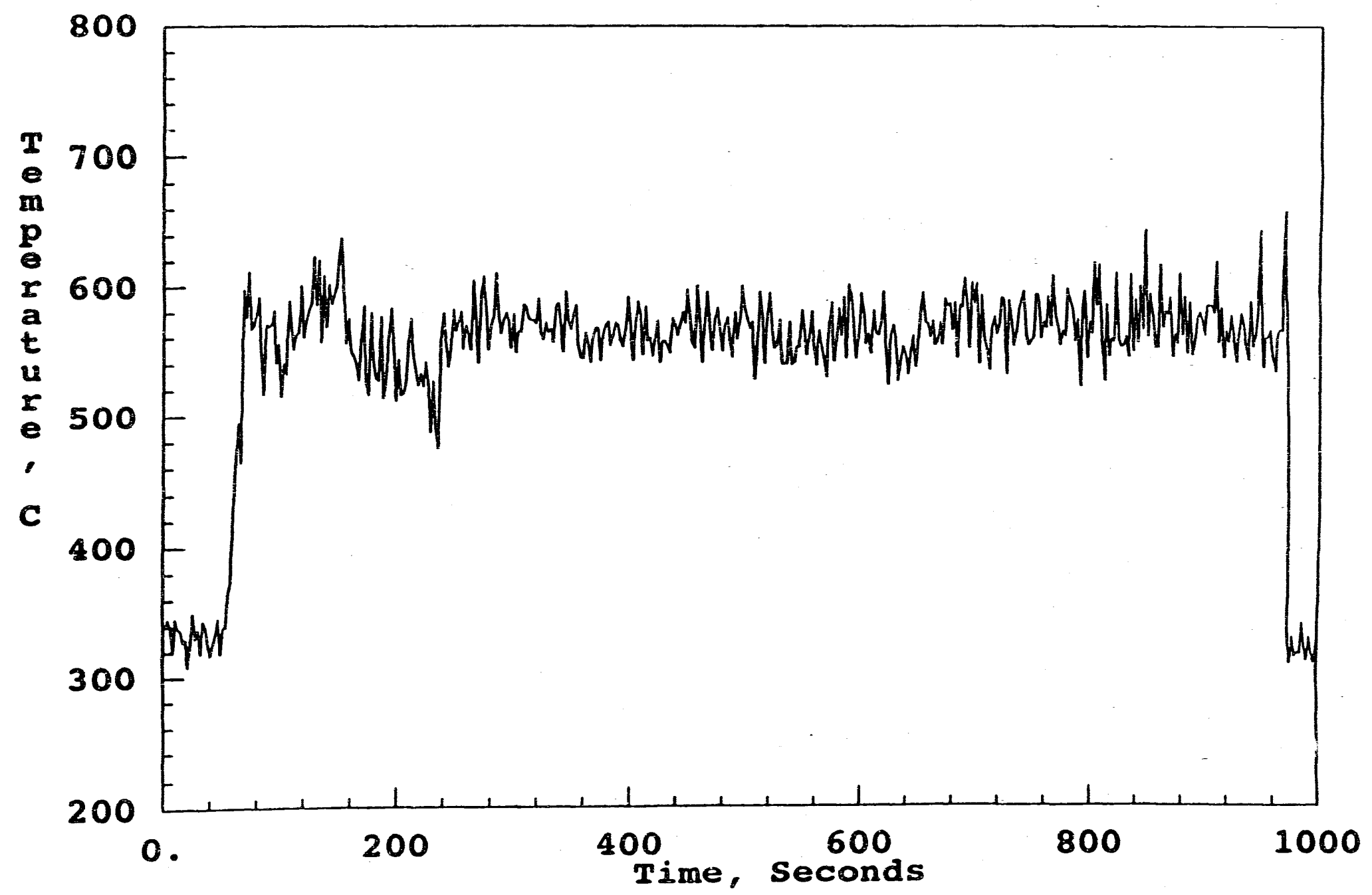




\begin{tabular}{|l|l|}
\hline $\begin{array}{l}\text { Figure 4a. Spherocarb } \\
\text { before heating in } \mathrm{N}_{2}\end{array}$ & $\begin{array}{l}\text { Figure 4c. Spherocarb } \\
\text { before heating in air }\end{array}$ \\
\hline $\begin{array}{l}\text { Figure 4b. Spherocarb } \\
\text { after heating in } \mathrm{N}_{2}\end{array}$ & $\begin{array}{l}\text { Figure 4d. Spherocarb } \\
\text { after heating in air }\end{array}$ \\
\hline $\begin{array}{l}\text { Figure 5a. 1200K Char } \\
\text { before heating in } \mathrm{N}_{2}\end{array}$ & $\begin{array}{l}\text { Figure 5c. 1200K Char } \\
\text { before beating in air }\end{array}$ \\
\hline $\begin{array}{l}\text { Figure 5b. 1200K Char } \\
\text { after heating in } \mathrm{N}_{2}\end{array}$ & $\begin{array}{l}\text { Figure 5d. 1200K Char } \\
\text { after heating in air }\end{array}$ \\
\hline $\begin{array}{l}\text { Figure 6a. 1600K Char } 1600 \mathrm{~K} \text { Char } \\
\text { before heating in } \mathrm{N}_{2}\end{array}$ & $\begin{array}{l}\text { Figure 6d. 1600K Char } \\
\text { after heating in air }\end{array}$ \\
\hline
\end{tabular}




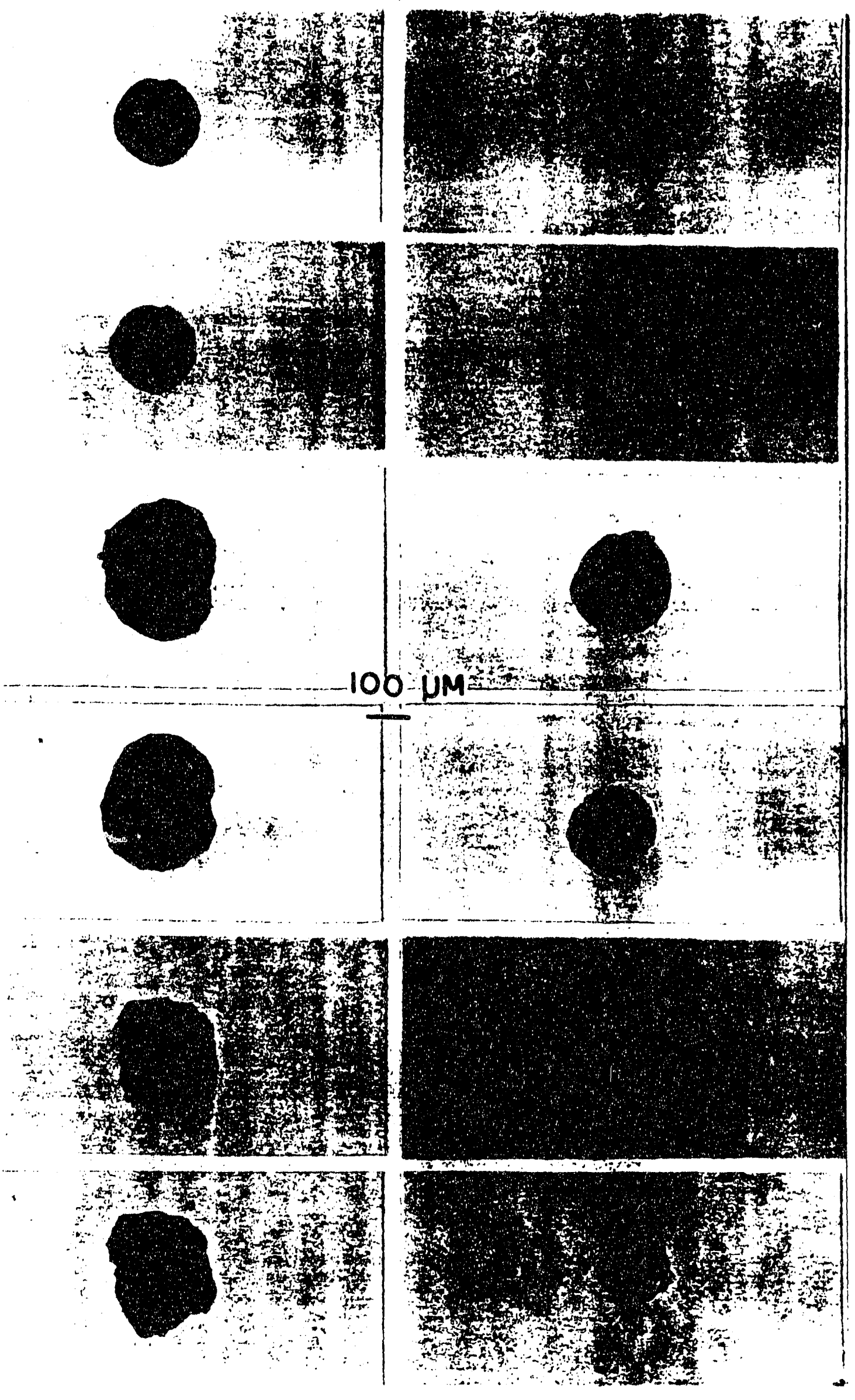




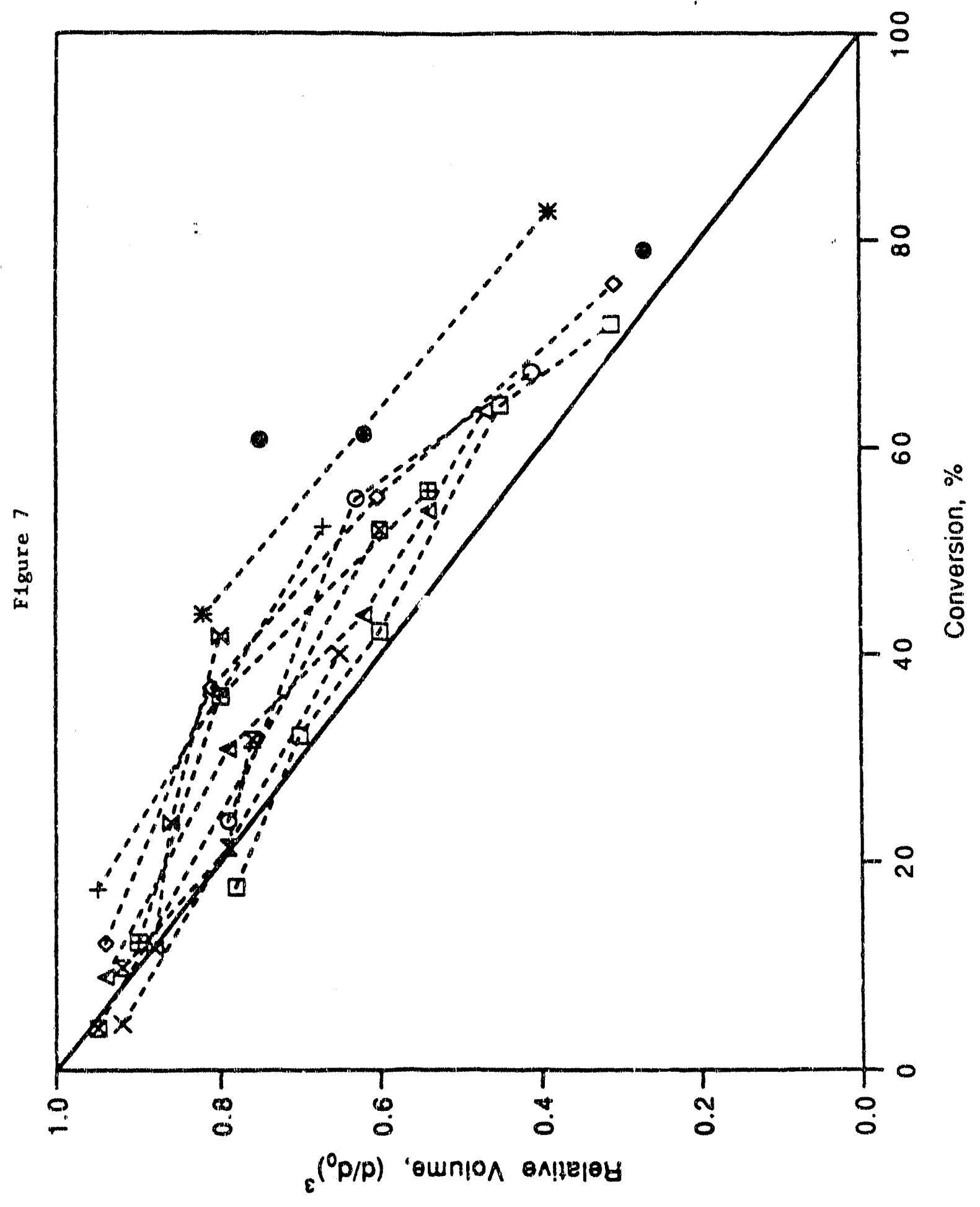


Figure 8

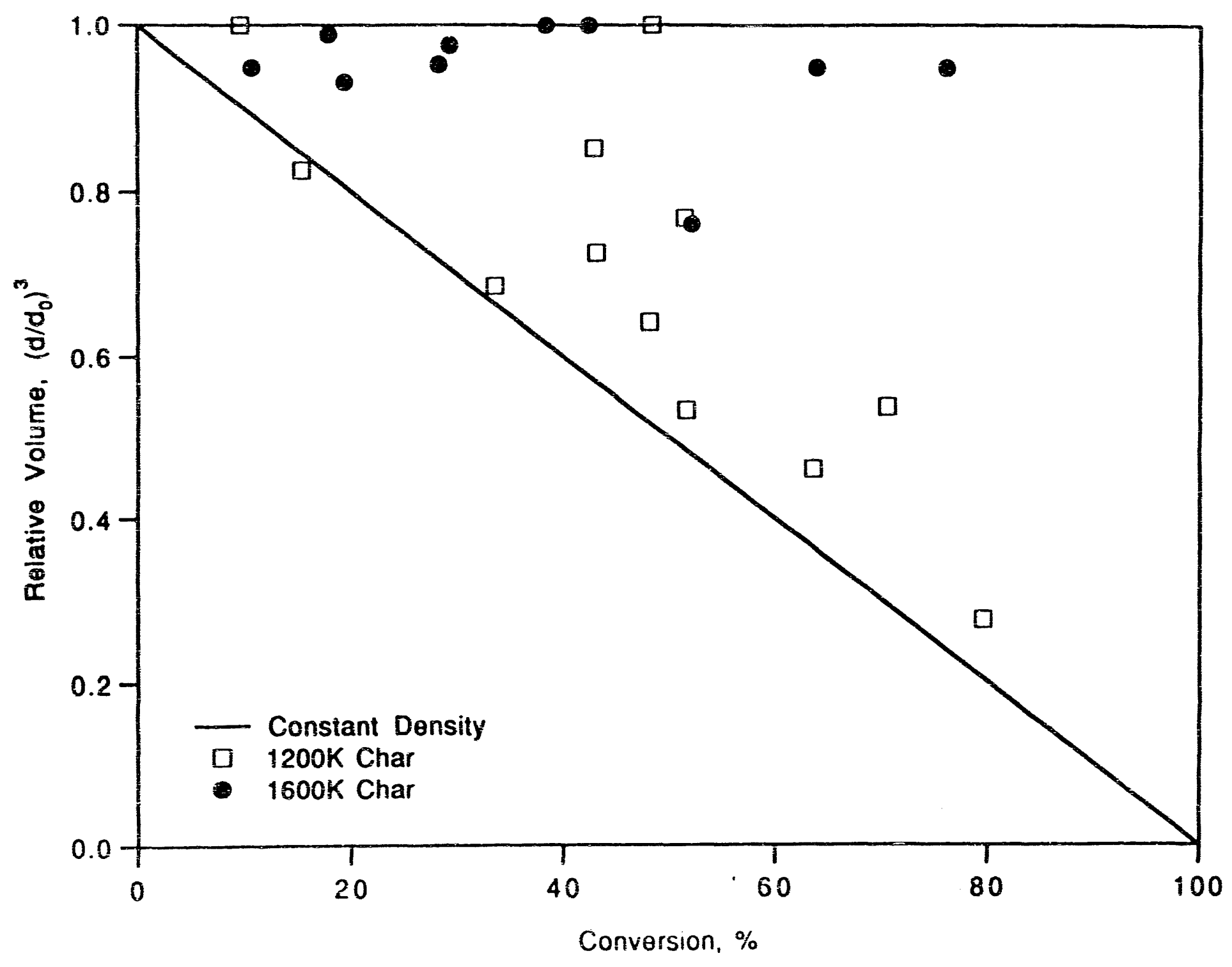




\title{
Laser Ignition of Levitated Char Particles
}

\author{
B. A. Wong*, G. R. Gavalasł and R. C. Flagan† \\ Department of Environenental Engineering Science \\ †Department of Chemical Engineering, California Institute of Technology, \\ Pasadena, California 91125
}

\begin{abstract}
The temperature history of a char particle heated by a carbon dioxide laser to ignition was studied in the electrodynamic balance. The experiments were conducted using Spherocarb particles, 140 to $240 \mu \mathrm{m}$ in diameter, and char particles from a bituminous coal, 150 to $300 \mu \mathrm{m}$ in diameter. In a typical experiment, a charged char particle was suspended in the electrodynamic balance and heated by a $500 \mathrm{~ms}$ pulse of radiation from a $\mathrm{CO}_{2}$ laser. The temperature of the particle was measured with an optical pyrometer: The oxygen concentration in the ambient gas, initially only nitrogen, was slowly increased as successive laser pulses were given, until the particle ignited. Once ignition occurred, the particle lost charge and dropped from the center of the balance. The particle temperature profile at ignition shows the ignition delay predicted by Semenov's thermal explosion theory. The measured temperature traces could be described well by calculations treating the particle as a sphere and using rate parameters given in the literature.
\end{abstract}

- Present address: Chemical Industry Instioute of Toxicology, P. O. Box 12137. Research Triangle Park, NC 27709. 


\section{Introduction}

In pulverized coal combustion, small particles, typically $50 \mu \mathrm{m}$ in size are burned while entrained in the combustion gases. As a coal particle heats up, it devolatilizes and pyrolyzes. The remaining material, char, is a porous, primarily carbonaceous material. The carbon reacts with the oxygen in the surrounding atmosphere, generating heat. Ignition occurs when the heat produced by the exothermic oxidation reaction exceeds the heat loss from the system due to conduction, convection and radiation. This concept of ignition applies to an entire system, e.g., a cloud of coal particles in a furnace, as well as to an individual particle (Field et al. $i^{1}$ Essenhigh et al. ${ }^{2}$ ). Two mechanisms of ignition have been identified for coal particles, homogeneous and heterogeneous (Essenhigh et al. ${ }^{2}$ ). Homogeneous ignition occurs when the devolatilizing gases react with oxygen to ignite first, producing a flame front that initially stands off from the particle but eventually reaches the char surface as the devolatilization ceases. Heterogeneous ignition occurs directly on the particle surface as oxygen reacts with the char particle. Experimental (Howard and Essenhigh, ${ }^{3}$ ) and theoretical (Annamalai and Durbetaki ${ }^{4}$ ) results have demonstrated that the heterogeneous ignition mechanism dominates for smaller ( $<350 \mu \mathrm{m}$ diameter) coal particles. The ignition characteristics of coal or char are important to the fundamental understanding of the coal combustion process. Historically, ignition was studied, not only for application in furnaces and combustors, but also because of safety concerns. Coal piles, coal dust, and dust of other materials such as grain have been known to occasionally explode and burn. Research was initiated to determine the cause of, and prevent such unplanned explosions (Essenhigh et al. ${ }^{2}$ ). Research into the ignition process continues as part of the broad area of research in coal combustion fundamentals in efforts to improve efficiency and minimize fouling, waste products and pollution in current combustor technology. The development of new technologies, such as coal-fired diesel engines, coal gasification and liquefaction and magneto-hydrodynamics will also benefit from a better understanding of coal combustion fundamentals.

The criteria used to define ignition is based on Semenov's thermal explosion theory (Essenhigh et al. ${ }^{2}$; Chen et al..$^{5}$; Thomas et al. ${ }^{6}$ ). The classical conditions for ignition state that the heat loss from the particle, $Q_{\ell}$ must be equal to the heat generated, $Q_{B}$

$$
Q_{l}=Q_{8}
$$

and that the heat loss curve must be tangent to the heat generation curve 


$$
\frac{d Q_{e}}{d T}=\frac{d Q_{g}}{d T}
$$

More generally, ignition occurs when the heat generation equals or exceeds the heat loss (Essenhigh et al. ${ }^{2}$, Chen et al. ${ }^{5}$ )

$$
Q_{\ell} \geq Q_{\text {g }}
$$

The ignition limit defined by equations 1,2 and 3 is illustrated in Figure 1 which shows the heat loss and gain for a $50 \mu \mathrm{m}$ diameter coal particle in a hot gas as a function of particle temperature (Field et al., ${ }^{1}$ ). The dotted lines show the heat loss and heat generation for the particle in a hot gas with $10 \%$ oxygen at $900 \mathrm{~K}$. At point $A$ the curves intersect, i.e., $Q_{\ell}=$ $Q_{B}$, but the tangency requirement is not met, so the particle reaches an equilibrium temperature without igniting. If the particle temperature increases, the heat loss is greater than the heat gain, and the particle will cool back to the equilibrium temperature. If the particle temperature undergoes a slight decrease, the heat gain becomes greater than the heat loss, and the particle warms back to the equilibrium temperature. The solid curves show the heat loss and heat generation for the particle in $10 \%$ oxygen at $1235 \mathrm{~K}$. Under these conditions, the reaction with oxygen causes the particle temperature to increase to about $1360 \mathrm{~K}$, at which point (B), the heat loss and heat gain curves are equal and, also, tangent, indicating the ignition limit. Any perturbation in temperature above this value will cause the particle temperature to increase further since the heat generation rate is greater than the heat loss rate. The firal steadystate temperature of the ignited particle is attained at the point $C$ at which the two curves again intersect. The dashed curves show the heat loss and heat generation for the particle in $10 \%$ oxygen at $1400 \mathrm{~K}$. The heat generation is significantly greater than the heat loss, until the boundary layer diffusion of oxygen becomes the limiting factor to any further temperature rise, and the curves intersect at point $D$. Mass loss has not been considered explicitly in this simple model. Instead, we have determined the steadystate temperature that would result if the particle temperature rise occurred very rapidly compared to its loss of mass by oxidation.

A detailed examination of char ignition requires solving the unsteady energy balance

$$
m C_{p} \frac{d T}{d t}=Q_{\ell}-Q_{q}
$$


in conjunction with a model of the oxidation process. Here, is the mass of the particle, is the heat capacity, is the temperature, and is the time. In Figure 2, the dotted curve shows the temperature of a $50 \mathrm{~m}$ particle immersed in a gas at $900 \mathrm{~K}$. The particle temperature increases and then levels out at the temperature corresponding to the intersection of the heat loss and heat gain curve (point $\mathrm{A}$ ) in Figure 1. For the same particle immersed in a gas at 1235K, the curve (solid line) plateaus at the ignition temperature, and then rapidly increases. The inflection point in this curve corresponds to point B in Figure 1. The length of time spent in the plateau is known as the ignition delay or induction time (Essenhigh et al. ${ }^{2}$; Bandyopadhyay and Bhaduri, ${ }^{7}$ Thomas et al. ${ }^{6}$ ). The temperature rises until it plateaus at point $\mathrm{C}$. The dashed curve shows the rapid temperature rise of a particle at a surrounding temperature of $1400 \mathrm{~K}$. At this high temperature, the particle ignites without the ignition delay (Thomas et al. ${ }^{6}$ ) and the temperature rises to a new steady-state in which oxidation is limited by the external diffusion of oxygen to the particle.

There have been many studies of the ignition process, with special interest in the ignition temperatures of coal or char particles and the relationship to particle diameter. Different techniques were devised to accomplish the three major steps in these experiments; holding or isolating the particle, heating the particle, and monitoring the transient particle temperature and identifying ignition. Bandyopadhyay and Bhaduri ${ }^{7}$ placed a coal particle onto a fine platinum wire and inserted the wire into a furnace. The insertion step was repeated after increasing the temperature of the furnace until an ignition flash was observed. Karcz et al. ${ }^{8}$ placed a single coal particle on the tip of a quartz needle and inserted the needle into a heated furnace. As in the experiments of Bandyopadhyay and Bhaduri, the insertion was repeated with the furnace temperature increased stepwise until ignition was observed. Ubhayakar and Williams ${ }^{9}$ mounted a small carbon particle on the end of a glass fiber and heated the particle with a ruby laser pulse. The particle was monitored by a highspeed camera that recorded the igniting particle as a bright spot on the film. The temperature of the particle was also monitored by dual-wavelength optical pyrometry. Cassel and Liebman ${ }^{10}$, Chen et al. ${ }^{5}$ and Seixas and Essenhigh ${ }^{11}$ injected particles into a heated drop-rube furnace, and observed them with a photomultiplier rube. The temperature of the furnace was gradually increased until a flash was seen, indicating ignition. Gomez and Vastola ${ }^{12}$ injected particles into a heated gas strearn, and analyzed the resultant gases for $\mathrm{CO}$ and $\mathrm{CO}_{2}$. The ratio of the two gas concentrations was used to distinguish between heterogeneous and homogeneous ignition. Ignition was also confirmed by light emission measurements. Tognotti, et al. ${ }^{13}$ placed milligram quantities of coal or char in a thermogravimetric analyzer (TGA) in an inert $\left(\mathrm{N}_{2}\right)$ or oxidizing atmosphere, and slowly 
ramped the temperature. The ignition temperature was defined as the point at which the weight vs. temperature curve for the coal or char in the oxidizing atmosphere deviated from that in the inert atmosphere. In all of the above experiments, the ignition temperature was found to decrease with increasing particle size, in agreement with the thermal explosion theory. The activation energies determined from these experiments encompass a wide range of values ( 11 to $50 \mathrm{kcal} /$ mole) because of the variety of coals and chars tested, and probably because of other differences from experiment to experiment. Essenhigh et al. ${ }^{2}$ have reviewed early theories as well as more recent theoretical and experimental work on ignition.

These approaches have a number of drawbacks. In the experiments where a single coal particle is mounted on a thin wire (Bandyopadhyay and Bhaduri; ${ }^{7}$ Karcz et al.; 8 Ubhayakar and Williams $^{9}$ ) the effects of the physical contact on the energy balance have been assumed negligible. In the experiments which detect ignition by visual or optical detection (Chen et al.;5 Bandyopadhyay and Bhaduri; ${ }^{7}$ Karcz et al.; 8 Cassel and Leibman; ${ }^{10}$ Seixas and Essenhigh; ${ }^{11}$ Gomez and Vastola ${ }^{12}$ ) the determination of ignition is dependent on the spectral sensitivity of the selected detector. Only Ubhayakar and Williams ${ }^{9}$ measured the actual particle temperature. Most investigators inferred particle temperature from the ambient value.

Ideally, one would like to isolate a single particle free of physical contact, rapidly heat the particle, and measure its temperature directly. In this paper we present an experimental investigation of ignition that more closely approaches this ideal. In our experiments, electrically charged char particles were levitated in an electrodynamic balance and heated with laser radiation. This type of electrodynamic thermogravimetric analyzer has been previously used in studies of char particle oxidation (Spjut et al.14; Bar-Ziv et al. ${ }^{15}$ ). The balance is an improved version of Millikan's oil-drop apparatus. In the electrodynamic balance, a charged particle is suspended in a DC field between two end-cap electrodes, as in the Millikan cell. In the midplane between the electrodes, a ring electrode surrounds the particle. When the particle is at the center of the cell it is not affected by the alternating field. If, however, it is displaced from that null point in any direction, the particle experiences an alternating force that increases with displacement. The particle then oscillates but lags the AC field in phase due to inertia and aerodynamic drag. The timeaverage force experienced by the particle drives it back toward the center of the cell. With the addition of this dynamic focussing, a particle that is levitated electrostatically can be subjected to rather strong forces without being lost. The historical background of the electrodynamic balance has been reviewed by Davis ${ }^{16}$. The balance has been used in 
previous studies of ignition processes. Nelson et al. ${ }^{17}$ used a form of the electrodynamic balance to suspend metal particles, which were ignited by a pulsed Nd-doped glass laser. Liebman et al. ${ }^{18}$ also used a quadrupole levitator to suspend magnesium particles for ignition by a Nd-doped glass laser. Bar-Ziv ${ }^{15}$ reports on some ignition studies in the electrodynamic thermogravimetric analyzer in his review article on single particle char combustion kinetics. We report here on the use of an electrodynamic balance to study laser-induced ignition of a freely levitated char particle.

\section{Experimental}

The use of the electrodynamic balance for single particle studies is well documented (Spjut et al.; ${ }^{14}$ Davis; ${ }^{16}$ and Monazam et al.; ${ }^{19}$ Bar-Ziv et al. ${ }^{15}$ ). The electrode configuration in the electrodynamic balances most commonly used has a hyperboloidal geometry. The electric field in the hyperboloidal geometry balance is well-characterized (Davis ${ }^{16}$ ), but this understanding is not critical to its use. Many other electrode geometries have been used in previous applications of the electrodynamic balance (Davis; ${ }^{16}$ Amold and Folan ${ }^{20}$; Davis et al. ${ }^{21}$ ). Sloane and Elmoursi ${ }^{22}$ have theoretically examined the characteristics of a number of electrode arrangements. We used hemispherical endcap electrodes and a right cylinder ring as illustrated in Figure 3. The electric field near the center of this balance, and therefore its operating characteristics, very closely approximates that of the hyperboloidal geometry (Sloane and Elmoursi ${ }^{22}$; Wong ${ }^{23}$ ). The electrode cell was housed in an evacuable stainless steel chamber with total volume of $250 \mathrm{~cm}^{3}$. The atmosphere in the chamber was controlled by introduction of gases with the desired composition.

A 20-Watt Carbon Dioxide laser (Advanced Kinetics MIRL-20) was used to heat the particle. The laser was modified to produce a TEM-O1* beam. In this mode, the cross-section of the beam appears to be doughnut-shaped rather than Gaussian shaped as in more common TEM-00 mode. The TEM-01* mode was selected because when the particle is heated, thermophoretic and photophoretic forces tend to push the particle away from the area of highest intensity (Greene ${ }^{24}$ ). In a Gaussian beam, then, the particle tends to be pushed out of the laser beam. The particle will remain trapped in a doughnut mode beam. The laser beam is directed by mirrors into the top of the chamber through a $\mathrm{KCl}$ window, and the beam is focused onto the particle with a $\mathrm{ZnSe}$ lens. The lens can be moved vertically to focus or defocus the beam with respect to the particle, changing the intensity of the be'm incident on the particle. 
The TEM-01* mode of the laser was very sensitive to laser temperature and power variations, therefore laser pulsing could not be controlled by pulsing the power supply. An external shutter was constructed from refractory and attached to a pneumatic piston. The laser beam was uncovered or covered in 3 to 4 milliseconds by the shutter. The length of time that the shutter was opened was controlled electronically.

A 5-mW HeNe laser (Melles Griot) was directed through the bottom of the chamber onto the particle for illumination. The particle was observed with a microscope and with a catadioptric microscope (Questar) and video camera combination. The images from the video camera were recorded on a video cassette recorder. The particle image was also focused onto a position-sensitive-detector (PSD) (Hamamatsu). The outputs from the PSD were connected to a proportional-integral-derivative (PID) controller which fed back to the DC voltage control. Thus, any force causing the particle to deviate vertically from the center in the vertical plane would cause the PID controller to adjust the DC voltage restoring the particle back to the center of the chamber.

The temperature of the particle was monitored by a two-color optical pyrometer, pictured schematically in Figure 4. Radiation from the particle was collimated by a $\mathrm{CaF}_{2}$ lens, and then split by a coarse grating beam splitter. The two beams then passed through $\mathrm{CaF}_{2}$ focusing lenses and interference filters at 1.48 and $3.42 \mu \mathrm{m}$ and onto an InGaAs and an InSb detector. The output from the detectors was processed with a log-ratio amplifier, and monitored with a PC-based data acquisition system. The optical pyrometer was calibrated by inserting a type $R$ thermocouple into the chamber with the bead placed at the center of the cell in place of the particle. The thermocouple was heated by the $\mathrm{CO}_{2}$ laser while the thermocouple output and the pyrometer output were recorded. The pyrometer output is plotted against the thermocouple temperature in Figure 5.

The gas composition in the chamber was varied by using a 3-liter glass vessel as a continuous flow stirred tank reactor (CSTR). Nitrogen was passed through the vessel and through the chamber. At the onset of the experiment, oxygen was admitted into the CSTR. The output from the CSTR was then a $\mathrm{N}_{2}-\mathrm{O}_{2}$ mixture that was slowly increasing in oxygen. This mixture flowed through the chamber and into an oxygen analyzer (Beckman, Model 755). The TGA chamber also acted as a CSTR, but with a much shorter residence time so that concentration of oxygen was very close to that of the larger vessel.

Two materials were used in this study. The first was Spierocarb, a highly porous synthetic carbon intended for use as a gas chromatograph column packing. (Alltech purchases this material from Analabs and markets it as "Carbosphere." Because 
Spherocarb is the trade name more commonly found in literature references, we shall call the material Spherocarb). Because of its high pososity, relative freedom from impurities, and highly spherical shape, this material has been used in many carbon oxidation studies (Waters et al..$^{25}$; Floess ${ }^{26}$; Bar-Ziv et al. ${ }^{15}$ ). The second material studied was char from PSOC 1451 bituminous coal previously characterized by Sahu et al. ${ }^{27}$.

\section{Procedure}

An experiment was started by presetting the $A C$ and $D C$ voltages of the electrodynamic balance to previously determined values. A small amount of char was placed on a small electrode and pushed under the bottom end-cap electrode. A Zerostat (Discwasher, Inc.) anti-static device was used to generate a short high voltage pulse to the electrode. Char particles on the electrode acquired charge and were repelled from the electrode through the opening in the botto:n electrode into the electrodynamic cell, where some were captured by the $\mathrm{AC}$ field. The $\mathrm{AC}$ and $\mathrm{DC}$ voltages were manipulated to isolate a single particle. Following the suspension of an isolated particle the chamber was flushed with nitrogen. The dimensions of the particle were then measured with an eyepiece micrometer. After these preliminaries, the $\mathrm{CO}_{2}$ laser was pulsed by opening the shutter for 500 milliseconds. During this pulse, the output from the pyrometer, the balancing voltage, and the position were recorded on a PC-based data acquisition system. The temperature rise observed in the absence of oxygen provided the data needed to calculate the laser energy absorbed by the particle. Oxygen was then admitted into the CSTR and as the $\mathrm{N}_{2}-\mathrm{O}_{2}$ mixture of increasing $\mathrm{O}_{2}$ concentration was very slowly passed through the chamber, additional laser pulses were administered until the particle ignited.

\section{Results}

The time-temperature history of a Spherocarb particle undergoing a laser pulse in nitrogen is shown in Figure 6a. The solid line connects experimental data points. It can be seen that the particle temperature increases, reaches a steady state level and then drops when the laser pulse ends. Figure $6 \mathrm{~b}$ shows the same particle heated in $20 \%$ oxygen. The steady state temperature is now higher, due to iscreased rate of carbon oxidation. At each laser pulse the oxygen concentration was about $\leqslant \%$ higher than that present at the previous pulse. This particular Spherocarb particle ignited when the oxygen concentration reached $40 \%$, as illustrated in Figure $6 c$. The temperature trace shows an ignition delay time of approximately 300 milliseronds. 
The vertical position trace of a Spherocarb particle in nitrogen is shown in Figure 7a, where 0 denotes the center of the chamber. Prior to the laser pulse, the particle is oscillating with an amplitude of the order of $\pm 15 \mu \mathrm{m}$. When the particle is pulsed, the oscillation changes, but the particle does not deviate from the center of the chamber. This pattern was generally observed for subsequent pulses as shown in Figure 7b. Figure 7c shows that for a particle suspended in $40 \%$ oxygen, the amplitude of the oscillations, initially very small, greatly increases during heating. Finally, when the particle reaches a temperature of 1200 to $1300 \mathrm{~K}$, it begins to lose charge (Dudek et al. ${ }^{28}$ ), and the particle eventually drops from the center of the chamber, as shown by the position trace.

Figure 8 shows the heat loss and heat generation curves for a Spherocarb particle exposed to different oxygen concentrations. The curves are analogous to those in Figure 1. The heat isss curve is the labeled solid line. The horizontal solid line represents the heat generation curve in nitrogen. Since the only source of heat is the laser, the particle temperature is constant, and the line is horizontal. The short-dashed line is the heat generation in $20 \%$ oxygen. This curve intersects the heat loss curve, indicating a stable temperature, without ignition. The long-dashed line shows the heat generation curve at $40 \%$ oxygen. This curve is above the heat loss curve, satisfying equations (2) and (3), so the particle ignites. The region in Figure $6 c$ where the particle temperature rises slowly corresponds to the area where the heat generation and heat loss curves are close to each other.

The temperature trace of a $300 \mu \mathrm{m}$ bituminous char particle laser-heated in nitrogen is shown in Figure 9a. The steady-state temperature trace fluctuates somewhat due to the more irregular shape and uneven heating of the char particle. In 10\% oxygen, Figure $9 \mathrm{~b}$ shows that the particle temperature dips slightly, then returns to a steady state level, until the laser pulse is off. The video recording shows that the dip in the temperature is due to movement and rotation of the unevenly heated particle. When the oxygen pressure reaches $15 \%$, the particle ignites. Figure $9 \mathrm{c}$ shows that ignition was attained after a short induction time.

The vertical position trace of the bituminous char particle is shown in Figures 10a,b and $c$. When the laser is pulsed on, the particle undergoes a larger displacement from that of a Spherocarb particle, and rises in the chamber. This is evidently because of the greater buoyancy effect on the lower density char. As with the Spherocarb particles, the igniting char particle drops out of the center because of charge loss. 


\section{Discussion}

In a simple analysis of particle ignition, a spherical and isothermal particle is assumed to be at rest relative to the surrounding gas. The heat loss to the gas may be written in the form of Newton's law of cooling. The heat transfer coefficient is determined from the Nusselt number, which equals 2 for spheres at low Reynolds numbers, as in this case. The contribution of radiation to the particle heat loss is small but increases as the temperature of the particle increases. The heat loss due to conduction and radiation for a sphere are:

$$
\begin{aligned}
& H_{c}=\frac{k\left(T_{Q}-T_{g}\right)}{r} \\
& H_{r}=\varepsilon \sigma\left(T_{p}^{A}-T_{g}^{A}\right)
\end{aligned}
$$

where $k$ is the thermal conductivity of air, $T_{p}$ is the particle temperature, $T_{g}$ is the gas temperature, $r$ is the particle radius, $\varepsilon$ is the particle emissivity, and $\sigma$ is the StefanBoltrman constant.

The rate of carbon oxidation, $R_{C}$, is generally expressed in the simple form

$$
R_{C}=A e^{\left(-E_{\otimes} / R T_{p}\right)} P_{O_{2}}^{n}
$$

where $E_{a}$ is the activation energy, $R$ is the gas constant, $A$ is the pre-exponential factor, $\mathrm{PO}_{2}$ is the pressure of oxygen, and $\mathrm{n}$ is the reaction order. The heat generation term is then given by:

$$
H_{g}=R_{C} Q_{e f f}
$$

where $Q_{\text {eff }}$ is the heat released by carbon oxidation. The time dependent equ tion (3) can therefore be written as

$$
m C_{p} \frac{d T}{d t}=4 \pi a^{2}\left(H_{g}+H_{1}-H_{c}-H_{r}\right)
$$

The term $\mathrm{H}_{1}$ is the heat gain from absorption of the laser energy. 
The value of the heat capacity, $\mathbf{C}_{\mathbf{p}}$, for Spherocarb was taken from Monazam et al.19. An apparent activation ene $\mathrm{gy}, \mathrm{E}_{\mathrm{a}}$, of $20 \mathrm{kcal} / \mathrm{mole}$ and a reaction order with rerpect to oxygen, $n$, of one-half was assumed, as determined by Waters et al. ${ }^{25}$ in their study of Spherocarb oxidation in the temperature range of 1400 to $2200 \mathrm{~K}$. The diffusion of oxygen through the porous char matrix becomes the limiting factor in the carbon oxidation rate at these temperatures. The particle temperatures being measured were approaching this range, hence these apparent rate parameters were selected. Also in the experiment by Waters et $\mathrm{al}{ }^{25}$, it was determined that the oxidation products were $\mathrm{CO}$ and $\mathrm{CO}_{2}$ in a $65 \%$ to $35 \%$ ratio, and $Q_{\text {eff }}$ was calculated accordingly. Table I gives the values used for each parameter and the literature source.

The value of $\mathrm{H}_{1}$ was determined from the particle temperature trace when heated in nitrogen. In the absence of oxygen, $\mathrm{H}_{\mathrm{g}}$ is zero, and at steady state, $\mathrm{H}_{\mathrm{l}}=\mathrm{H}_{\mathrm{c}}+\mathrm{H}_{\mathrm{r}}$. After $H_{1}$ was determined, the time dependent equation (9) was solved using a fourth-order Runge-Kutta routine. The preexponential factor was varied until a reasonable fit of the curve to the experimental data from the ignition event was obtained.

The calculated temperature traces are shown by the dashed lines in Figures $6 \mathrm{a}$ to $6 \mathrm{c}$ and $9 \mathrm{a}$ to $9 \mathrm{c}$. The good agreement between calculated traces and measured traces for the nitrogen atmosphere (Figures $6 \mathrm{a}$ and $9 \mathrm{a}$ ) simply reflects the choice of the parameter, $\mathrm{H}_{1}$. which was adjusted to match those two traces. The calculated laser intensity is listed in Table 2. The density parameter was adjusted to match the initial slope of the calculated trace to the measured trace in a nitrogen atmosphere. The density values are larger than the density of $600 \mathrm{~kg} / \mathrm{m}^{3}$ found for Spherocarb particles by D'Amore et al. ${ }^{29}$, but they cluster around the value of $1050 \mathrm{~kg} / \mathrm{m}^{3}$ used by Monazam et al. ${ }^{19}$ when he measured the heat capacity of Spherocarb.

Table 2 shows the fitted parameters for several particles. The fitted pre-exponential factors ranged from 3.6 to 6.1. The preexponential factor that was determined by Waters et al. ${ }^{25}$ was $10.6 \mathrm{Kg} \mathrm{m}^{-2} \mathrm{~s}^{-1}$ (mole $\left.\mathrm{O}_{2} \mathrm{~m}^{-3}\right)^{-n}$. Although the preexponential factor is the nominal fitting parameter, $Q_{e f f}$ and $\mathrm{P}_{\mathrm{O}_{2}}^{\mathrm{n}}$ can also be lumped in with the exponential factor. Therefore, the uncertainty in the fitted exponential value is also indicative of uncertainties in Qeff and $\mathrm{P}_{\mathrm{O}_{2}}^{\mathrm{n}}$.

The calculated trace in Figure $6 \mathrm{~b}$ was determined using the fitted parameters from Figures $6 \mathrm{a}$ and $6 \mathrm{c}$. It appears to overpredict the measured temperature. This discrepancy may be due to experimental error such as fluctuations in the laser power, or it may be due 
to the uncertainties in the $Q_{\text {eff }}$ and $P_{\mathrm{O}_{2}}^{\mathrm{n}}$ as mentioned previously. A general trend of increasing steady state temperature with increasing oxygen concentration could be detected, however, the scatter in the data was substantial, and the relationship could not be quantified.

Sahu et al. ${ }^{30}$ determined an apparent activation energy of $17 \mathrm{kcal} / \mathrm{mole}$ for char made from PSOC 1451 bituminous coal with a preexponential factor of $107.1 \mathrm{~g} \mathrm{~cm}^{-2} \mathrm{~s}^{-1}$ atm-1. When the apparent activation energy is used, and the preexponential factor varied to achieve a reasonable fit, Figure $9 \mathrm{c}$ results.

There are an number of problems with this experiment which are not apparent from the results presented. The first is related to the laser stability. The laser power, as measured on a power meter, was subject to fluctuations and occasionally drifted over a long period of time. To minimize the effect of drift, the experiments were performed only when it appeared that the laser was operating stably and the power was not drifting. However, the fluctuations were always present. Another difficulty was that the laser heated the particle from the top only. Video recordings of a Spherocarb particle during heating clearly show a thermal gradient across the particle. Thus, the model used to describe the experiments is an oversimplification. Bar-Ziv et al. ${ }^{15}$, and Monazam et al. ${ }^{19}$ addressed this problem for a particle heated on opposite sides and concluded that the maximum temperature difference between the surface and center of the particle was about $8 \mathrm{~K}$ for a particle $1000^{\circ} \mathrm{C}$ above ambient. They concluded that this difference may be disregarded for most combustion studies. For one sided heating, however, the temperature difference is greater, although the magnitude of the temperature gradient is not known.

A particle heated on one side might lead to ignition at a point, or a very small area, as discussed by Levendis et $\mathrm{al}^{31}$. Those authors used two-color pyrometry to measure the temperature of a char particle burning in a drop-tube furnace. They observed signal intensities which increased in the individual detectors while the ratio of the signal intensities remained relatively constant, indicating a relatively uniform temperature. They attributed the increase in signal intensity to localized ignition on the particle surface which gradually spread over the surface of the particle. In the present experiments we did not measure the individual signal intensities but only their ratios therefore, it is unknown whether the detector signal levels are changing while their ratio remains constant. Observations from the video recording of the particle ignition do not show localized ignition on a Spherocar particle. The particle appears to glow uniformly as the temperature nears the ignition point (although saturation of the video camera precludes quantitative interpretation of these 
images). As the particle ignites, it appears to expand to about twice its original diameter. This expansion may be due to an oscillation of the particle that is too rapid to be resolved by the video camera, or it may result from camera saturation. At this point, the particle loses a significant amount of charge, and drops from the center of the chamber. No hot spots are visible, no jetting is observed, and Spherocarb particles always move in the downwards direction. Hence, it is believed that the Spherocarb particles are igniting uniformly across the surface of the particle. In contrast, there is clear evidence of localized ignition on char particles. Video recordings show that, when a coal char particle is heated, small areas glow considerably more intensely than other areas. Since the char is irregularly shaped, this is not unexpected. Even when a char particle ignites, hot spots often are visible.

\section{Conclusions}

This experiment has shown that ignition experiments are feasible in the electrodynamic balance With the particle suspended without physical contact, heat transfer other than by conduction and radiation is avoided. The particle remperanure is measured by the optical pyrometer and does not need to be calculated from the ambient temperature. There are some difficulties which need $w$ t: addressed in onder to increase the utility of this experiment. The first is the temperature gradient along the particle due to heating from the top side only. When we attempted to heat from both sides, the particle bounced around excessively. The solution might be using a more powerful laser, such as used by Monazam et al. ${ }^{19}$, in the Gaussian mode. The problem of charge loss at high temperatures also limits the usefulness of the electrodynamic balance somewhat in that the particle is lost once it reaches ignition temperatures. There are other techniques that can levitate an uncharged particle which are as yet untested for char oxidation studies.

The temperature traces of particles that ignited clearly show an induction time, or ignition time lag, as predicted by the solution of the time dependent equation for a heated particle. The effest of increasing the oxygen concentration is also seen in the increasing equilibrium temperature at sub-ignition conditions, though it was not cuancifiable in this study. A simple isothermal sphere model was used with parameters obtained from the literature which adequately predicted the experimentally obtained time-temperature histories of igniting Spherocarb paricles. A reasonable fit to the bituminous char oata was achieved using rate parameters determined by Sahu et al. ${ }^{30}$. These experiments frovide the first examples in which the oxidation of char during ignition is rigorously modeled and compared with existing literature data. The electrodynamic balance can be used in ignition 
experiments to measure the apparent char oxidation rate parameters, and probe particle-toparticle variations in the apparent kinetics.

\section{Acknowledgements}

This research was supported by the U.S. Department of Energy, University Coal Research Program under grants DE-FG22-89PC89765 and DE-FG22-88PC88911. 


\section{References}

(1) Field, M. A.; Gill, D. W.; Morgan, B. B.; Hawksley, P. G. W. Combustion of Pulverized Coal; The British Coal Utilisation Research Association, Leatherhead, 1967.

(2) Essenhigh, R. H.; Misra, M. K.; Shaw, D. W. Combust. Flame. 1989, 77, 3-30.

(3) Howard, J. B.; Essenhigh, R. H. Eleventh Symp. (Int.) Comb., The Combustion Institute, Pittsburgh, 1967, p. 399-408.

(4) Annamalai, K.; Durbetaki, P. Combust. Flame. 1977, 29, 193-208.

(5) Chen, M.-R.; Fan, L.-S.; Essenhigh, R. H. Proc. Twentieth Symp. (Int.) Comb. 1984, 1513.

(6) Thomas, G. R.; Stevenson A. J.; Evans, D. G. Combust. Flame. 1973, 21 , 133-136.

(7) Bandyopadhyay, S.; Bhaduri, D. Combust. Flame. 1972, 18, 411-415.

(8) Karcz, H.; Kordylewski, W.; Rybak, W. Fuel. 1980, 59, 799-802.

(9) Ubhayakar, S. K.; Williams, F. A. j. Electrochem. Soc. 1976, 123, 747.

(10) Cassel, H. M.; Leibman, I. Combust. Flame. 1959, 3, 467-475.

(11) Seixas, J. P. S.; Essenhigh, R. H. Combust. Flame. 1986, 66, 215-218.

(12) Gomez, C. O.; Vastola, F. J. Fuel. 1985, 64, 558-563.

(13) Tognotti, L.; Malotti, A.; Petarca, L.; Zanelli, S. Combust. Sci. and Tech. 1985 , $44,15-28$.

(14) Spjut, R. E.; Sarofim, A. F.; Longwell, J. P. Langmuir. 1985, 1, 355-360.

(15) Bar-Ziv, E.; Jones, D. B.; Spjut, R. E.; Dudek, D. R.; Sarofim, A. F. Combust. Flame. 1989, 75, 81-106.

(16) Davis, E. J. In Surface and Colloid Science. (E. Matijevic, ed.). Plenum Press, New York. Vol. 14, 1965.

(17) Nelson, L. S.; Richardson N. L.; Prentice, J. L., Rev. Sci. Instrum. 1968, 39, 744.

(18) Liebman, I.; Corry, J.; Perlee, H. E. Combust. Sci. and Tech. 1972, 5, 21-30.

(19) Monazam, E. R.; Maloney, D. J.; Lawson, L. O. Rev. Sci. Instrum. 1989, 60, $3460-3465$.

(20) Amold, S.; Folan, L. M. Rev. Sci. Instrum. 198\%, 58, 1732-1735.

(21) Davis, E. J.; Buehler, M. F.; Ward, T. L. Rev. Sci. Instrum. 1990, 61, 1281-1288. 
(22) Sloane, C. S.; Elmoursi, A. A. IEEE Trans. Ind. Appl. 1989, 25, 711-719.

(23) Wong, B. A. The Oxidation of Individually Levitated Char Particles, Ph.D. Thesis, Califormia Institute of Technology, 1991.

(24) Greene, W. M.; Spjut, R. E.; Bar-Ziv, E.; Longwell, J. P.; Sarofim, A. F. Langmuir. 1985, 1, 361-365.

(25) Waters, B. J.; Squires, R. G.; Laurendreau, N. M.; Mitchell, R. E. Combust. Flame. 1988, 74, 91-106.

(26) Floess, J. K.; Longwell, J. P.; Sarotim, A. F. Energy Fuels. 1988, 2, 18-26.

(27). Sahu, R.; Levendis, Y. A.; Flagan, R. C.; Gavalas, G. R. Fuel. 1988, 67, 275-283.

(28) Dudek, D. R.; Wright, D. A.; Longwell, J. P.; Sarofim, A. F.; Yeheskel, J. Combust. Sci. and Tech. 1990, 73, 447-461.

(29) D'Amore, M.; Dudek, D. R.; Sarofim, A. F.; Longwell, J. P. Powder Technol. $1988,56,129-134$.

(30) Sahu, R.; Northrop, P. S.; Flagan, R. C.; Gavalas, G. R. Combust. Sci. Tech. 1988, 60, 215-230.

(31) Levendis, Y. A.; Sahu, R.; Flagan, R. C.; Gavalas, G. R. Fuel. 1989, 68, 849-85j. 
Table 1

Parameters Used in Model

\begin{tabular}{|c|c|c|}
\hline Parameter & Value & Source \\
\hline Heat Capacity, $C_{p}$ & $0.4 \frac{\mathrm{cal}}{\mathrm{g} \text { degK }}$ & Monazam et al., 1989 \\
\hline Thermal Conductivity, $k$ & $\begin{array}{l}\mathrm{k}_{0}\left(\frac{\mathrm{T}_{\mathrm{p}}+\mathrm{T}_{\mathrm{g}}}{2 \mathrm{~T}_{0}}\right)^{0.75} \\
\frac{\mathrm{cal}}{\mathrm{cm} \mathrm{s} \operatorname{deg} \mathrm{K}}\end{array}$ & Field et al., 1967 \\
\hline Emissivity & 0.8 & Monazam et al., 1989 \\
\hline Activation Energy, $\mathrm{E}_{\mathrm{a}}$ & $20 \frac{\mathrm{kcal}}{\mathrm{mole}}$ & Waters et al., 1988 \\
\hline Reaction order, $\mathrm{n}$ & 0.5 & Waters et al., 1988 \\
\hline Heat Release, Qeff & $\begin{array}{l}0.35 \mathrm{Q}_{\mathrm{CO}_{2}}+0.65 \mathrm{Q}_{\mathrm{CO}} \\
(40.82 \mathrm{kcal} / \mathrm{mole})\end{array}$ & Waters et al., 1988 \\
\hline Particle Density & Fitted & \\
\hline Laser Intensity & Fitted & \\
\hline Preexponential, A & Fitted & \\
\hline $\begin{array}{l}\text { Activacion Energy, } E_{\mathbf{a}} \\
\text { for char }\end{array}$ & $17 \mathrm{kcal} / \mathrm{mole}$ & Sahu et al., 1988b \\
\hline Preexponential, A for Char & Fitted & \\
\hline
\end{tabular}


Table 2

Spherocarb Experiments

\begin{tabular}{|cccccc|}
\hline Series & $\begin{array}{c}\text { Size } \\
\mu \mathrm{m}\end{array}$ & $\begin{array}{c}\text { Laser Intensity } \\
\mathrm{W} / \mathrm{m}^{2}\end{array}$ & $\begin{array}{c}\text { Density } \\
\mathrm{kg} / \mathrm{m}^{3}\end{array}$ & $\begin{array}{c}\mathrm{A} \\
\mathrm{kg} / \mathrm{m}^{2} \mathrm{~s}(\mathrm{KPa})^{.5}\end{array}$ & $\begin{array}{c}\mathrm{P}_{\mathrm{O}_{2}} \\
\%\end{array}$ \\
\hline 1 & 100 & $3.13 \times 10^{6}$ & 110 & 3.6 & 50 \\
2 & 98 & $4.65 \times 10^{6}$ & 1200 & 4.2 & 13 \\
3 & 75 & $4.11 \times 10^{6}$ & 1000 & 6.1 & 25 \\
4 & 99 & $3.04 \times 10^{6}$ & 800 & 3.73 & 40 \\
5 & 99 & $3.45 \times 10^{6}$ & 1100 & 5.0 & 35 \\
6 & 105 & $3.46 \times 10^{6}$ & 1000 & 3.6 & 35 \\
7 & 82 & $4.54 \times 10^{6}$ & 1000 & 3.6 & 25 \\
8 & 79 & $3.35 \times 10^{6}$ & 1000 & 5.2 & 30 \\
9 & 95 & $3.54 \times 10^{6}$ & 1100 & 4.0 & 25 \\
\hline
\end{tabular}




\section{Figure Captions}

Figure 1. Rate of heat loss or gain for a $50 \mathrm{~m}$ diameter particle at $900 \mathrm{~K}$ (small-dashed lines), 1235K (solid lines) and 1400K (large-dashed lines). Physical parameters are from Field et al (1967). The lettered points are described in the text.

Figure 2. Curve showing ignition induction time for a $50 \mathrm{~m}$ particle (solid line). The curves and the lettered points correspond to the same conditions as in figure 1.

Figure 3. Schematic of the electrodynamic balance electrodes, heating system, and position monitoring system.

Figure 4. Schematic of the optical pyrometer

Figure 5. Calibration Curve for the optical pyrometer

Figure 6. Temperature trace for a $198 \mathrm{~m}$ diameter spherocarb particle. Experimental data are shown in open circles. a. Laser pulse in nitrogen gas. b. Laser pulse in $20 \%$ oxygen. c. Laser pulse in $40 \%$ oxygen.

Figure 7. Vertical position of the Spherocarb particle. a. Spherocarb pulsed in nitrogen. b. Spherocarb pulsed in 20\% oxygen. c. Spherocarb pulsed in $40 \%$ oxygen.

Figure 8. Rate of heat generation and heat loss for a $198 \mathrm{~m}$ diameter spherocarb particle. The solid line shows the heat gain in nitrogen. The dash-dotted line shows the heat gain in 20\% oxygen. The dashed line shows the heat gain in 40\% oxygen. The dash-dot-dot line shows the heat loss curve.

Figure 9. Temperature traces for a $300 \mathrm{~m}$ diameter char particle produced from PSOC 1451 bituminous coal. Experimental data are shown in open circles. a. Laser pulse in nitrogen gas. b. Laser pulse in 10\% oxygen. c. Laser Pulse in $15 \%$ oxygen.

Figure 10. Vertical position of the bituminous char particle. a. Char pulsed in nitrogen. b. Char pulsed in 10\% oxygen. c. Char pulsed in 15\% oxygen. 
Figure 1

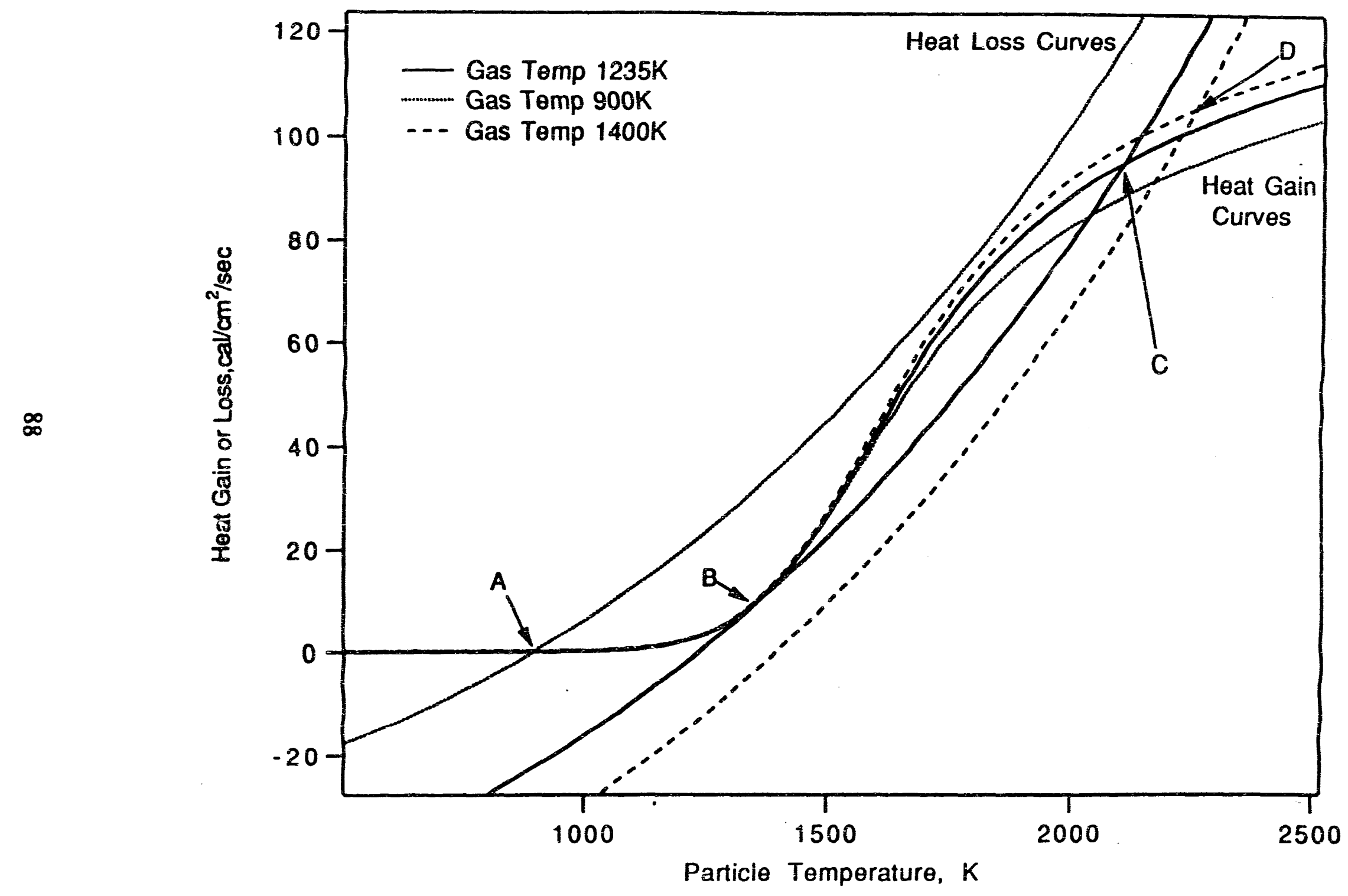




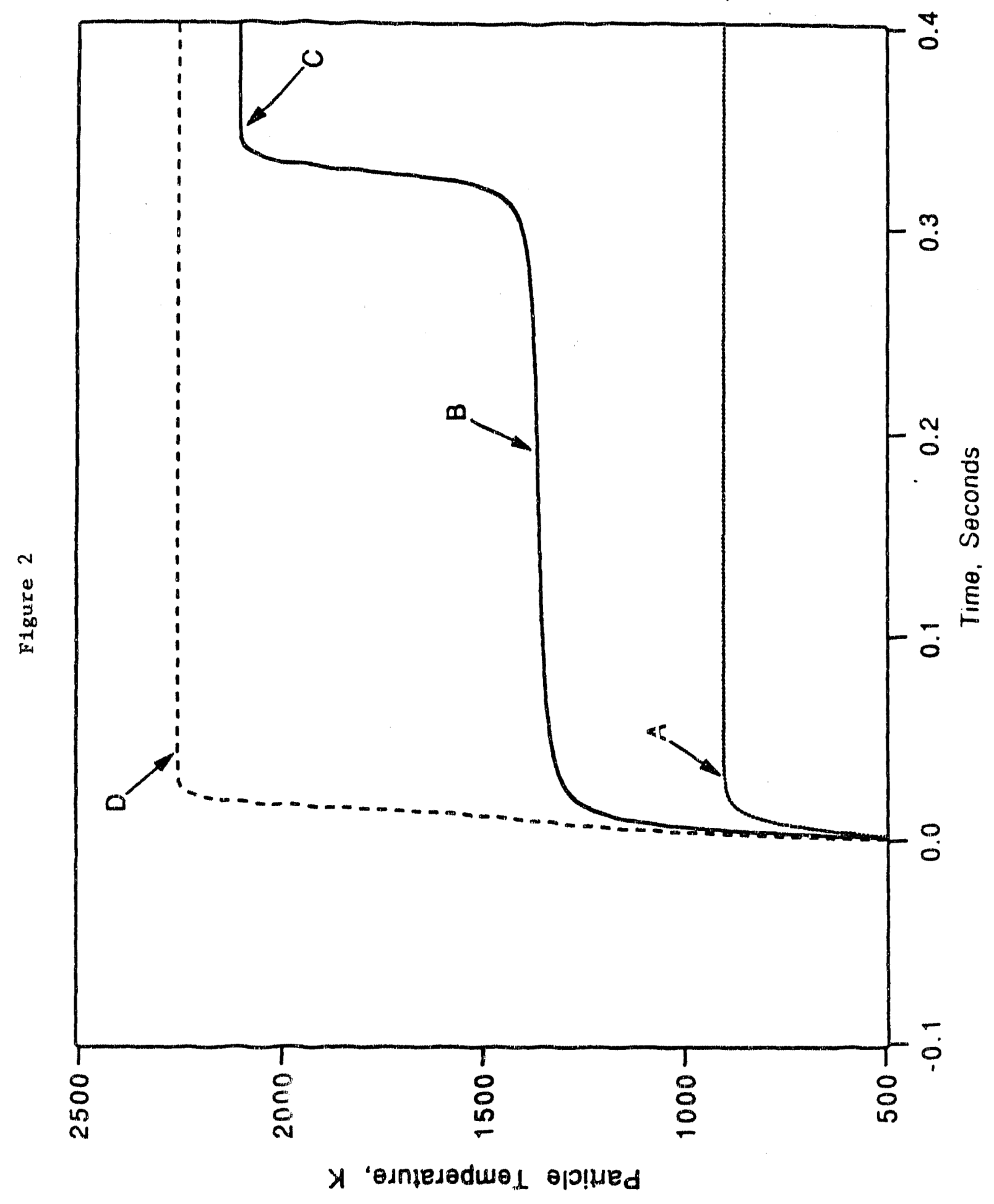




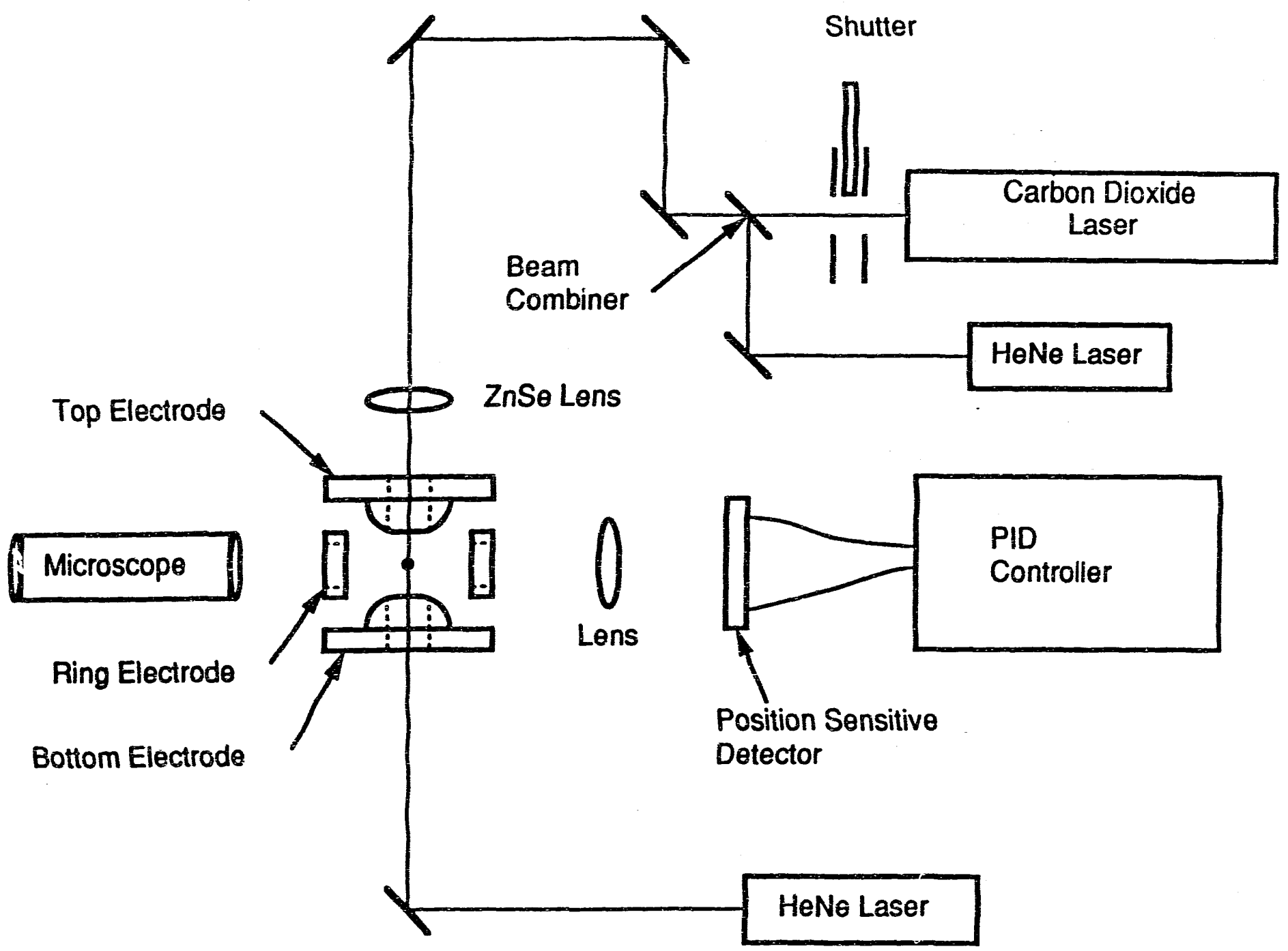

Figure 3. Schematic of the EDTGA 


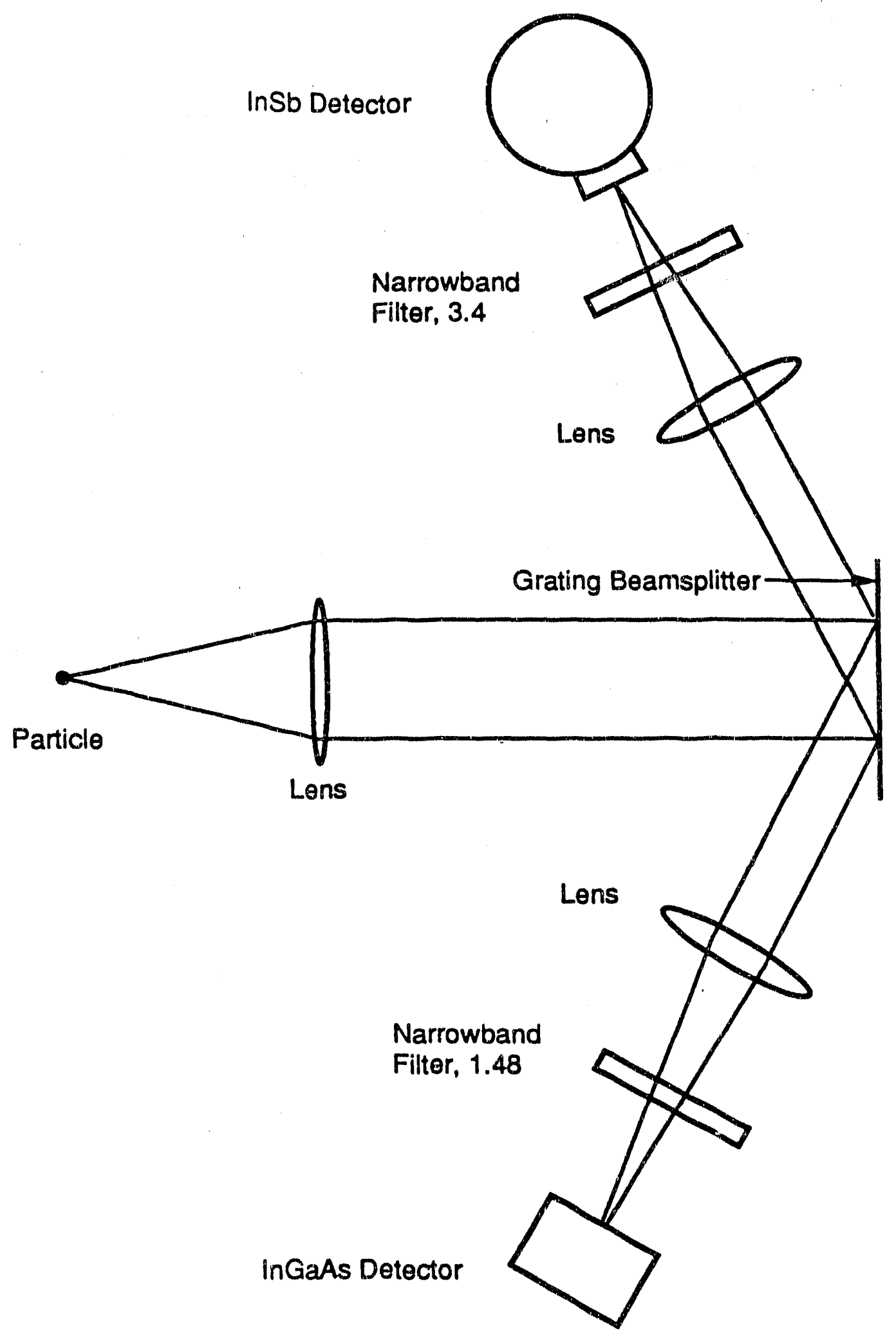

Figure 4. Pyrometer Schematic 
Figure 5

Pyrometer Calibration, Type R TC InSb offset $2.0 \mathrm{v}$
RPYRO19.CAL, $8-3-89$

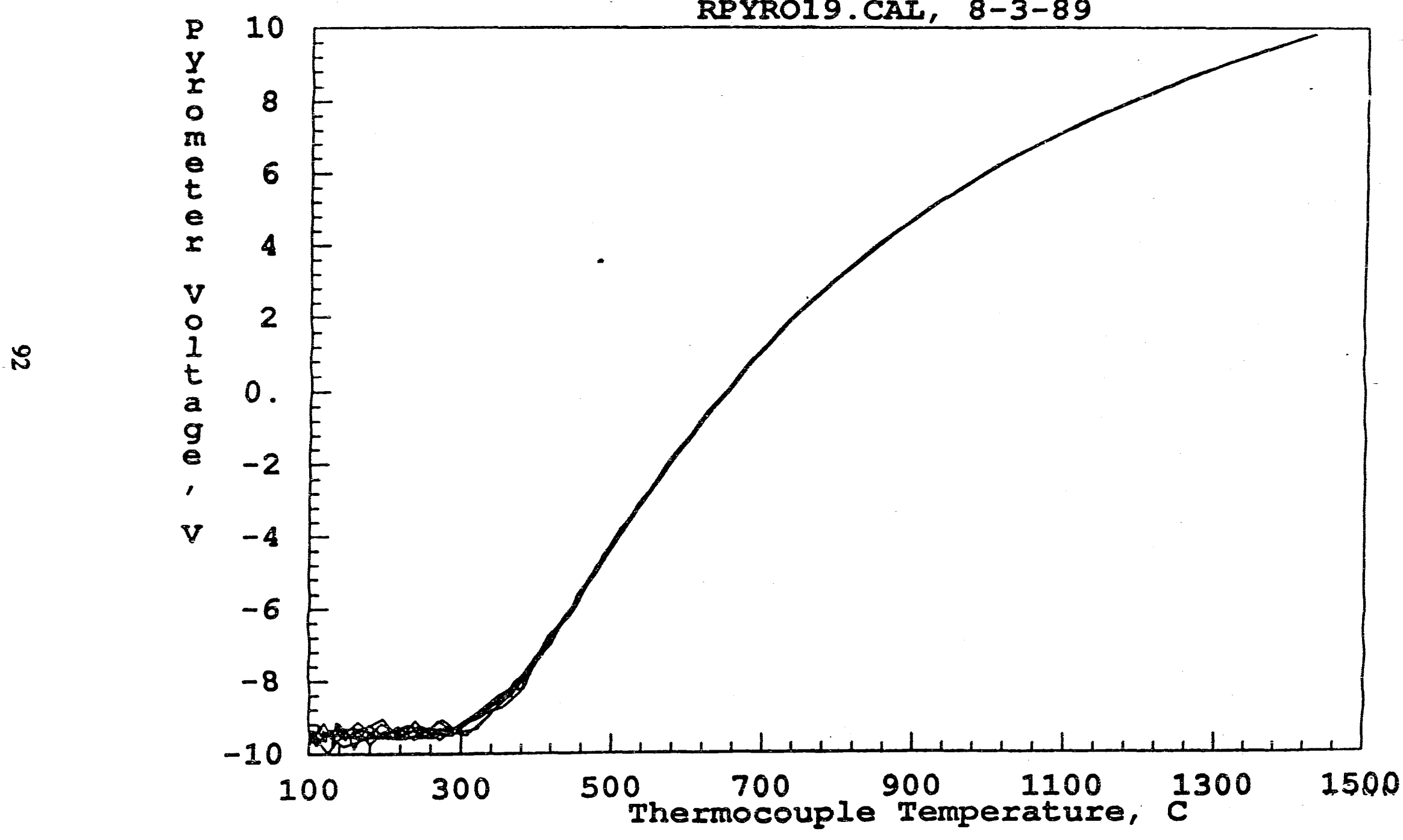




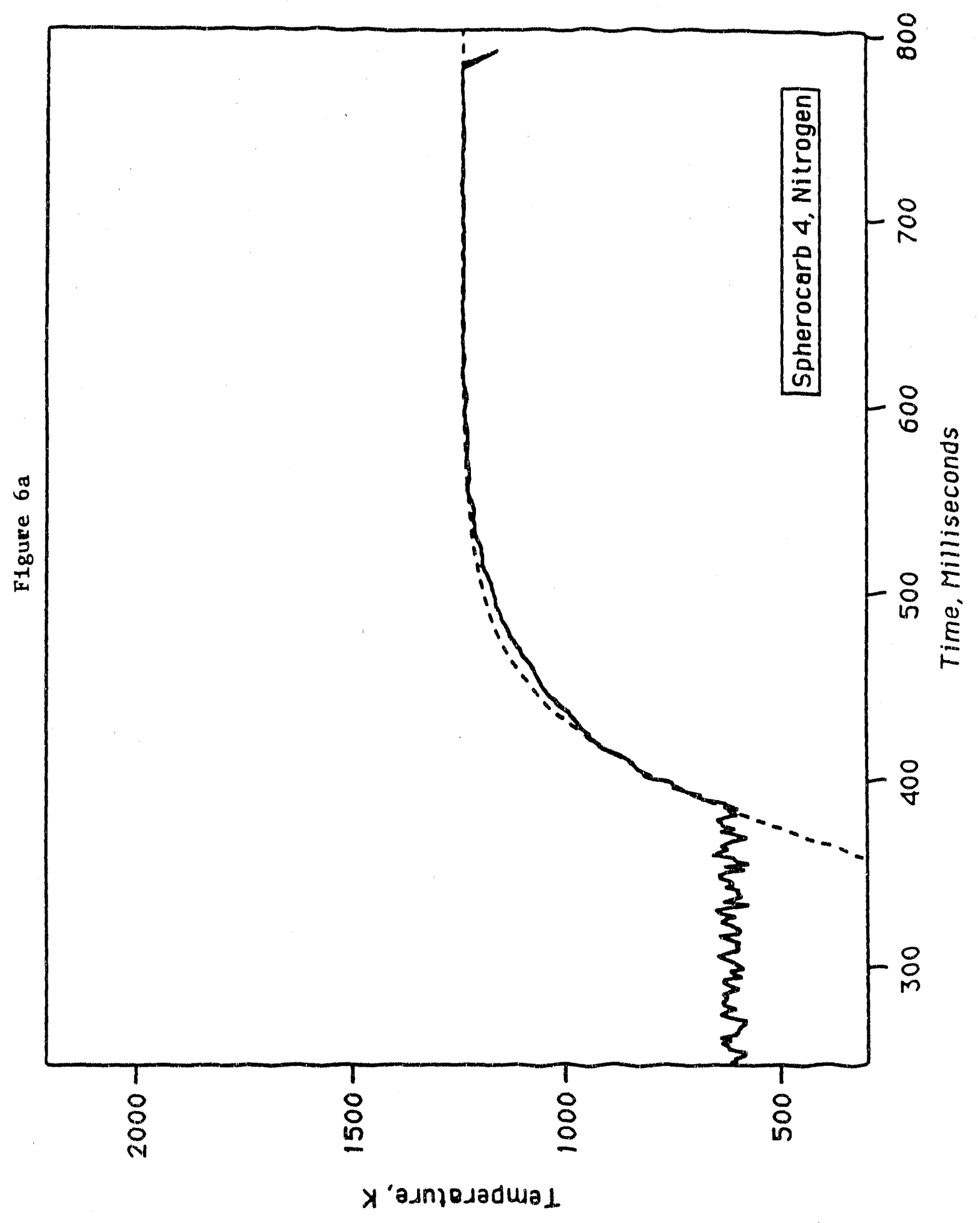


Figure 6b

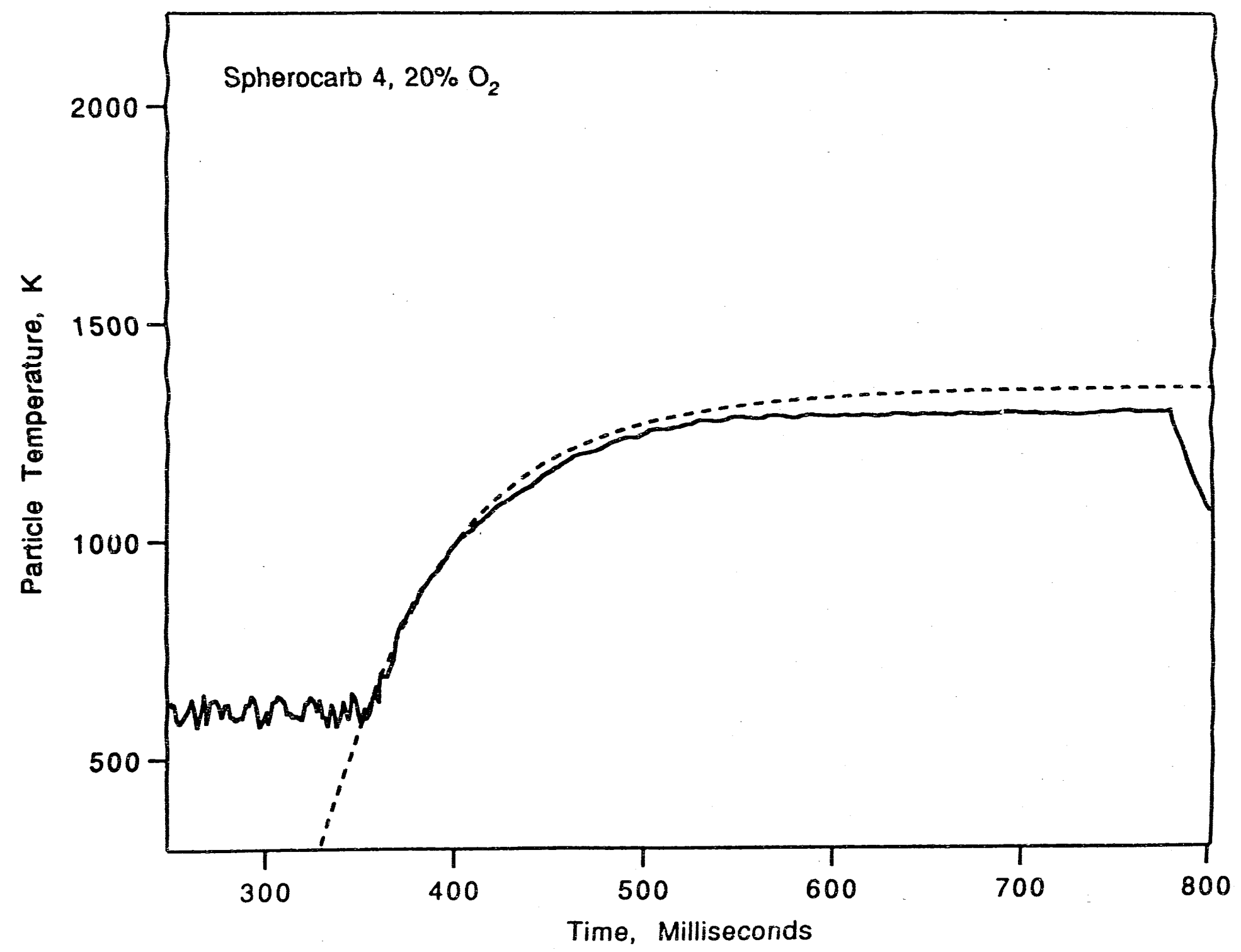




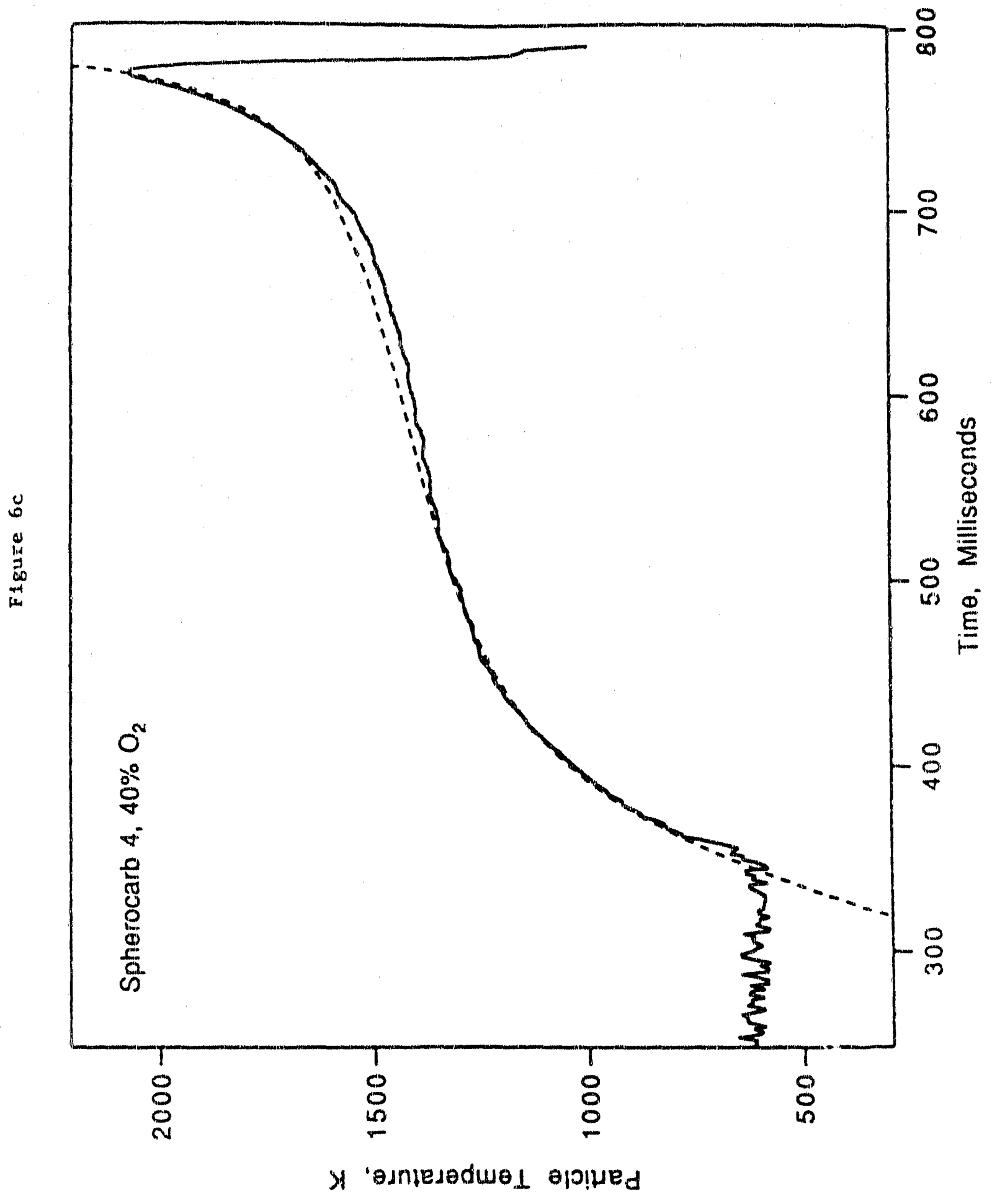


Figure $7 a$

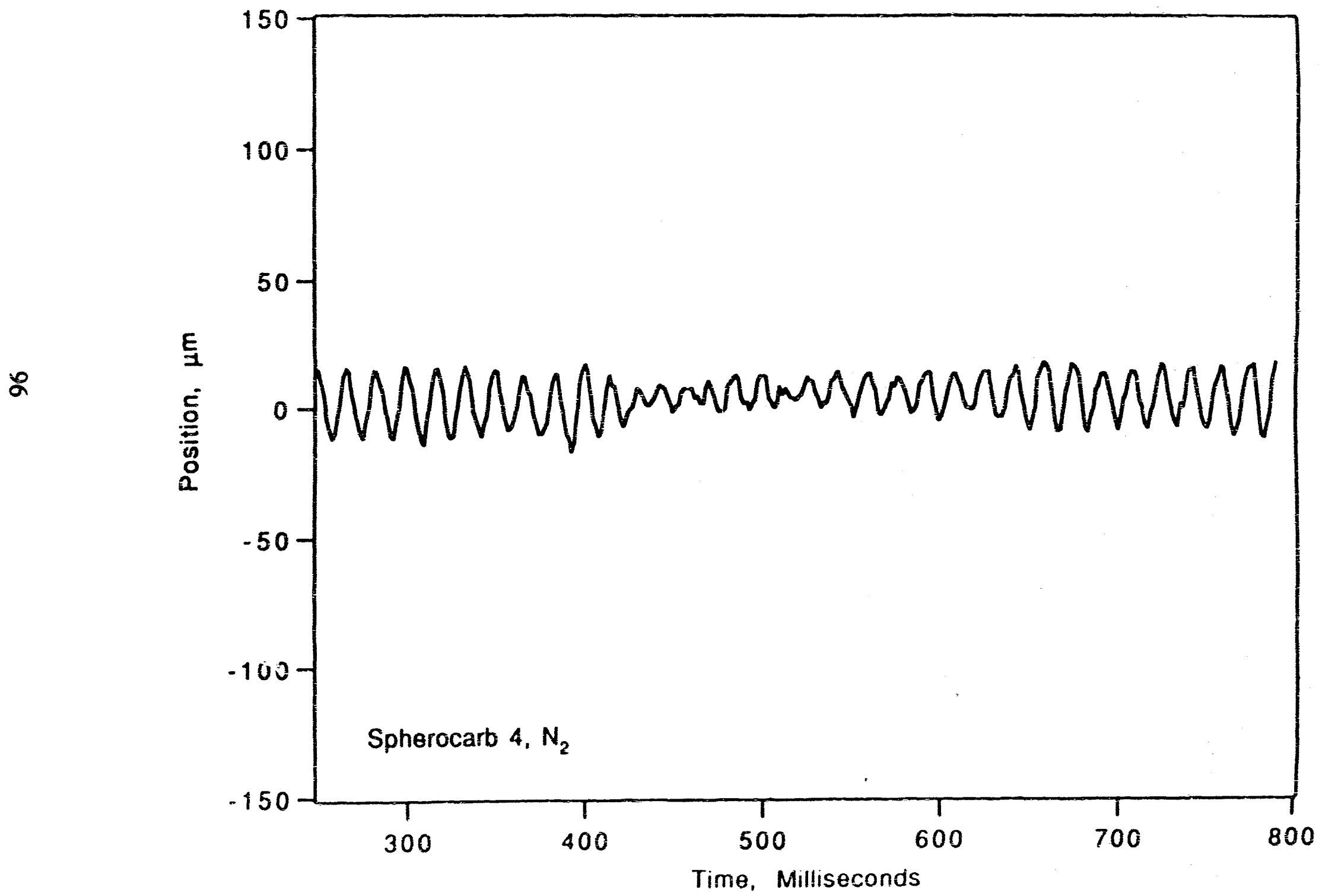


Figure Tb

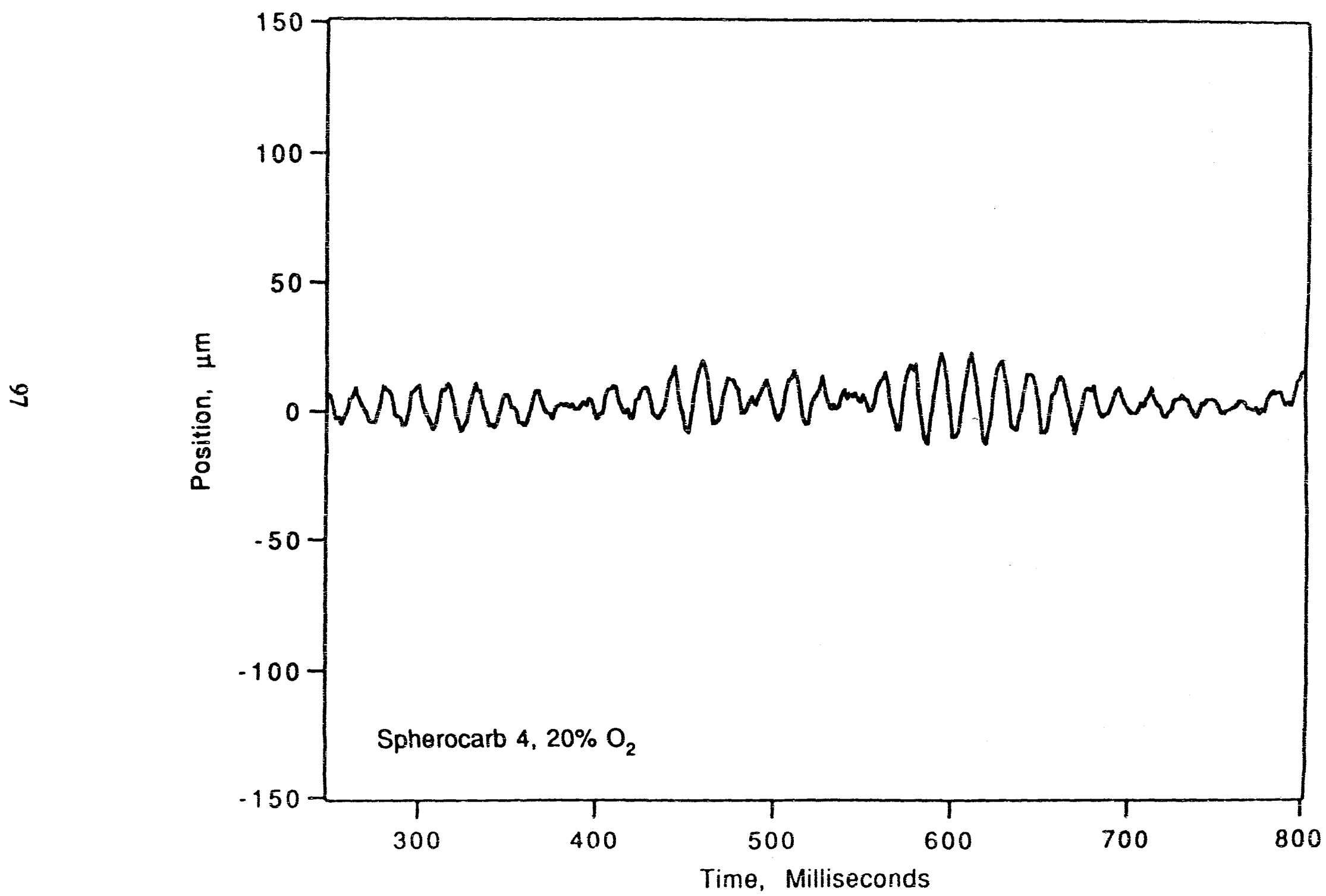


Figure $7 c$

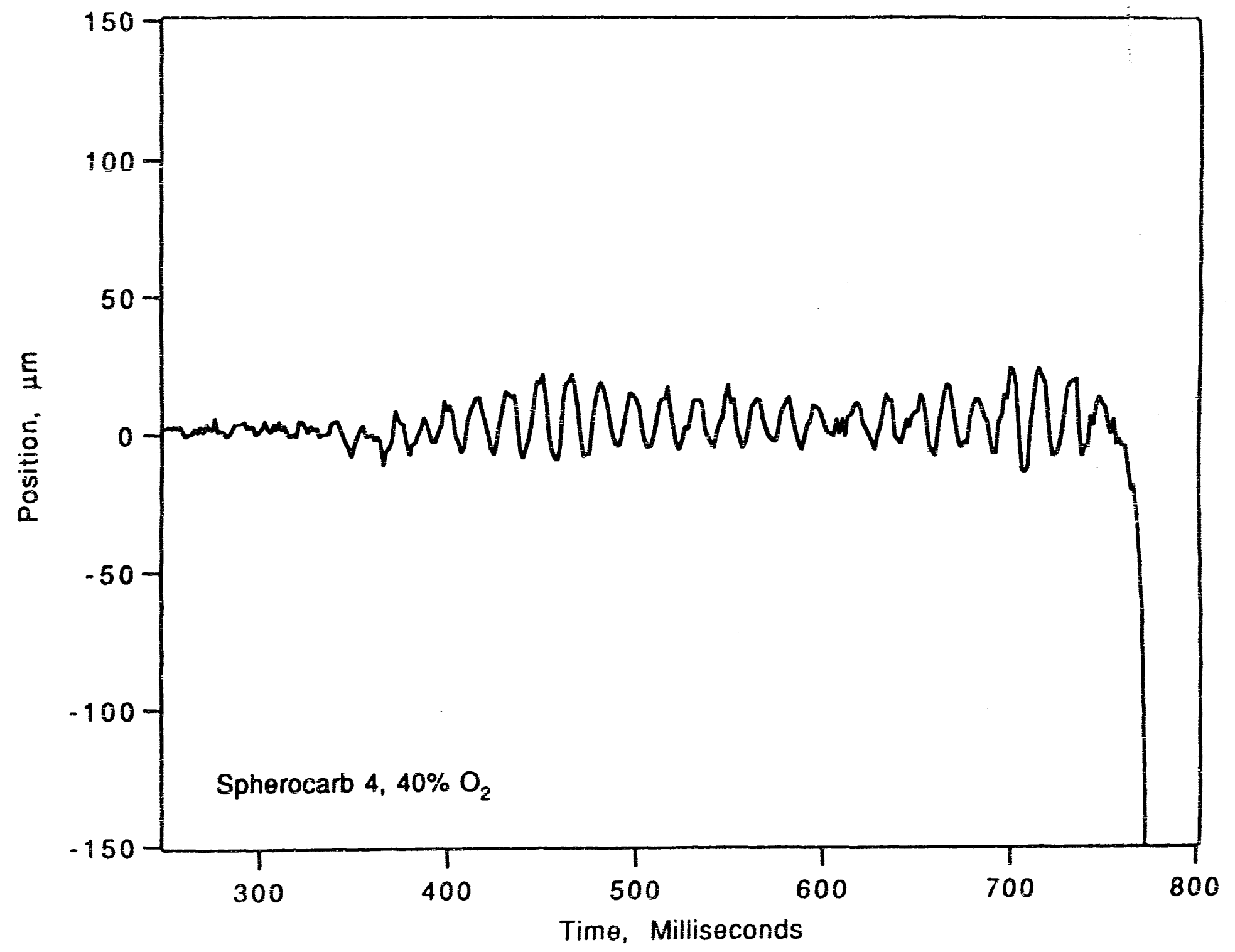


Figure 8

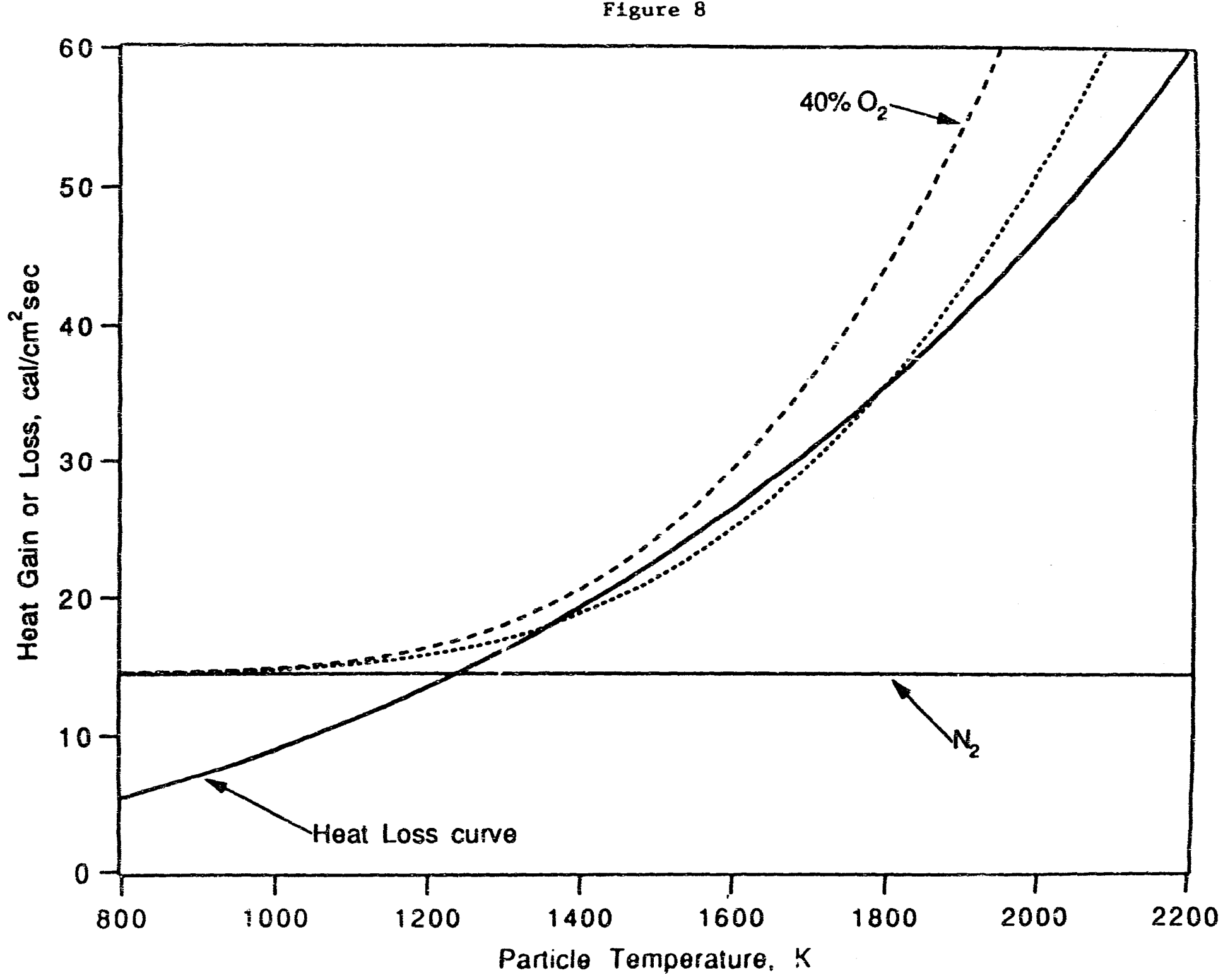




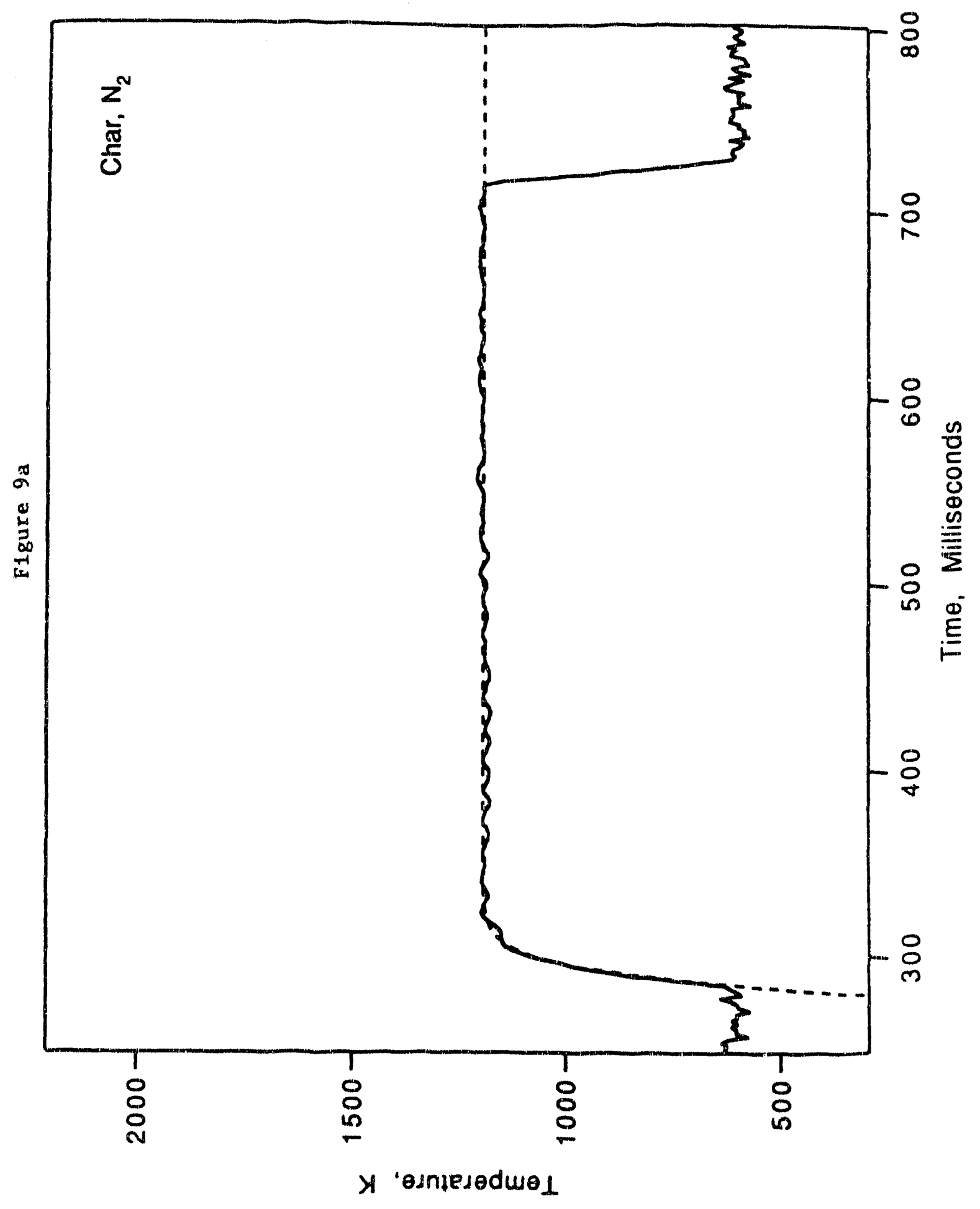




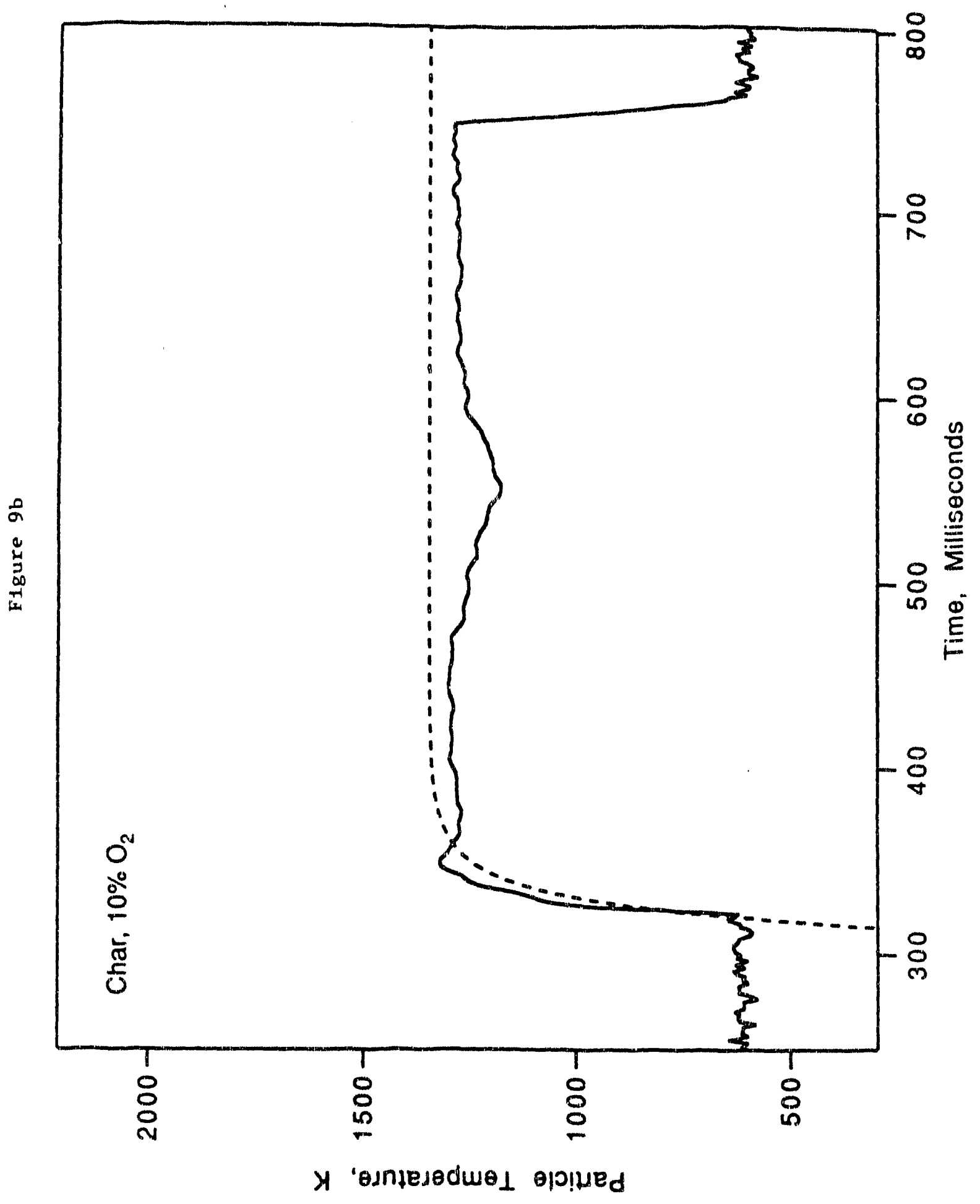




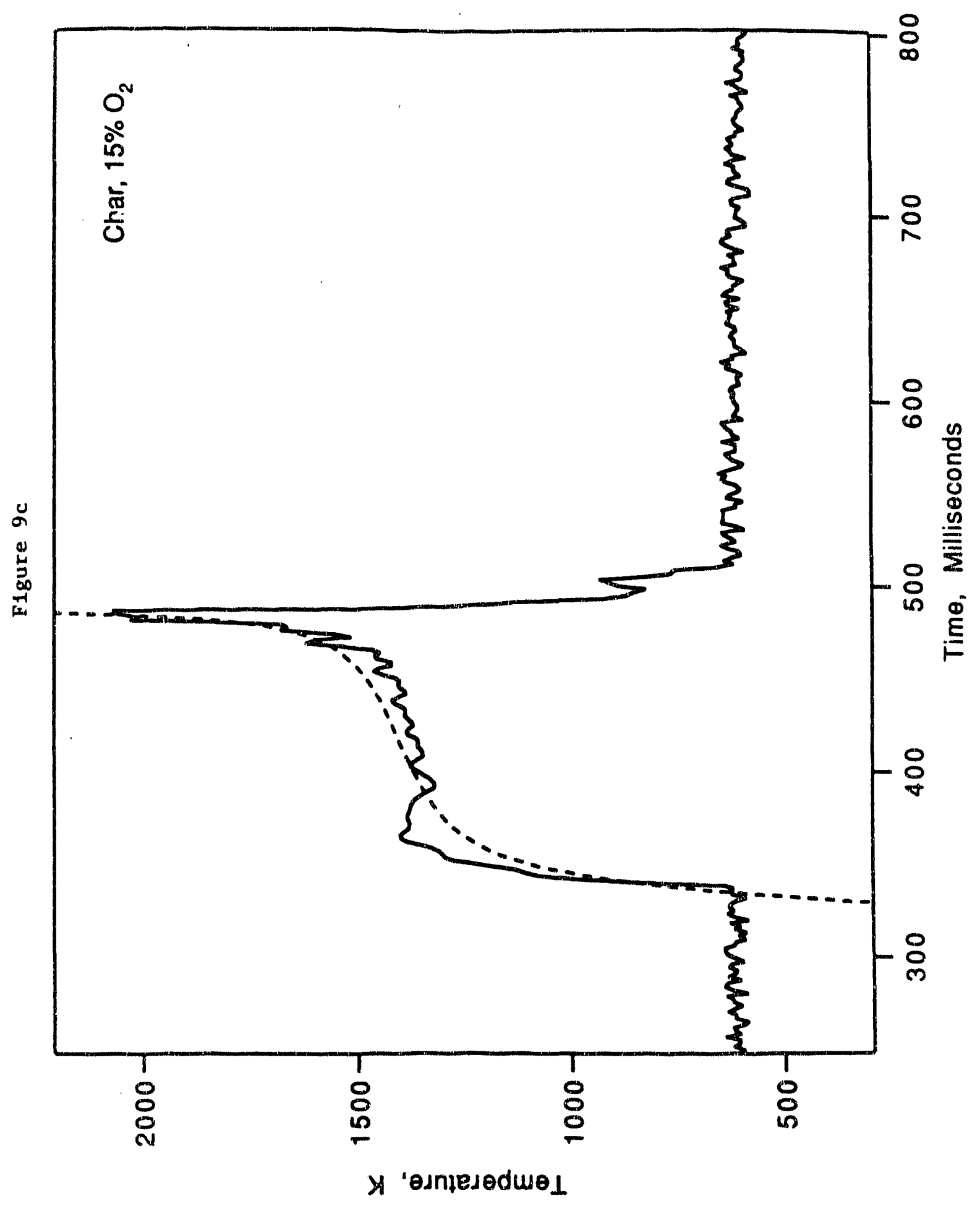


Figure 10a

ธ్

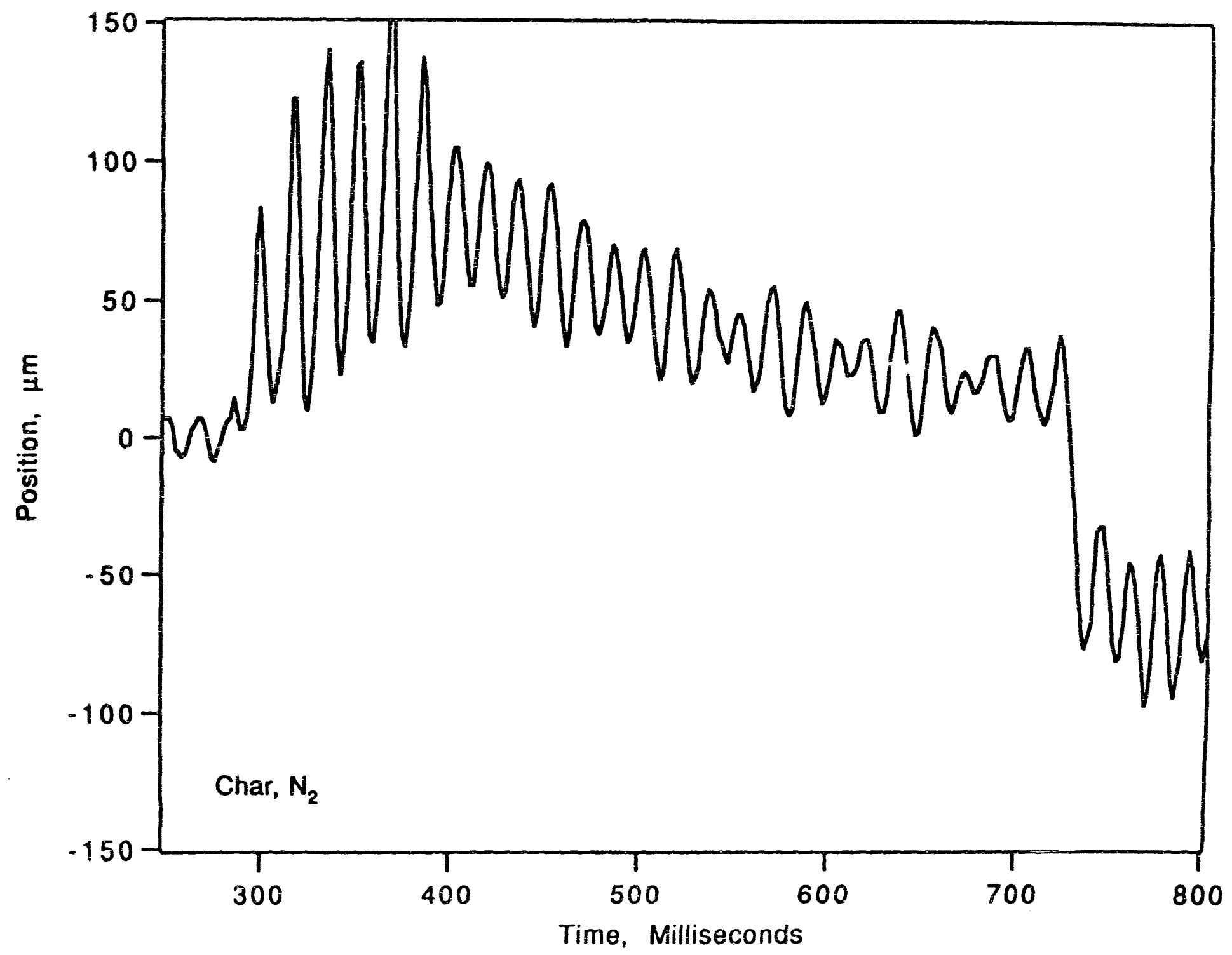


Figure $10 b$

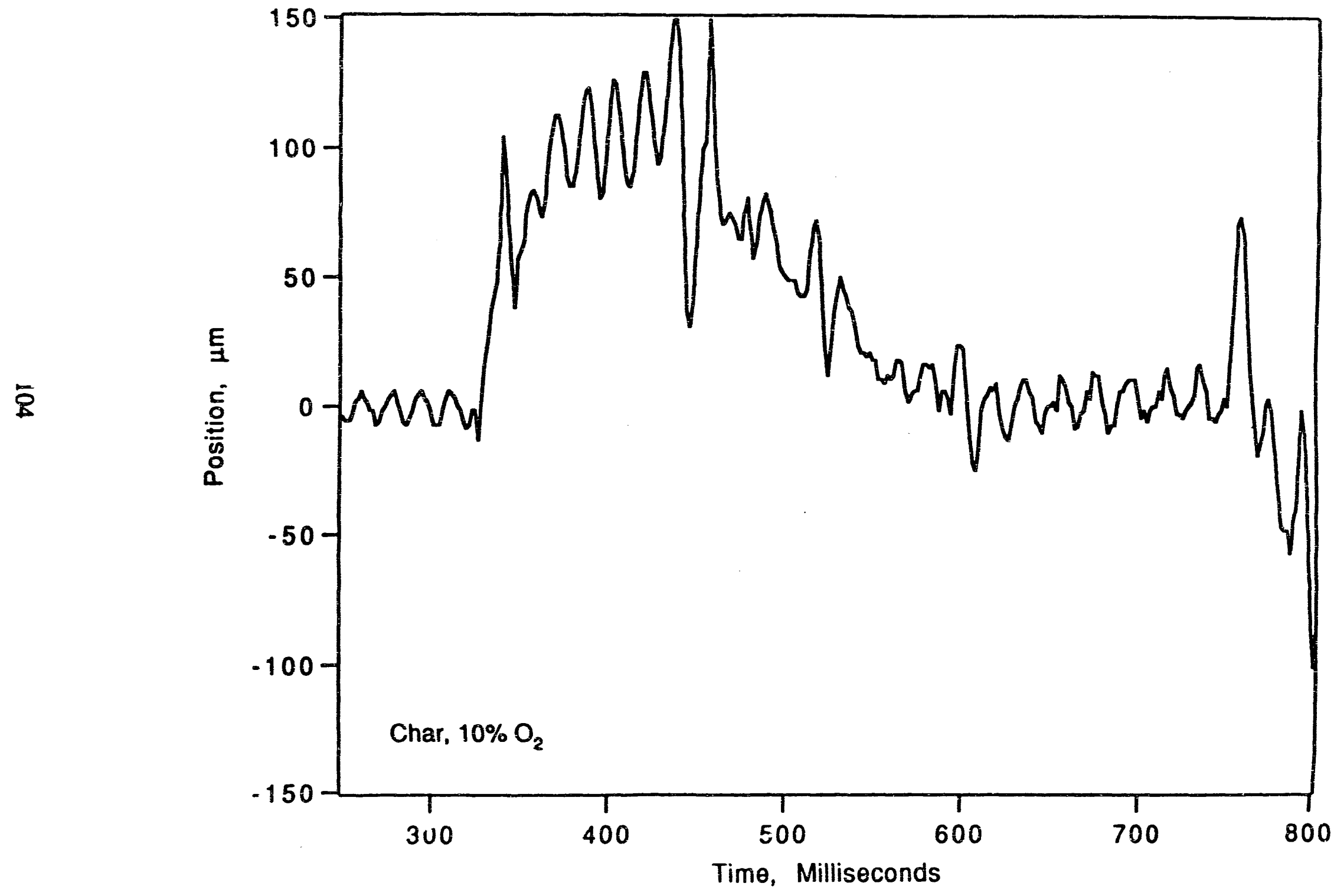


F1gure 10c

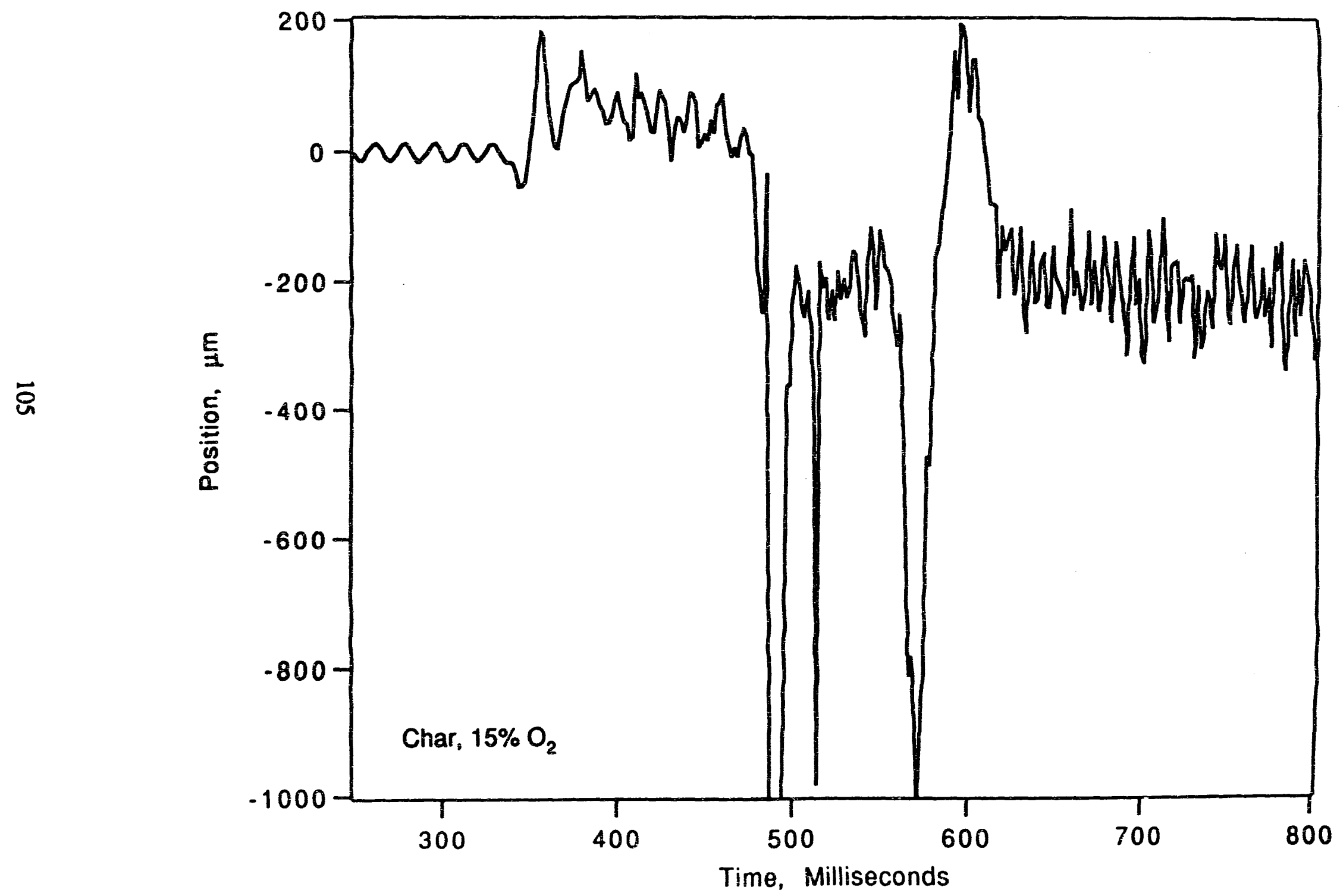




\section{CHAPTER 4}

\section{A THEORETICAL STUDY OF COMBUSTION OF NONSPHERICAL PARTICLES}

(Manuscript to be published in Combustion Science and Technology) 


\title{
A Theoretical Study of Combustion of Nonspherical Particles
}

\author{
Moon Kyu CHOI and George R. Gavalas \\ Chemical Engineering 210-41 \\ California Institute of Technology \\ Pasarena CA 91125
}

Submitted to $C u m b$. Sci. and Tech.

\begin{abstract}
A theoretical study is carried out of the combustion of nonspherical carbonaceous particles in the regime of shrinking core reaction. The first problem addressed is the calculation of the pseudosteady temperature and oxidation rate for a particle of given stape. This problem involves the solution of the external tiffurion and heat conduction equations with the reaction entering as a boundary condition over the particle aurface. Using the boundary integral metbod, the problem is reformulated as a system of two coupled integral equations which are solved numerically by suitable discretization. Tha complete transient problem addressing the evolution of particle shape and particle temperature during burnout, is sim. ilarly formulated by the boundary integral method and solved numerically. Over a broad range of parameters, the pseudosteady particle temperature and rate of oxidation are very nearly equal to those of spherical particles of equal volume and surface area respectively. The transient solutions obtained for parameters typical of pulverized combustion show that during burnout the particle becomes increasingly nonspherical. As expected, nonspherical particles buru faster than spherical particles of the same initial volume, but the difference in burnout times is less than $20 \%$ for initial aspect ratios between one and three.
\end{abstract}




\section{NOMENCLATURE}

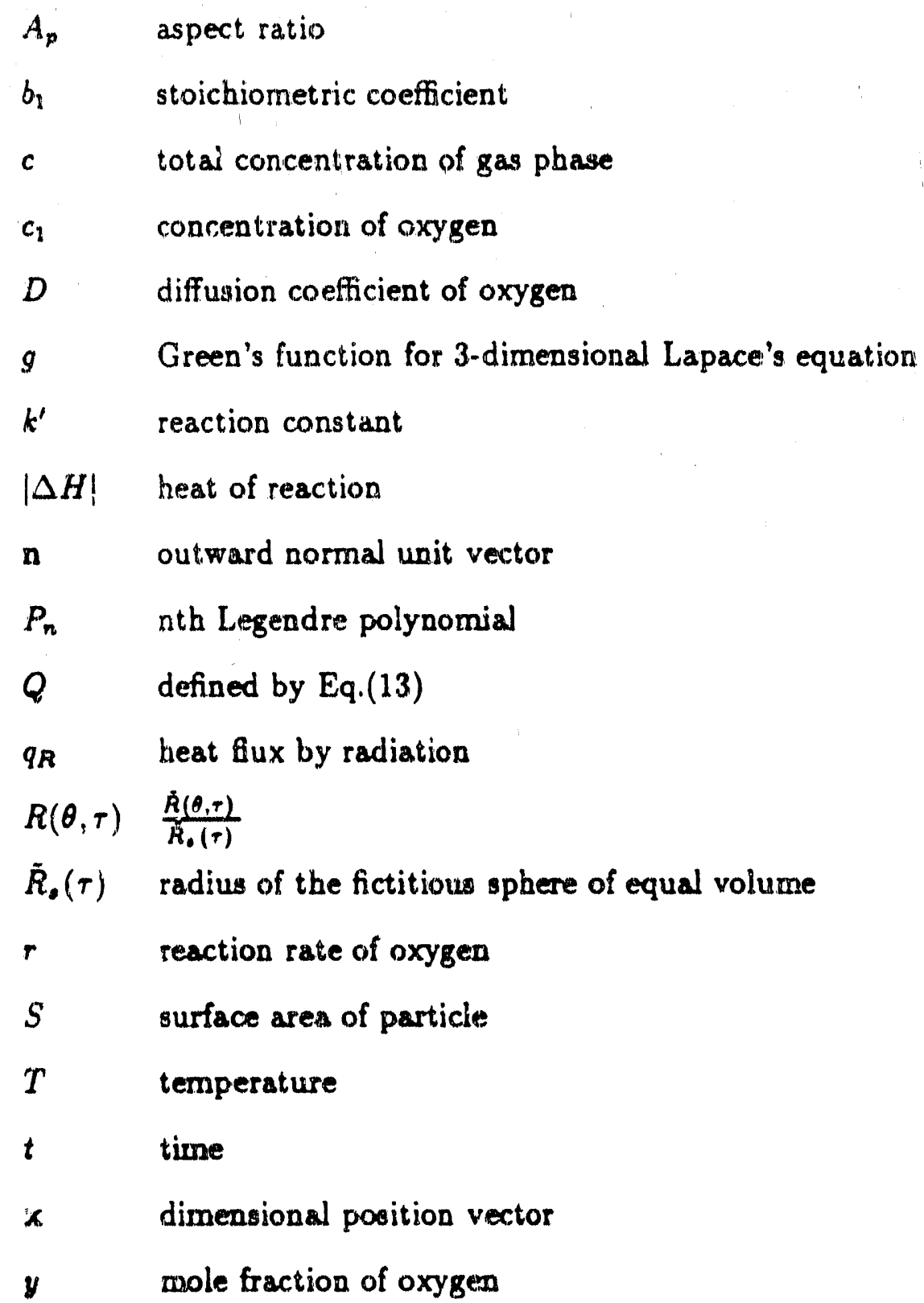

Greek letters 


$\begin{array}{ll}\beta_{n} & \text { coefficients used in expanding } R(\theta, \tau) \\ \epsilon & \text { emissivity of particle } \\ \lambda & \text { thermal conductivity of gas phase } \\ \rho & \text { radial variable } \\ \rho_{p} & \text { particle density } \\ \tau & \text { dimensionless time variable } \\ \Omega & \text { surface boundary of domain }\end{array}$

Subscripts
$\infty \quad$ quantity evaluated using the bulk temperature
$v \quad$ sphere of equal volume
$s \quad$ sphere of equal surface area

\section{INTRODUCTION}

The analysis of particle(coal char, coke, etc.) combustion has undergone significant refinement over the years. Early analyses exemplified by the reports of Field et al.(1967) and Field(1969) employed simple heat and mass transfer coefficients and assumed shrinking core reaction. The analysis was later extended to include a detailed account of external beat and mass transfer while retaining shrinking core oxidation(Ubhayakar,1976 ; Libby and Blake,1979 ; Annamalai and Durbetaki,1979). Further extensions invoked considerations of intraparticle diffusion, reaction and pore growth. A comprehensive review of work up to 1984 has been published by Sotirchos et al.(1984). Regardless of the treatment afforded to internal and external diffusion, all previous investigations treated the reacting particles as spherical thus 
avoiding the mathematical and computaitonal complications entailed by nonspherical geometry. In the present paper we explore the effect of nonspherical shape on the reaction rate, particle temperature and other combustion charateristics.

Grinding coal, coke, etc. produces particles of widely varying size and shape. Upon heating and devolatilization, bituminous coal particles tend to become smoother and more spherical, while particles of other coals retain their original shape. The nonuniformity of shape and size arising from grinding and devolitilization can cause a spread in the time for complete burnout, the maximum particle temperature, and the size distribution of flyash, all important properties for coal combustion practica. In this paper we explore the effect of the initial shape on the combustion history of a particle. We consider the instantaneous temperature and oxidation rate for a given particle shape, and the evolution of the particle shape as reaction progresses. We also examine the degree to which the combustion of nonspherical particles can be approximated by that of spherical particles of appropriate size.

As we relax the assumption of spherical shape we are forced to make orher simplifications or restrictions in order to contair the mathematical-computaional effort. The analysis is thus restricted to shrinking core combustion, spatially uniform transport coefficients and negligible Stefan flow. Furthermore, we only consider particle shapes which are rotationally symmetric and choose the initial shape to be a prolate or oblate spheroid. With these simplifications and restrictions the problem becomes one of external diffusion and heat conduction with the reaction entering as a boundary condition on the particle surface. We treat this problem numerically using the boundary integral method which converts the spatial differential equations to integral equations over the particle surface and thereby reduces the computational 
effort. Although not explicitly considered, the case of negligible pore diffusion resistance, such that the particle size and shape remain constant during burnout, is also subsumed in the analysis developed here.

\section{THE PSEUDOSTEADY PROBLEM}

In this section we formulate the pseudosteady problem, i.e., for a given particle shape and free stream conditions, calculate the particle temperature and the reaction rate. In a strict sense, these pseudosteady properties are not exactly realized, because the particle shape evolves with oxidation. However, except for a brief initial transient, the thermal inertia is negligible and the particle temperiture approaches and remains close to the pseudosteady temperature corresponding to the instantaneous particle shape. Having established that pseudosteady relation, in the next section we examine the evolution of particle shape due to the reaction.

Figure 1 shows a motationally symmetric particle with $O$ being the particle center aud $\mathrm{Oz}$ the axis of symmetry. Although not essential, we shall also assume that the particle has a plane of symmetry perpendicular to $O_{z}$. The particle surface $\Omega$ is then defined by some equation

$$
\rho=F(\theta, t), \quad 0<\theta<\pi
$$

where $\rho$ is the distance from the center $O$ and, because of the plane of symmetry, $F(x-\theta, t)=F(\theta, t)$.

Physical parameters such as the thermal conductivity and the diffusivity are functions of temperature with an approximate porer dependence (Hirschfelder et al., 1954),

$$
\lambda \propto T^{0.5}, \quad D \propto T^{1.5}
$$


Thus the tharmal conductivity $\lambda$ and the product $c D$ are represented as

$$
\lambda=\lambda_{\infty}\left(\frac{T}{T_{\infty}}\right)^{0.8}, c D=c_{\infty} D_{\infty}\left(\frac{T}{T_{\infty}}\right)^{0.5}
$$

with the subscript $\infty$ denoting free stream properties.

In a further approximation, the product $c D_{i j}$ of total concentration and any diffusion coefficient will be taken as spatially uniform, equal to its value at the particle surface $\Omega$. Moreover, the flux of oxygen will be described by the approximate expression $-D c \nabla y$, where $y$ is the oxygen mo: fraction and $D$ is the binary diffusion coefficient for the $\mathrm{O}_{2}-\mathrm{N}_{2}$ pair. This simple flux expression neglects the minor convective contribution due to the relative velocity between particle and free stream, the "Stefan flow" ierms induced by multicomponent diffusion, and the direct contributions of pressure and temperature gradients included in the Stefan-Maxwe:l equations.

The approximation of spatially uniform $c D$ was evaluated for a spherical particle where the exact and approximate problems could be solved in closed form(see Appendix). Even when surface and free stream temperatures differed by $640^{\circ} \mathrm{C}$, the error in the reaction rate was less than $8 \%$. The error committed by neglecting the Stefan flow depends mainly on the magnitude of the surface reaction rate. The analytical solution available for a spherical particle suggests that this error is less than $10 \%$ for the range of parameters used in the numerical calculations. In view of the modess magnitude of these errors we believe that the two approximations are reasonable for evaluating differences in the combustion rate, burnout time, etc.. between a spherical and a nonspherical particle.

With the above approximations, the oxygen mole fraction $y$ and the tempera. ture $T$ satisfy the equations

$$
\nabla^{2} y=0
$$




$$
\nabla \cdot(\lambda \nabla T)=0
$$

with boundary conditions at the free stream

$$
\rho \rightarrow \infty: y \rightarrow y_{\infty} ; T \rightarrow T_{\infty} .
$$

The boundary conditions on the particle surface will be based on two additional assumptions : uniform particle temperature and shrinking core reaction(high Thiele modulus). The relevance of the latter assumption depends on several factors among which particle temperature, particle size, and porous structure. A particle initially burning in the shrinking core mode(decreasing size, constant density) after a certain reduction in size will switch to a mode of decreasing size and density.

On the basis of the last two assumptions, the boundary condition for the oxygen mole fraction becomes

$$
\rho \in \Omega: c D \frac{\partial y}{\partial n}=r\left(p_{1}, T\right)
$$

where $p_{1}=y P$ is the partial pressure of oxygen on the surface. There are two boundary conditions for the temperature

$$
\rho \in \Omega: T=T,
$$

where $T$, is the unknown particle temperature, and

$$
\int_{\Omega}\left[\lambda \frac{\partial T}{\partial n}-q_{R}+r|\Delta H|\right] d S=0
$$

where $q_{R}$ is the net radiative flux, $r$ is the rate of oxygen consumption per unit external area of the particle. This latter condition is simply a thermal energy balance for the whole particle between heat generated by the reaction and heat lost 
by radiation and conduction. It must be noted that whereas $T_{0}$ is uniform over the surface, $p_{1}=y P$ and $\frac{\partial T}{\partial n}$ are variable. The radiative flux $q_{R}$ will be taken as

$$
q_{R}=\sigma \varepsilon\left(T_{s}^{4}-T_{\infty}^{4}\right)
$$

where the temperature of the surrounding surfaces is taken equal to that of the free stream, and a common emmisivity is used for all radiating surfaces.

For a spherical particle of radius $a$, Eqg. (2)-(7) can be reduced easily to the solution of two equations in the unknowns, $y_{n}, T_{n}$,

$$
\begin{gathered}
\frac{P D\left(T_{0}\right)}{R_{g} T_{s} a}\left(y_{\infty}-y_{0}\right)=r\left(P y_{\bullet}, T_{0}\right) \\
\frac{\lambda\left(T_{0}-T_{\infty}\right)}{a}+\sigma \epsilon\left(\dot{T}_{0}^{4}-T_{\infty}^{4}\right)=\left|\Delta H_{\bullet}\right| r\left(P y_{0}, T_{0}\right) .
\end{gathered}
$$

If the reaction is first order with Arrhenius temperature dependence,

$$
r=k^{\prime} p_{1}=A \exp \left(-E / R_{\imath} T_{\bullet}\right) P_{y_{\rho}},
$$

Eqs. (9) and (10) can be combined in a single equation for $T_{0}$ :

$$
\frac{\lambda\left(T_{0}-T_{\infty}\right)}{a}+\sigma \epsilon\left(T_{a}^{4}-T_{\infty}^{4}\right)=\left|\Delta H_{r}\right| \frac{A \exp \left(-E / R_{g} T_{s}\right) P y_{\infty}}{1+Q\left(T_{s}\right)}
$$

where

$$
Q\left(T_{a}\right)=\frac{k^{\prime}\left(T_{0}\right) R_{g} T_{b} a}{D\left(T_{0}\right)}=\frac{A R_{0} T_{0} a}{D\left(T_{0}\right)} \exp \left(-E / R_{0} T_{0}\right) .
$$

Equation (12) exhibits the well-known multiplicity and ignition phenomena.

\section{BOUNDARY INTEGRAL METHOD}

For nonspherical particles the problem defined by Eqs.(2)-(7) can be reformulated using single layer and double layer potentials(Stakgold,10־7) into two integral 
equations for the surface values of $y$ and $\frac{\partial T}{\partial n}$. Once the two integral equations are solved numerically, the particle temperature, the total reaction rate, and the values of $T$ and $y$ outside of the particle can be computed, if desired. This approach, which is krown as the "boundary integral method", involves a much smaller number of unknowns than the finite difference method and is, accordingly, much more computationally economical. The boundary integral method has been used extensively in low Reynolds number hydrodynamics.

The integral form of Eq.(2) with boundary conditions (4) and (5) can be derived by standard potential theory, using a double layer potential. For any $x_{s} \in \Omega$ we have

$$
y\left(\mathbf{x}_{\mathbf{8}}\right)=2 y_{\infty}-\frac{1}{2 \pi} \int_{\Omega}\left[-y(\xi) \frac{\partial g}{\partial n}+g \frac{r\left(P y(\xi), T_{0}\right)}{(c D)_{s}}\right] d S_{\xi}
$$

where $\frac{\partial}{\partial n}$ is the outward normal derivative and

$$
g=\frac{1}{\left|x_{1}-\xi\right|}
$$

For axially symmetric particles, integration over the azimuthal angle converts the double integral in Eq.(14) to a single integral over the angular variable $\theta$ :

$$
y\left(\mathbf{x}_{\bullet}\right)=2 y_{\infty}-\frac{1}{2 \pi} \int_{0}^{\pi}\left[-y\left(\theta^{\prime}\right) \frac{\partial G}{\partial n}+G \frac{r\left(P y\left(\theta^{\prime}\right), T_{0}\right)}{(c D) .}\right] v(\rho) \sin \theta^{\prime} d \theta^{\prime}
$$

where

$$
\rho=F(\theta, t)
$$

and

$$
\begin{gathered}
v(\rho)=\rho^{2}\left[1+\frac{1}{\rho^{2}}\left(\frac{d F}{d \rho}\right)^{2}\right]^{1 / 2} \\
G=\int_{0}^{2 \pi} g d \phi
\end{gathered}
$$




$$
\frac{\partial G}{\partial n}=\int_{0}^{2 \pi} \frac{\partial g}{\partial n} d \phi
$$

Equation (16) is an integral equation in the unknown function $y(\theta)$, with $T$, appearing as an unknown parameter to be determined in conjunction with the energy equation.

An integral equation equivalent to (3), (4) and (6) can be derived using a single layer potential after introducing a new variable defined by

$$
\psi=\frac{\left(T / T_{\infty}\right)^{1+\alpha}-1}{\left(T_{s} / T_{\infty}\right)^{1+\alpha}-1}
$$

It is

$$
-\int_{\Omega} g \frac{\partial \psi}{\partial n} d S_{\xi}=4 \pi
$$

Integration over the azimuthal angle now yields

$$
-\int_{0}^{\pi} G \frac{\partial \psi}{\partial n} v(\rho) \sin \theta^{\prime} d \theta^{\prime}=4 \pi
$$

This is an integral equation in the unknown function $\frac{\partial \psi}{\partial n}(\theta)$ with the unknown $T$, appearing as a parameter. For any given $T_{0}$, Eq.(16) can be solved for $y(\theta)$, and Eq. (21) for $\frac{\partial \psi}{\partial n}(\theta)$, or $\frac{\partial T}{\partial n}(\theta)$. The unknown $T_{0}$ can then be determined from Eq. $(7)$.

\section{THE TRANSIENT PROBLEM}

The transient problem is a conceptually simple extension of the pseudo-steady problem. It is still assumed that the oxygen mole fraction $y$ and temperature $T$ satisfy the pseudosteady equations (2) and (3) and boundary conditions (4)(6). However, boundary condition (7) does not apply any more since the particle temperature is variable; it is replaced by

$$
\rho_{p} C_{p} V_{p} \frac{d T_{p}}{d t}=\int_{\Omega}\left[\lambda \frac{\partial T}{\partial n}-q_{R}+r|\Delta H|\right] d S
$$


where $\rho_{p}, C_{p}$ and $V_{p}$ are the density, specific heat, and volume of the particle. An auditional equation is needed governing the changing particle shape on account of carbon consumption. This is

$$
\begin{gathered}
\frac{\partial F(\theta, t)}{\partial t}=-\frac{b_{1}}{\rho_{\mathbf{p}}} r\left(p_{1}, T_{\mathrm{o}}\right) \sigma(\theta, t) \\
t=0 ; F=F_{0}(\theta)
\end{gathered}
$$

where the shape function $F$ was introduced by Eq.(1). $F_{0}$ is the initial value of $F$, $b_{1}$ is the stoichiometric coefficient between grams of carbon and moles of oxygen $\left(b_{1}=24\right.$ if $\mathrm{CO}$ is the only product), $\rho_{p}$ is the particle density and $r$ is the reaction rate in moles of oxygen per unit surface area per unit time. The factor $\sigma(\theta, t)$ converts a displacement of the surface perpendicular to itself due to the reaction to a displacement along OP (see Figure 1). One can easily derive

$$
\sigma(\theta, t)=\left[1+\left(\frac{1}{F} \frac{\partial F}{\partial \theta}\right)^{2}\right]^{1 / 3}
$$

As before, Eqs.(2)-(6) are equivalent to the two integral equations (16) and (21), therefore the transient problem is governed by Eqs. (16), (22) supplemented by $(23)-(25)$.

\section{NUMERICAL RESULTS FOR THE PSEUDO-STEADY PROBLEM}

As a preliminary to the solution of Eqs. (16) and (22) it is necessary to evaluate the functions $G$ and $\frac{\partial G}{\partial n}$ defined as integrals of the Green's function $g$ and its normal derivative $\frac{\partial g}{\partial n}$ (Eqs. (18),(19)). Carrying out these integrations yields $G$ and $\frac{\partial G}{\partial n}$ in terms of three complete elliptic integrals which were evaluated by the approximating polynomials given in Abramowitz and Stegun(1972). Next, equations (16) and (22) 
were discretized using the values of the unknowns $y$, and $\frac{\partial \psi}{\partial n}$ at $2 N+1$ discrete points over $0<\theta<\pi$ and evaluating the integrals by an 8 -point Gaussian quadrature. By this discretization, Eq.(22) was converted to a system of $2 \mathrm{~N}+1$ linear equations for the values of $\frac{\partial \psi}{\partial n}$ at the discrete points in $0<\theta<\pi$. This linear system was decoupled from the rest of the equations and had to be solved only once.

The other integral equation, Eq.(16), was discretized into a system of $2 \mathrm{~N}+1$ nonlinear equations(or linear equations for a first order reaction) in the $2 \mathrm{~N}+1$ unknown values of $y$. This system contained the unknown surface temperature $T$, as a parameter and was solved in conjunction with Eq.(7) by successive substitutions. To this end, Eq.(7) was rewritten as

$$
\int\left(q_{R}-\lambda \frac{\partial T}{\partial n}\right) d S=\int r|\Delta H| d S
$$

But on the surface

$$
r=c D \frac{\partial y}{\partial n}=c_{\infty} D_{\infty}\left(\frac{T_{a}}{T_{\infty}}\right)^{1.3} \frac{\partial y}{\partial n}
$$

so that

$$
\left(\frac{T_{0}}{T_{\infty}}\right)^{1.5}=\frac{\int\left(q_{R}-\lambda \frac{\partial T}{\partial n}\right) d S}{c_{\infty} D_{\infty} \int \frac{\partial_{y}}{\partial n}|\Delta H| d S}
$$

Starting from an initial guess of $T_{0}$, Eq.(16) was solved for $\frac{\partial y}{\partial n}$ and Eq.(22) gave $\frac{\partial T}{\partial n}$. The values of $\frac{\partial y}{\partial n}$ and $\frac{\partial T}{\partial n}$ were introduced into the right side of Eq.(27) to yield an improved value for $T_{0}$, and the procedure was repeated until successive values of $T_{s}$ differed by less than one degree. Convergence took 5 to 10 iterations depending on the shape of the particle.

Table I gives the values used in the calculations. With the exception of the oxygen concentration in the free stream, these values were taken from a paper by Sahu et al.(1988). These authers had estimated the oxidation rate for shrinking 
core combustion of a bituminous coal char as

$$
R_{a}=107.1 \exp (-17,000 / R T) \mathrm{gcm}^{-2} \mathrm{~s}^{-1} \mathrm{~atm}^{-1}
$$

which yields the value of $k_{\infty}^{\prime}$ listed in Table 1 .

Numerical results for the pseudosteady problem are presented in Figures 2-4. Figure 2 shows the particle temperature vs. $Q_{\infty}$. At each value of $Q_{\infty}$, various prolate and oblate spheroids of equal volume but different aspect ratios are considered. The temperature varies significantly with $Q_{\infty}$ but is insensitive to the shape, with the curves for both prolate and oblate spheroids of different aspect ratios essentially coinciding. This insensitivity on particle shape seems to be due to the approximate cancellation of two opposite effects. Increasing the aspect ratio decreases the local mass transfer coefficient on the particle surface, thereby decreasing the heat release. The same increase of the aspect ratio decreases the local heat transfer coefficient as well, thereby decreasing the heat loss. The sensitivity of the particle temperature to the particle shape may be higher in other operating regions, e.g., at higher gas temperatures or oxygen contents where :-effect of radiative heat transfer would be more pronounced. It should be further noted that for the set of parameters used here(Table I), all particle temperatures shown in Figure 2 correspond to the upper(ignited) branch of the usual ignition diagram.

Figure 2 also shows the normalized reaction rate vs. $Q_{\infty}$ for particles of different shapes. For any given particle shape, the normalized rate initially decreases with increasing $Q_{\infty}$, then levels off and remains constant as $Q_{\infty}$ increases beyond 1 . At low values of $Q_{\infty}$ the normalized rate is equal to the ratio of the surface area of the particle to that of a sphere of equal volume. As $Q_{\infty}$ increases, the rate ratio falls below the surface area ratio, and eventually reaches a limiting value as the reaction 
becomes mass transfer limited. For fixed $Q_{\infty}$, the rate ratio increases significantly with the aspect ratio, with the oblate spheroids yielding higher reaction rates than the corresponding prolate spheroids. For aspect ratios between 1 and 3.2 the rate for the prolate and oblate spheroids was no more than $20 \%$ and $28 \%$ higher than that of a sphere of equal volume.

Figure 3 shows the surface area normalized with respect to that of a sphere of equal volume as a function of aspect ratio for prolate and oblate spheroids. Oblate spheroids have a somewhat higher surface area than prolate spheroids of the same aspect ratio. At the highest aspect ratio of 3.2 used in most calculations the prolate and oblate spheroids have surface area 20 and $29 \%$ higher than a sphere of the same volume. Figure 4 shows the total rate normalized by the total rate of a sphere of equal surface area vs. $A_{p}$ for different values of $Q_{\infty}$. For the whole range of $Q_{\infty}$ and $A_{p}$ examined, the rate is within $3 \%$ of the rate of a sphere of equal surface area. From the standpoint of the instantaneous total reaction rate, therefore, a nonspherical particle can be closely represented by a spherical particle of equal surface area. The curves for a few of the prolate spheroids show oscillatory behavior, which seems to be due to numerical errors, but in these curves the normalized total rate is very close to unity.

\section{NUMERICAL RESULTS FOR THE TRANSIENT PROBLEM}

The transient problem consists of Eqs. (23) and (24) with the respective initial conditions. Eq.(24) was written at $M$ discrete points of $\theta, \theta_{1}=0, \cdots, \theta_{M}=\pi / 2$ which were more densely distributed at the points of higher curvature, i.e., near $\theta=0$ for prolate spheroids. $M$ was chosen in the range 25 - 50. Each evaluation of the right side of these equations required solving the pseudosteady equations (16), 
(22) for $y$ and $\frac{\partial \psi}{\partial n}$ (giving $\frac{\partial T}{\partial n}$ ). Equations (23) and (24) become increasingly stiffer with decreasing Damköhler number $Q_{\infty}$ because small $Q_{\infty}$ implies rapid change of shape in terms of the dimensionless time, $\uparrow$ defined by

$$
\tau=\frac{b_{1}\left(k_{\infty}^{\prime}\right)^{2} y_{\infty}}{\rho_{\infty} c_{\infty} D_{\infty}}
$$

In view of the lack of explicit expressions for the right sides of the differential equations, we could not conveniently use a stiff equation solver. Instead we used the explicit fourth order Runge-Kutta method with step size control, decreasing the step size as integration progressed to compensate for the gradually increasing aspect ratio. In the calculations reported below, the time increment $\Delta r$ varied from 0.1 to 0.01 .

Figure 5 shows the fractional conversion vs. dimensionless time for particles of the same initial volume but different initial aspect ratios. The conversion curves for different aspect ratios are quite close to each other. For example, the dimensionless time to 0.95 conversion changes from 3.1 for $A_{p}(0)=1$ to 2.7 for $A_{p}(0)=3.2$. Figure 6 shows the aspect ratio as a function of dimensionless time for particles of different initial aspect ratios. The aspect ratio increases with time for all particles and this increase accelerates with increasing $A_{p}$. Thus, a particle with initially nearly spherical shape will change little during burnout(curve for $A_{p}(0)=1.667$ ) while a particle with initial $A_{p}(0)=3.2$ will become much more elongated $\left(A_{p} \simeq 4.3\right)$ when the dimensionless time reaches 2.5 , i.e., at 0.95 conversion. Figure $i$ shows the evolution of particle temperature during burnout. The temperature transients of particles of different initial aspect ratios, but equal volume, nearly coincide. Although not portrayed in Figure 7, the calculations also show that for any given initial particle shape, the transient temperature rapidly approaches and remains 
close to the pseudosteady temperature corresponding to the instantaneous particle volume.

\section{CONCLUSIONS}

An analysis of nonspherical particle combustion was carried out using the boundary integral method. For particles of equal volume, the pseudosteady temperature is nearly independent of shape, but the combustion rate increases with increasing aspect ratio. The local combustion rate varies moderately over the particle surface increasing with the distance from the particle center. The total combustion rate depends on the particle surface area alone, i.e., particles of equal surface area but different volumes and shapes have the same rate. This dependence on the surface area is less than linear, becoming linear only in the limit of low Damköhler numbers.

The effect of initial particle shape on the burnout transient was explored for a set of parameters typical of a bituminous coal char burning in the shrinking core regime. The calculations show the particle shape to become increasingly nonspherical with the progress of combustion and this change to be more pronounced for particles with larger initial aspect ratios. For particles of equal initial volume, the burnout time decreases slightly with the initial aspect ratio. For example a particle of initial aspect ratio 3.2 require $12 \%$ less time to reach $80 \%$ burnout compared to a spherical particle of the same initial volume.

\section{APPENDIX}

The purpose of this appendix is to estimate the error made by treating the quantity $c D$ as temperature independent in the derivation of Eq.(2) from the equa- 
tion

$$
\nabla \cdot(c D \nabla y)=0
$$

This evaluation is carried out by comparing the approximate solution with the exact solution for a spherical barticle. In the case of a spherical particle, Eq.(3) can be easily integrated to obtain

$$
\frac{T}{T_{\infty}}=\left[1+\frac{\left(T / T_{\infty}\right)_{s}^{1.5}-1}{\rho / a}\right]^{\frac{1}{15}} .
$$

Equations $(A 1),(4),(5)$ can now be solved along with Eq.(A2) to obtain the dimensiouless surface concentration as

$$
y_{0}=\frac{y_{\infty}}{1+Q(1.5) \frac{\left(T_{0} / T_{\infty}\right)^{1.3}-\left(T_{0} / T_{\infty}\right)^{0.5}}{\left(T_{0} / T_{\infty}\right)^{1.5}-1}} .
$$

The approximate dimensionless surface concentration obtained from Eqs. (2), (4) and $(5)$ is

$$
y_{0, \text { approx }}=\frac{y_{\infty}}{1+Q}
$$

Eqs.(A3) and (A4) are the exact and approximate solutions to Eqs. (A1) and (3) for a sphere. The relative error between exact and approximate solutions is

$$
\left|\frac{y_{0}-y_{0, \text { approx }}}{y_{0}}\right|=\frac{Q}{1+Q}\left|(1.5) \frac{\left(T_{*} / T_{\infty}\right)^{1.5}-\left(T_{0} / T_{\infty}\right)^{0.5}}{\left(T_{0} / T_{\infty}\right)^{1.5}-1}-1\right|
$$

The quantity

$$
F\left(T_{1} / T_{\infty}\right)=\left|(1.5) \frac{\left(T_{0} / T_{\infty}\right)^{1.5}-\left(T_{0} / T_{\infty}\right)^{0.5}}{\left(T_{0} / T_{\infty}\right)^{1.3}-1}-1\right|
$$

is an increasing function of $T_{0} / T_{\infty}$ starting from zero at $T_{0}=T_{\infty}$ and remaining small. For example at $T_{0} / T_{\infty}=1.4, F\left(T_{0} / T_{\infty}\right)=0.08$ and the error is less than $8 \%$, in as much as the factor $Q /(Q+1)$ is less than one.

\section{Acknowledgements}

This research was supported by the U.S. Department of Energy, University Coal Research Program under grant DE-FG22-88PC88911. 


\section{REFERENCES}

Abramowitz, M. and Stegun, I.A.(1972). Handbook of Mathematical Functions, 8th ed., Dover, New York, pp.590-591.

Annamalai, K. and Durbetaki, P.(1979). Combustion Behavior of Char/Carbon Particles, Seventeenth Symposium(International) on Combustion, 169.

Field, M.A., Gill, D.W., Morgan, B.B. and Hawksley, D.W.G.(1967). Combustion of Pulverized Coal, BCURA, Leatherhead pp.189-208.

Field, M.A.(1969). Rate of Combustion of Size-Graded Fractions of Char from a Low-Rank Coal between $1200 \mathrm{~K}$ and $2000 \mathrm{~K}$. Combustion \& Flame, 13, 23 T.

Hirschfelder, J.O., Curtiss, C.F. and Bird, R.B.(1954). Molecular Theory of Gases and Liquids, Wiley, New York, pp.533-591.

Libby, P.A. and Blake, T.R.(1979). Theoretical Study of Burning Carbon Particles. Combustion \& Flame, 36, 139.

Mon, E. and Amundson, N.R.(1980). Diffusion and Reaction in a Stagnant Bound. ary Layer about a Carbon Particle. 4. Dynamic Behavior. Ind. Eng. (hem. Fund., 19, 243.

Sahu, R., Northrop, P.S., Flagan, R.C., and Gavalas, G.R.(1988). Char Combustion : Measurement and Analysis of Particle Temperature Histories, $\mathrm{Co}^{-} \mathrm{J}$. Sci. and Tech., 60, 215.

Sotirchos, S.V., Srinivas, B. and Amundson, N.R.(1984). Modelling of the Combustion of Single Char Particles. In Amundson, N.R. and Luss, D., Reviews in Chemical Engincering, D. Reidel Publishing Co., London.

Stakgold, I.(1972). Boundary Value Problems of Mathematical Physics, vol.II, Macmillan, New York, pp.88-193. 
Ubahyakar, S.K(1976). Burning Charateristics of a Spherical Particle Reacting with Ambient Oxidizing Gas at its Surface. Combustion \& Flame, 26, 23. 
Table I. The parameter values used in the calculations.

\begin{tabular}{|c|c|}
\hline Physical Parameters & Values Used \\
\hline $\begin{array}{r}\text { bulk temperature, } T_{\infty} \\
\text { initial radius of equivalent sphere, } \dot{R}_{s}(0) \\
\text { bulk mole fraction of oxygen, } y_{\infty} \\
\text { heat of reaction, }-\Delta H_{r} \\
\text { solid density, } \rho_{p} \\
\text { solid emissivity, } \epsilon \\
\text { diffusion coefficient of oxygen at } T_{\infty}, D_{\infty} \\
\text { thermal conductivity of gas at } T_{\infty}, \lambda_{\infty} \\
\text { activation energy, } E \\
\text { heat capacity of gas, } C_{p} \\
\text { total molar concentration at } T_{\infty}, c_{\infty} \\
\text { lst order reaction constant at } T_{\infty}, k_{\infty}^{\prime} \\
\text { dimensionless time, } \tau\end{array}$ & $\begin{array}{r}1600 \mathrm{~K} \\
25 \mu \mathrm{m} \\
0.1 \\
2.32 \times 10^{8} \mathrm{~J} / \mathrm{kgmol} \mathrm{O} \\
800 \mathrm{~kg} / \mathrm{m}^{3} \\
1 \\
2.80 \times 10^{-4} \mathrm{~m}^{2} / \mathrm{s} \\
5.38 \times 10^{-2} \mathrm{~J} / \mathrm{m}-\mathrm{s}-\mathrm{K} \\
17,000 \mathrm{cal} \\
2.5 \times 10^{4} \mathrm{~J} / \mathrm{kgmol} \cdot \mathrm{K} \\
7.62 \times 10^{-3} \mathrm{kgmol} / \mathrm{m}^{3} \\
0.2119 \mathrm{kgmol} \mathrm{O}_{2} / \mathrm{m}^{2}-\mathrm{s}_{-\mathrm{amm}} \\
63.135 \mathrm{sec}^{-1} t\end{array}$ \\
\hline
\end{tabular}




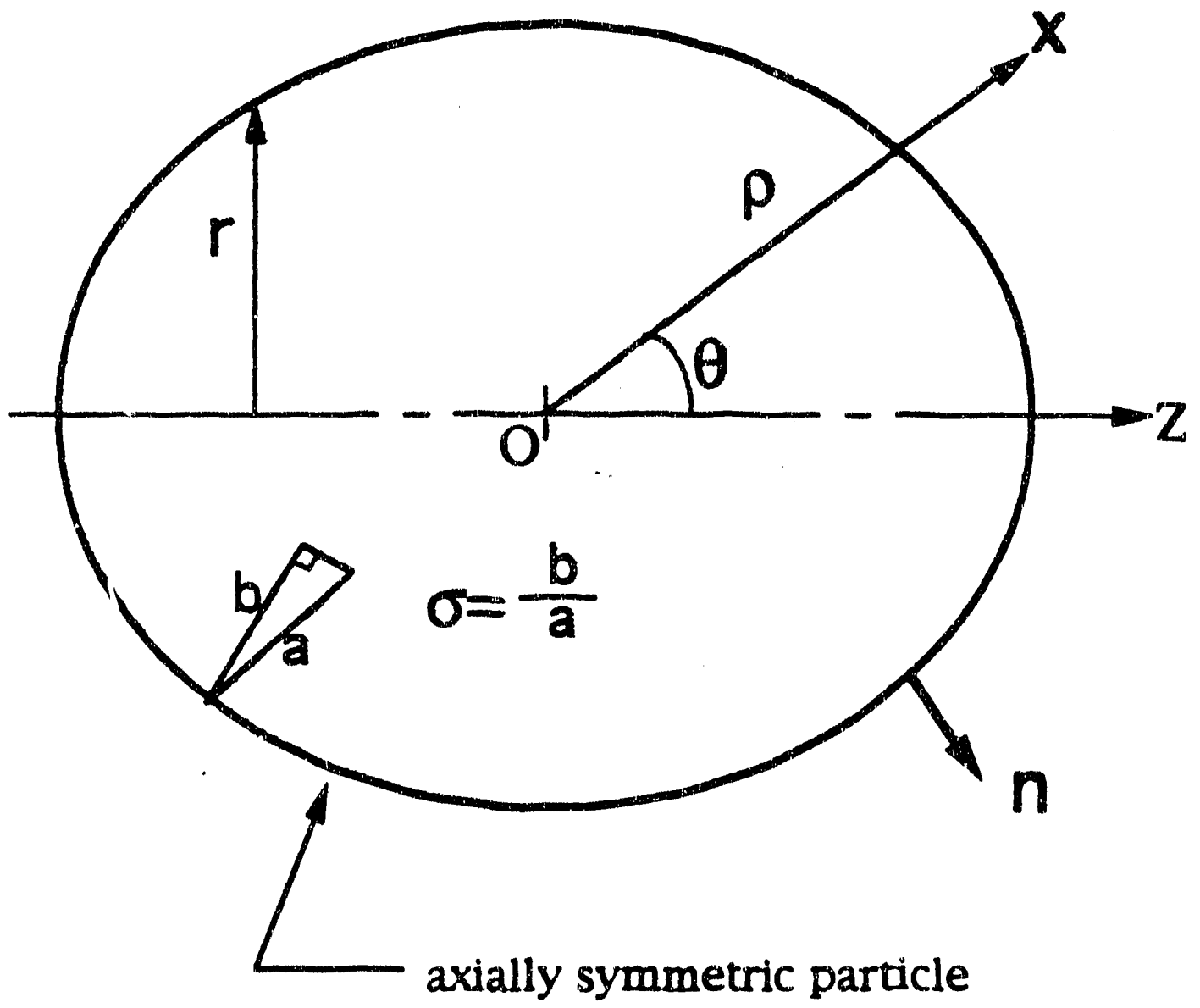

Figure 1. Geometry and notation for a nonspherical particle. 


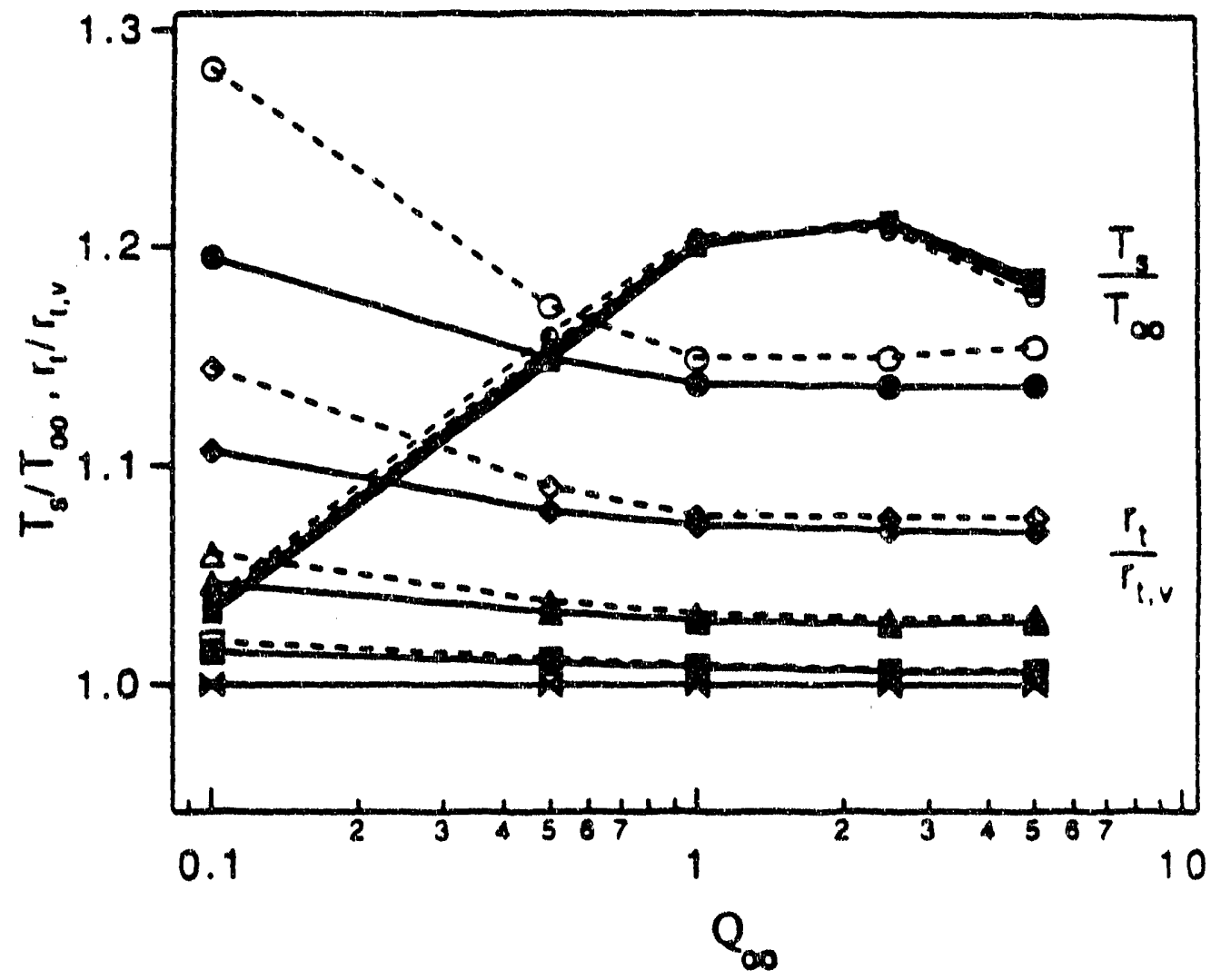

Figure 2. Pseudosteady particle temperature normalized by free stream temperature and reaction rate normalized by that of a sphere of equal volume vs. Damköhler number $\left(\infty: A_{p}=1 . \square: A_{p}=1.25 . \Delta: A_{p}=1.667 .0: A_{p}=2.294, O: A_{p}=3.2026:\right.$ solid lines : prolate spheroids, dashed lines: oblate spheroids). 


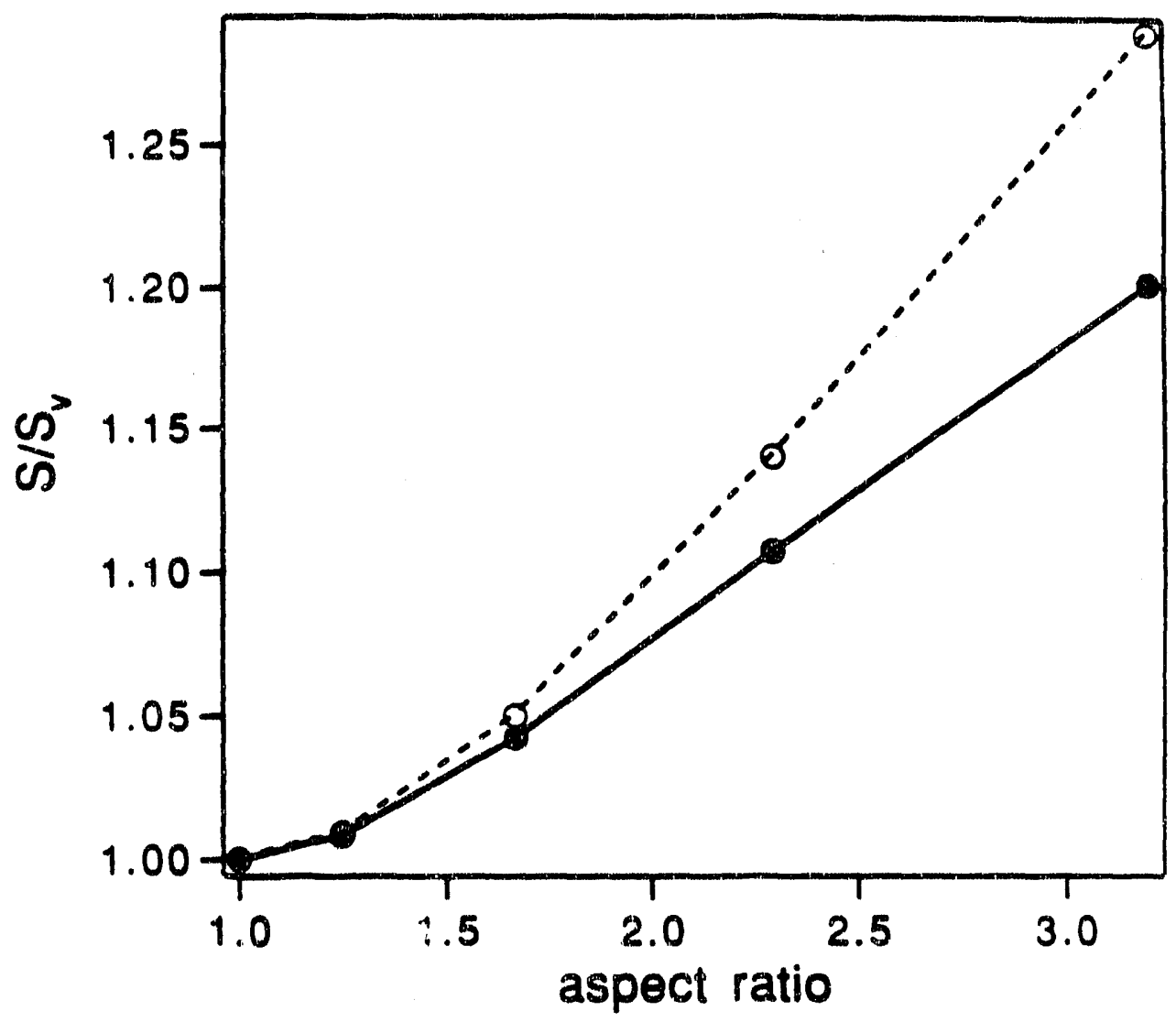

Figure 3. Surface area normalized by that of a sphere of equal volume is. Asiret ratio(solid lines : prolate spheroids, dashed lines : oblate spheroids). 


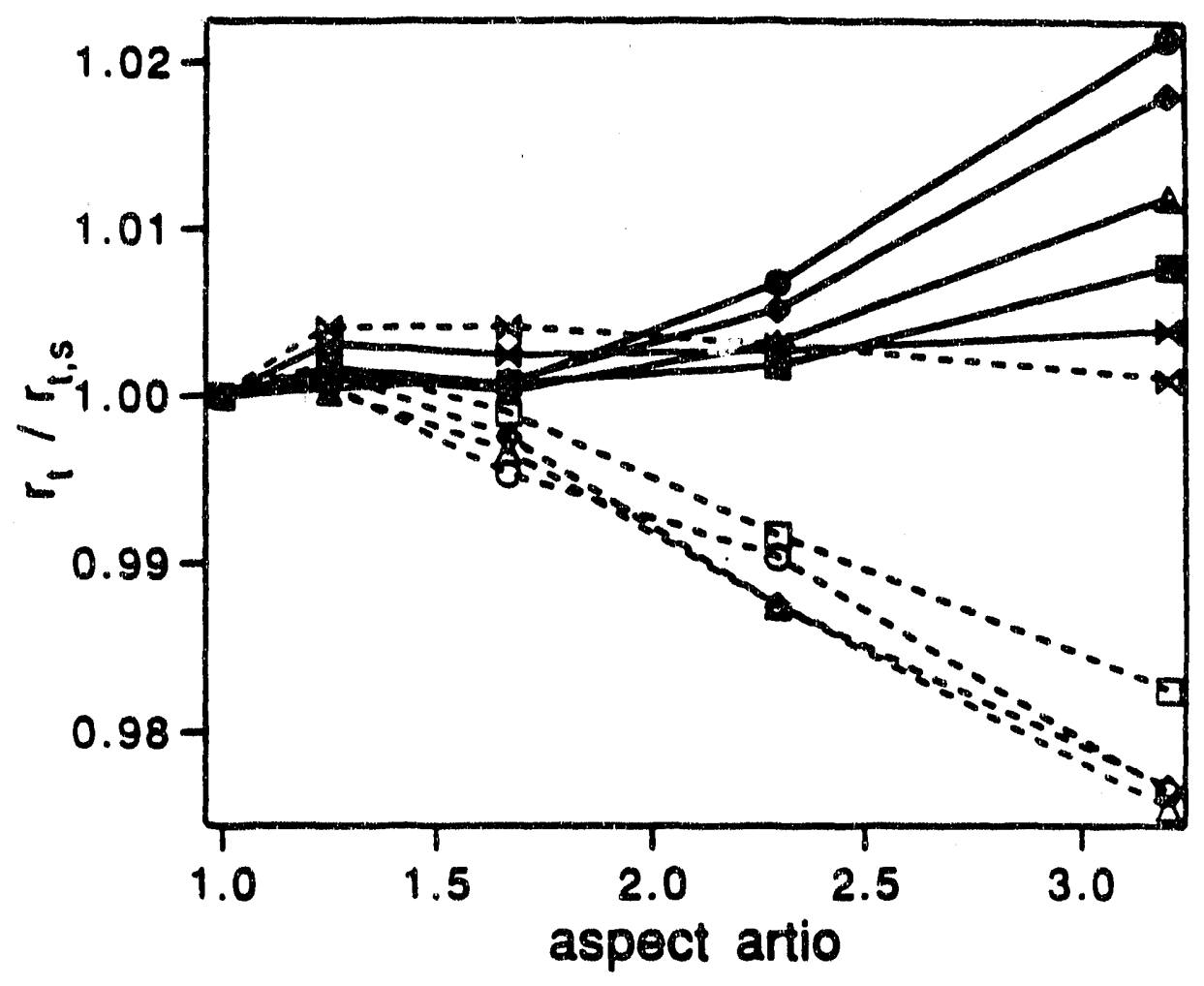

Figure 4. Total reaction rate normalized by that of a sphere of equal surface area

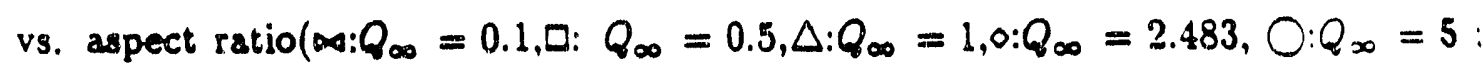
solid lines : prolate spheroids, dashed lines : oblate spheroids). 


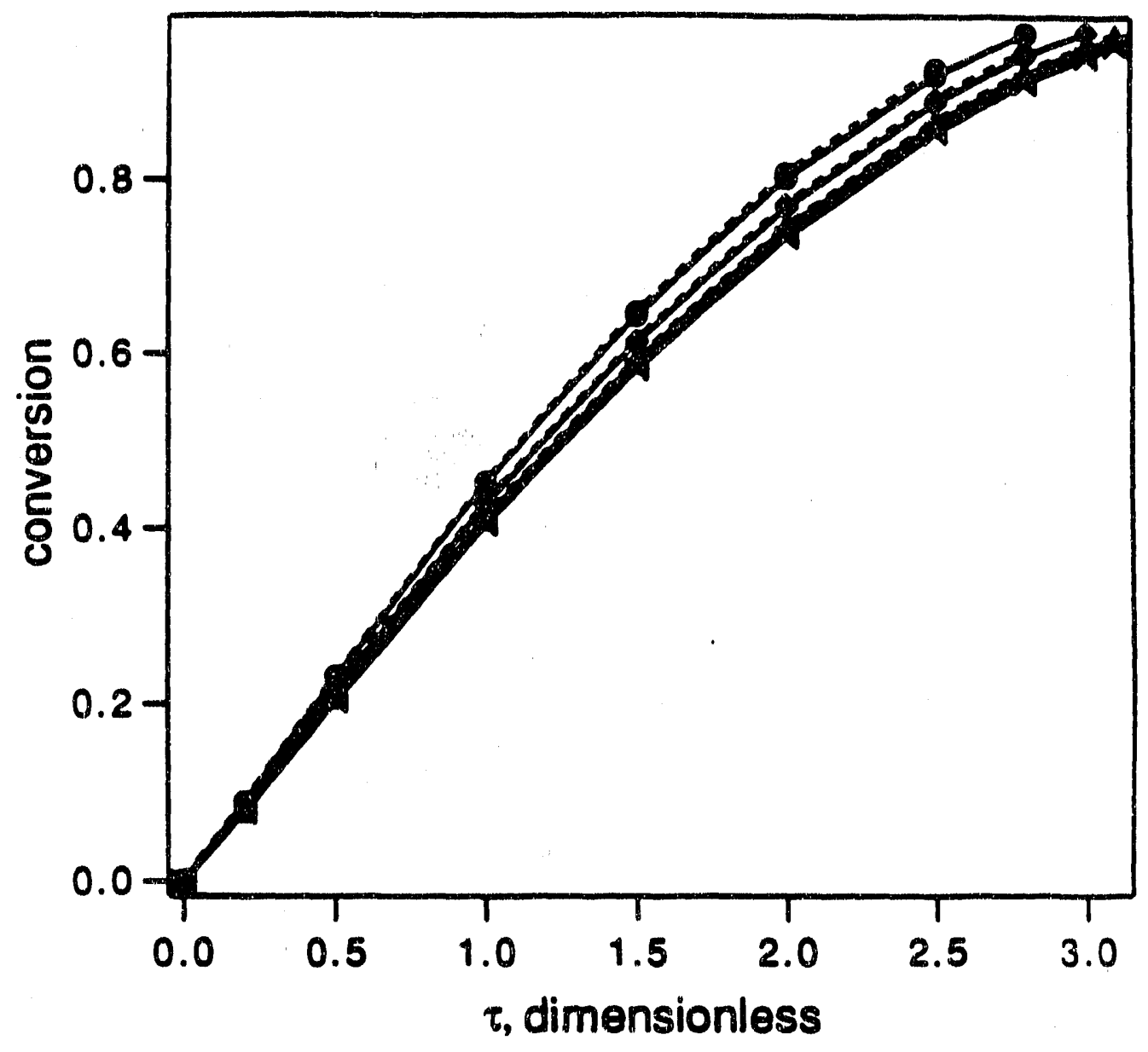

Figure 5. Conversion vs. dimensionless time for prolate and oblate spheroids $\left(\infty<: A_{p}(0)=1, \Delta: A_{p}(0)=1.667,0: A_{p}(0)=2.294, O: A_{p}(0)=3.2026\right.$ : solid lines : prolate spheroids, dashed lines : oblate spheroids). 


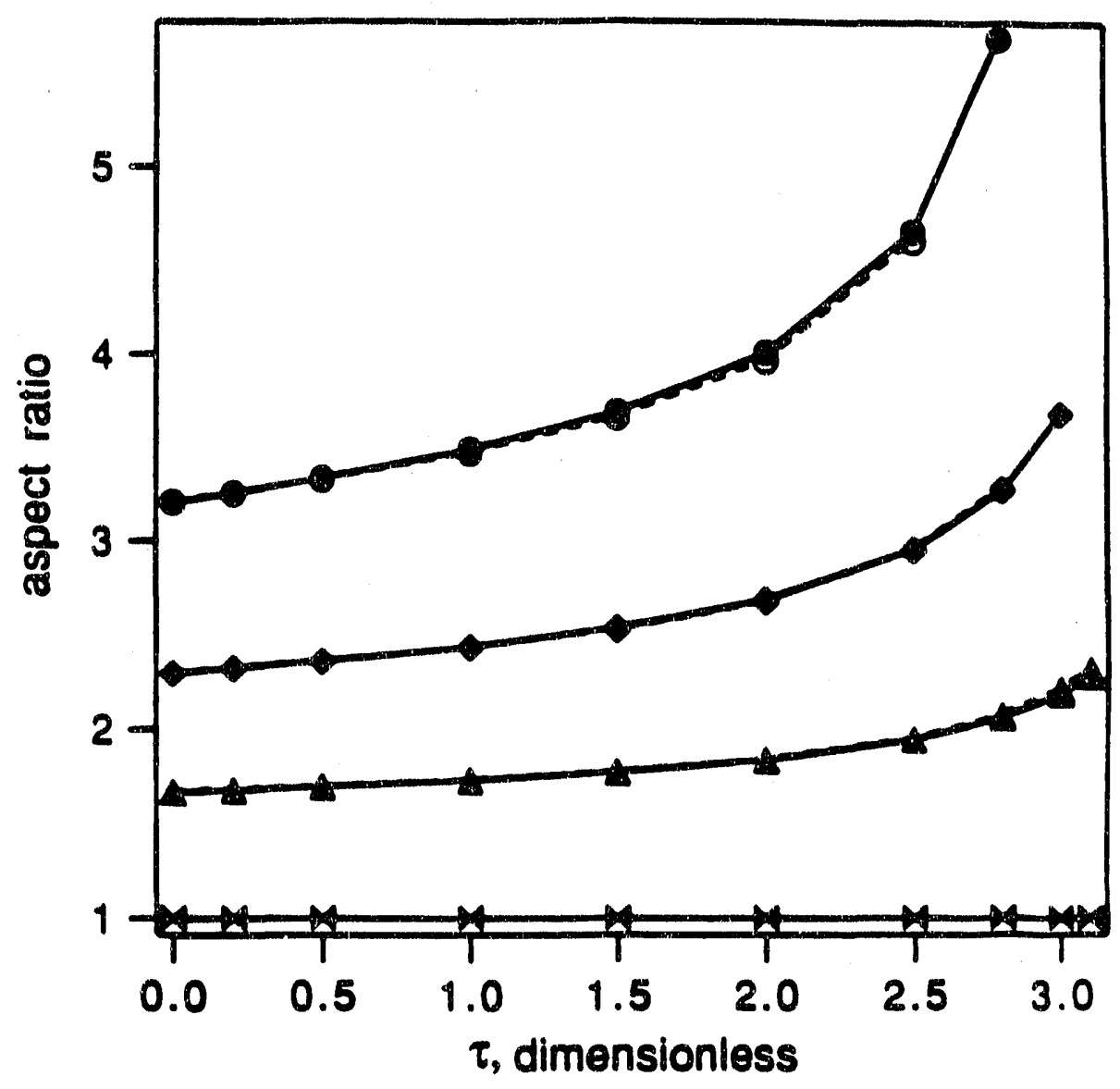

Figure 6. Aspect ratio vs. dimensionless time for prolate and oblate spheroids $\left(\infty: A_{p}(0)=1, \triangle: A_{p}(0)=1.667,0: A_{p}(0)=2.294, O: A_{p}(0)=3.2026\right.$; solid lines : prolate spheroids, dashed lines : oblate spheroids). 


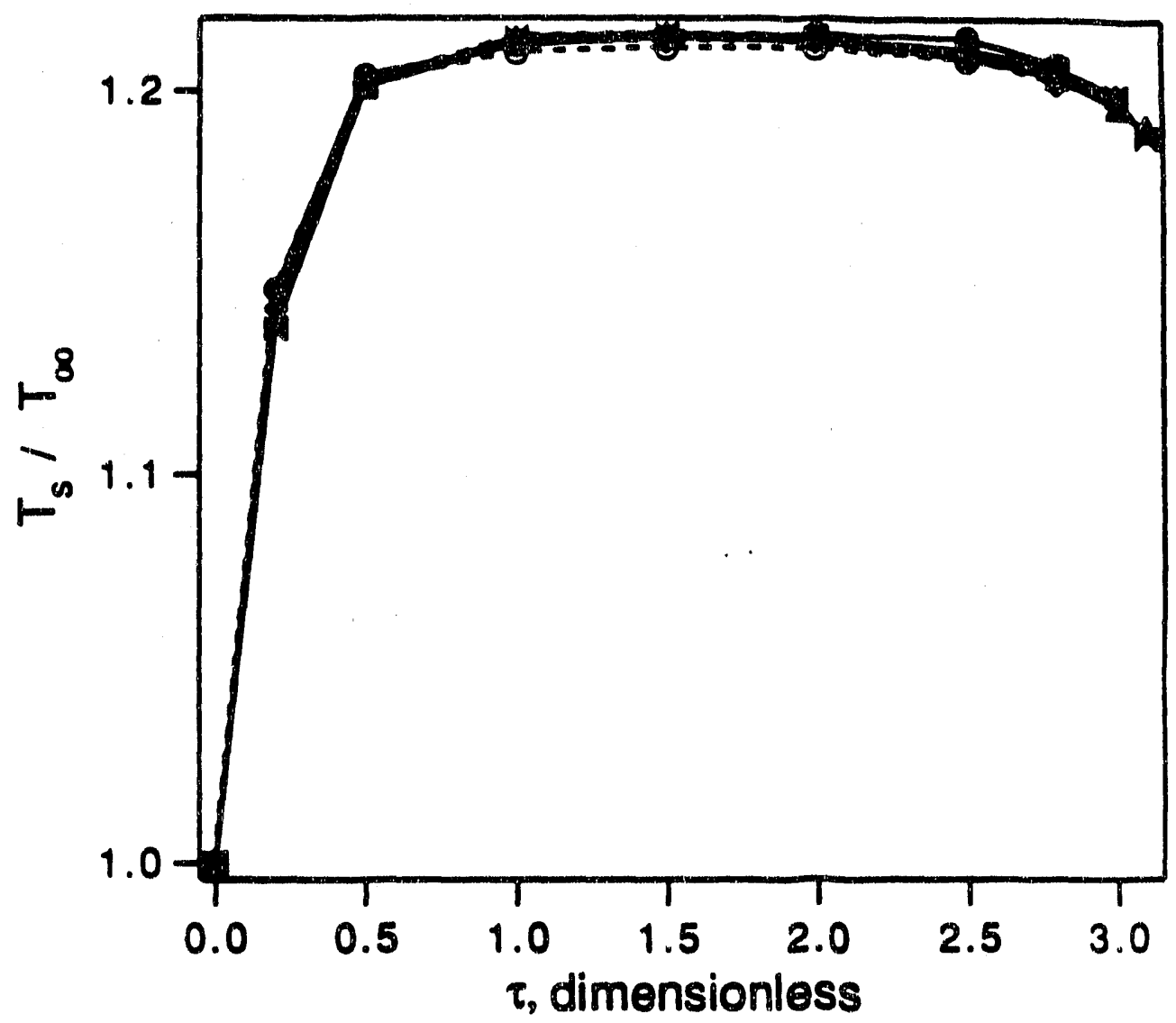

Figure 7. Transient particle temperature vs. dimensionless time for prolate and oblate spheroids $\left(\bowtie: A_{p}(0)=1, \triangle: A_{p}(0)=1.667, \circ: A_{p}(0)=2.294, \bigcirc: A_{p}(0)=3.2026\right.$ : solid lines : prolate spheroids, dashed lines : oblate spheroids). 


\section{CHAPTER 5}

\section{CONCLUSIONS}


A high volatile biruminous coal (Pittsburgh No. 8) was subjected to devolatilization and oxidation in an entrained larninar flow furnace. Devolatilization in pure nitrogen was carried out at $1200 \mathrm{~K}$ and $1600 \mathrm{~K}$ for residence times of $100 \mathrm{~ms}, 200 \mathrm{~ms}, 300 \mathrm{~ms}$ and $2 \mathrm{~s}$. Devolatilization with simultaneous oxidation was carried out in $1 \% \mathrm{O}_{2}$-balance nitrogen and $5 \% \mathrm{O}_{2}$-balance nitrogen.

Scanning electron microscopy shows that the gross morphological features of the char continue changing during at least the first $300 \mathrm{~ms}$ of devolatilization at $1600 \mathrm{~K}$ in pure $\mathrm{N}_{2}$. These changes include loss of mass--which is largely completed by the first $100 \mathrm{~ms}--$ rounding of the parti?s and gradual enlargement of large openings, or blowholes, at the surface. The BET surface area and total pore volume also increase during the first $300 \mathrm{~ms}$ of devolatilization.

Devolatilization was accornpanied by oxidation when the coal was treated in $1 \%$ $\mathrm{O}_{2}-\mathrm{N}_{2}$ or $5 \% \mathrm{O}_{2}-\mathrm{N}_{2}$ at $1600 \mathrm{~K}$. Even at $100 \mathrm{~ms}$ residence time in $1 \%$ oxygen the mass lors was $25 \%$ beyond the loss engendered by devolatilization in pure nitrogen. In $5 \% \mathrm{O}_{2}-\mathrm{N}_{2}$ the mass loss was significantly higher. These results suggest that in pulverized combustion, devolatilization and char burnout overlop significantly. The creatment of these two processes as consecutive, as done in combustion models, is clearly an approximation.

The variation of surface area with residence time in $1 \% \mathrm{O}_{2}-\mathrm{N}_{2}$ and $5 \% \mathrm{O}_{2}-\mathrm{N}_{2}$ was very different from that in pure $\mathrm{N}_{2}$. In the presence of oxygen the surface area increased until about $100 \mathrm{~ms}$ and then decreased. The decrease observed for times larger than 100 ms is probably due to loss of micropores by a densification process catalyzed by oxygen. Oxidation experiments with the thermogravimetric analyzer revealed a complex dependence of low temperature reactivity $\left(500^{\circ} \mathrm{C}\right)$ on the prior charring history. For chars that were prepared in pure nitrogen, the reactivity increased with the charring residence time at least up to $200 \mathrm{~ms}$ residence times. For chars prepared in $\mathrm{O}_{2}-\mathrm{N}_{2}$ mixtures, the reactivity decreased with the oxygen content in the charring atmosphere--at constant charring time. For fixed oxygen level in the charring atmosphere, the reactivity decreased with the 
charring time. This decrease of the reactivity with the oxygen level and the charring time can be attributed to a combination of two factors. One is the densification with loss of micropore surface area. The other is the selective depletion of the more reactive part of the carbonaceous structure during char preparation.

Single particle experiments were conducted with an electrodynamic balance (EDB) using a $\mathrm{CO}_{2}$ laser beam to heat the electrically levitated particle. The particle could only be heated to about $900^{\circ} \mathrm{C}$ beyond which charge loss occurred disrupting the levitation. Char particles that had been formed by devolatilization in pure nitrogen at $1200 \mathrm{~K}$ and $1600 \mathrm{~K}$ for two seconds were heated in pure nitrogen and in air. Heating in pure nitrogen at $900^{\circ} \mathrm{C}$ for up to 20 minutes did not induce any apparent changes in the size or shape of either the $1200 \mathrm{~K}$ char or the $1600 \mathrm{~K}$ char. In oxidation in air at temperatures below $900^{\circ} \mathrm{C}$ the $1600 \mathrm{~K}$ char particles reacted at constant size up to $60 \%$ conversion. In contrast the $1200 \mathrm{~K}$ char particles underwent significant size reduction under the same conditions. Since in both cases oxidation proceeded in regime I (strict reaction control) the shrinkage of the $1200 \mathrm{~K}$ char particles can only be explained by densification--loss of micropore volume. Moreover, this densification which occurs only for the "greener" $1200 \mathrm{~K}$ char requires the presence of oxygen.

The phenomena of densification and loss of surface area and reactivity observed in the TGA and EDB experiments have significant implications for particle combustion models. Existing models assume that oxidation enlarges the pores but does not affect the underlying structure or the intrinsic oxidation rate parameters. The results of the present experiments suggest that under certain conditions oxidation causes structural changes that affect the particle volume, micropore surface area, and intrinsic reactivity.

In connection with modeling particle combustion a theoretical study was carried out to evaluate the effect of particle shape on particle temperature, rate of combustion, and burnout time. For particles of equal volume, the pseudosteady temperature was found to be nearly independent of shape, but the combustion rate was found to increase with 
increasing aspect ratio. To a high degree of accuracy, the total combustion rate depends on the particle surface area alone, i.e., particles of equal surface area but different volumes and shapes have the same rate. The effect of initial particle shape on the burnout transient was explored for a set of parameters typical of a bituminous coal char burning in the shrinking core regime. The calculations show the particle shape to become increasingly nonspherical with the progress of combustion and this change to be more pronounced for particles with larger initial aspect ratios. For particles of equal initial volume, the burnout time decreases slightly with the initial aspect ratio. For example a particle of initial aspect ratio 3.2 requires $12 \%$ less time to react $80 \%$ burnout compared to a spherical particle of the same initial volume. 

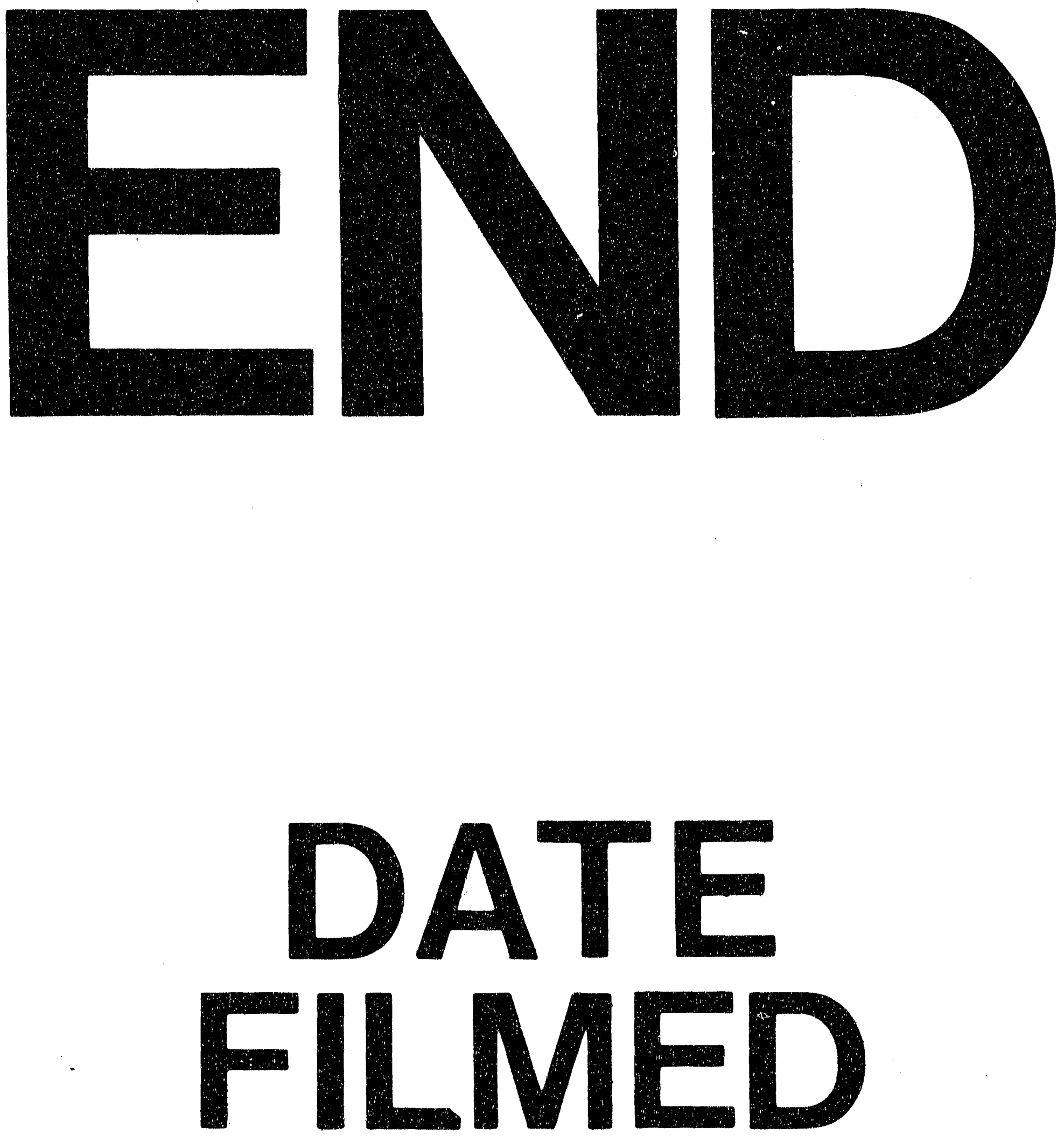

$\$$

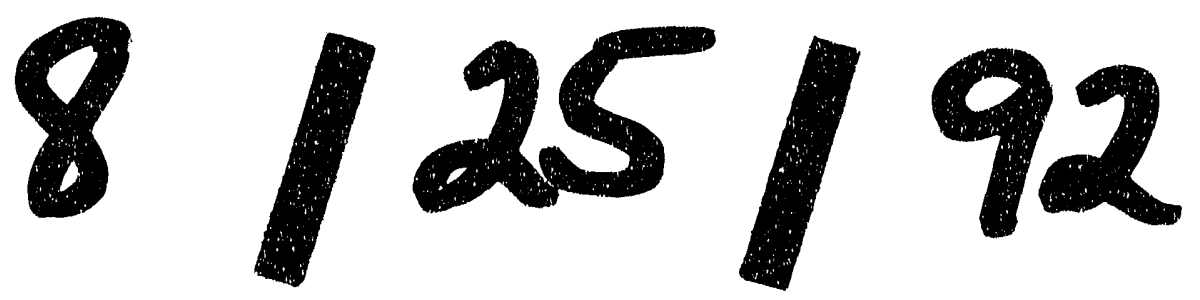


